EXAMINING CONTRACEPTIVE USE AND PERCEIVED SIDE EFFECTS AMONG TEEN GIRLS IN RURAL MISSOURI

\begin{tabular}{c} 
A Dissertation \\
presented to \\
the Faculty of the Graduate School \\
at the University of Missouri \\
In Partial Fulfillment \\
of the Requirements for the Degree \\
Doctor of Philosophy \\
\hline Dr. Virginia Ramseyer Winter, Dissertation Advisor \\
JULY 2021
\end{tabular}


The undersigned, appointed by the dean of the Graduate School of the University of Missouri-Columbia, have examined the dissertation entitled

\section{EXAMINING CONTRACEPTIVE USE AND PERCEIVED SIDE EFFECTS AMONG TEEN GIRLS IN RURAL MISSOURI}

presented by Mackenzie Cook Lee,

a candidate for the degree of doctor of philosophy,

and hereby certify that, in their opinion, it is worthy of acceptance.

Professor Virginia Ramseyer Winter

Professor Kelli Canada

Professor Clark Peters

Professor Wolfgang Wiedermann 


\section{ACKNOWLEDGEMENTS}

I would like to thank my dissertation chair, Dr. Virginia Ramseyer Winter. I appreciate her guidance and the opportunities she has given me throughout my doctoral program. Her mentorship has helped me grow as a researcher and a professional.

Thank you to Dr. Kelli Canada for her support not only during the dissertation process but throughout the program. Your passion for research as well as teaching is admirable and I am grateful to have been able to be your student. Thank you, Dr. Clark Peters, for challenging me and supporting me both in the classroom and throughout the program. Dr. Wolfgang Wiedermann, I cannot thank you enough for your generosity, patience, and willingness to help me through the statistical analysis.

Thank you to Dr. Susan Stiritz for the continued support throughout my academic journey and for igniting my passion for sexual health research. You are an amazing woman and I am honored to be your colleague and friend.

Finally, I would like to thank my husband, Michael, my parents, Thomas and Lisa Cook, and my sister Ashley Cook for supporting me, believing in me, and for your patience. I truly do not think I could have made it through this program without you all. I love you! 


\section{Table of Contents}

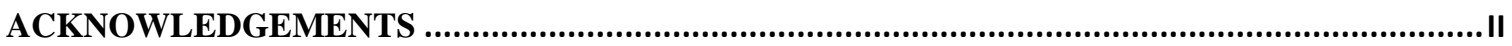

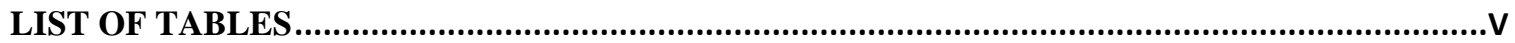

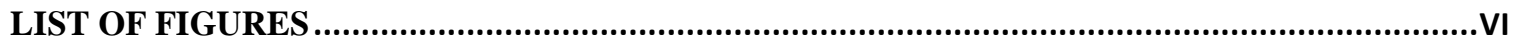

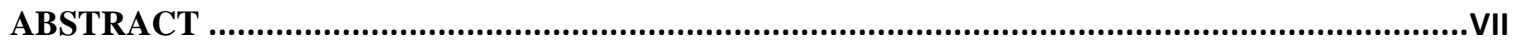

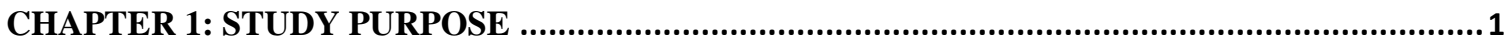

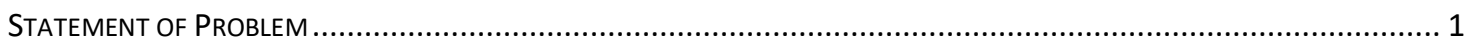

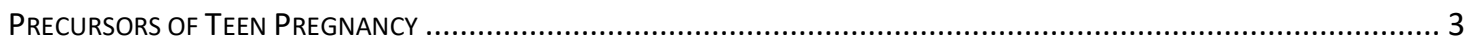

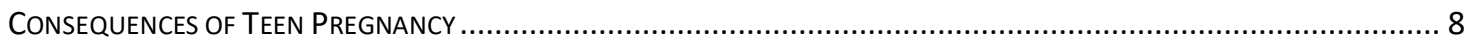

STUDY PURPOSE

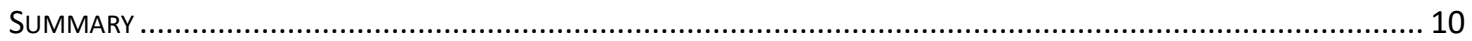

CHAPTER 2: REVIEW OF LITERATURE............................................................................. 11

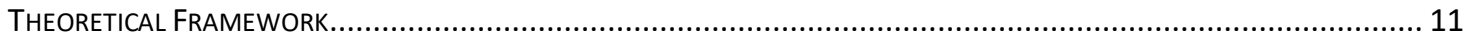

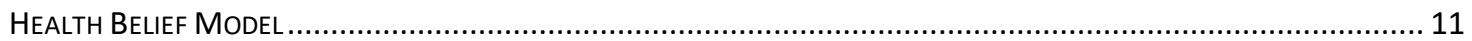

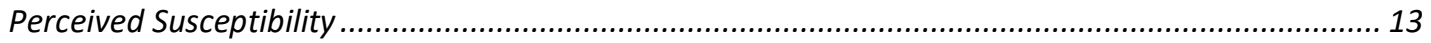

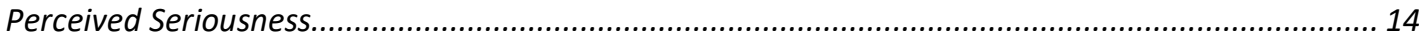

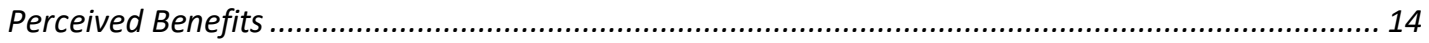

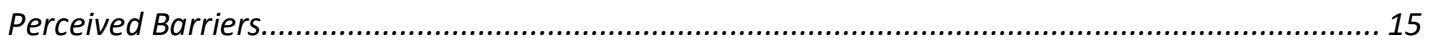

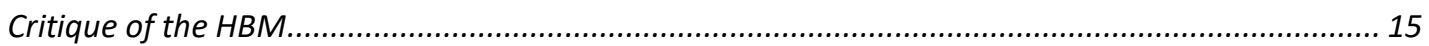

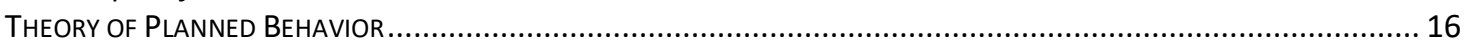

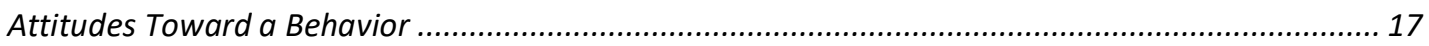

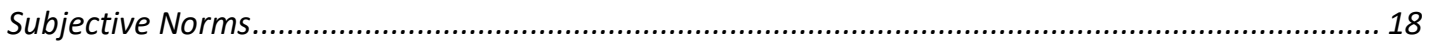

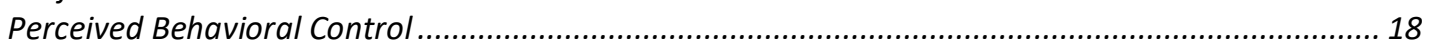

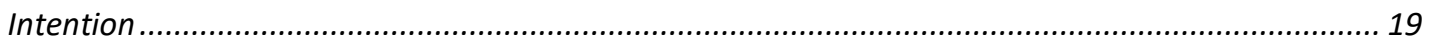

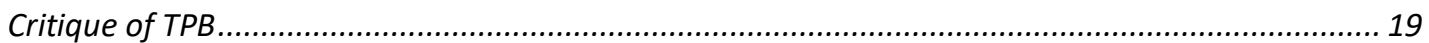

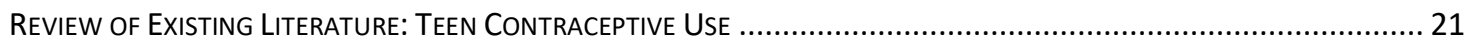

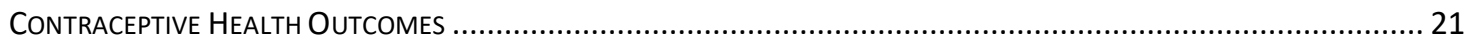

Perceived Side Effects and Attitudes Regarding Perceived Side Effects............................................. 26

Physician Influence on Perceived Side Effects of Contraceptives ........................................................ 31

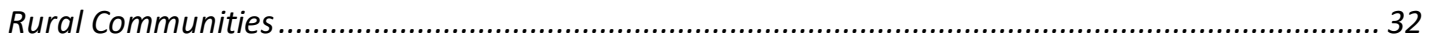

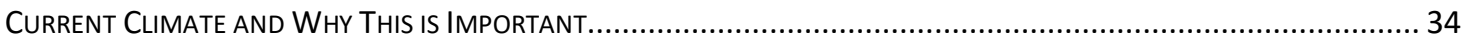

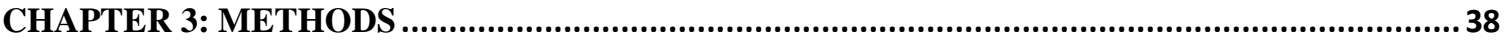

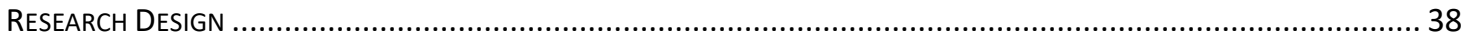

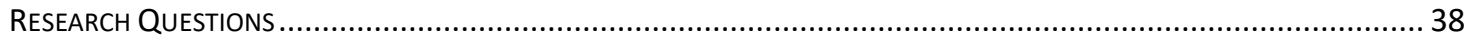

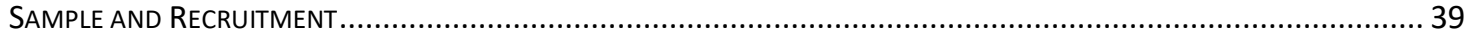

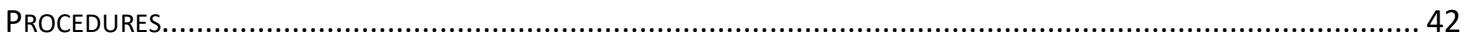

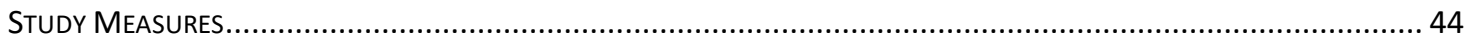

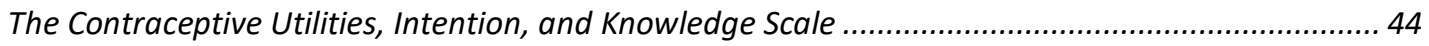

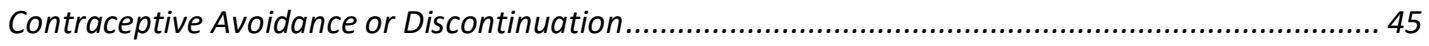

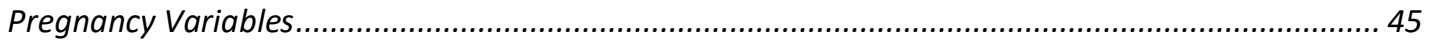

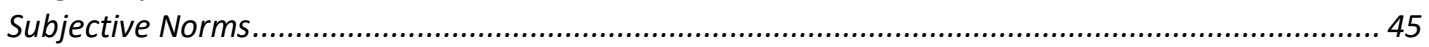

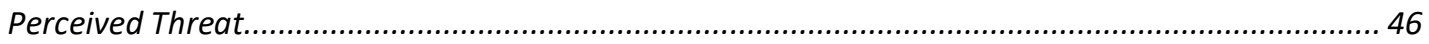

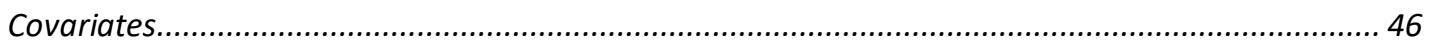

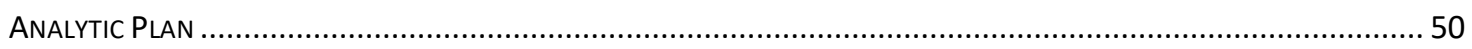

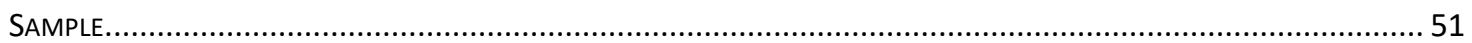

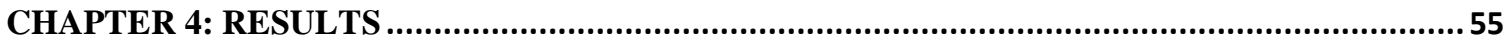


Research Question 1: Attitudes Regarding Contraceptive Side Effects ................................................. 55

ReSEARCh Question 2: Subjective Norms Attitudes About Contraceptive USE ........................................5 58

Research Question 3: Perceived Threat of Pregnancy or Contraceptive Side Effects..................................5 59

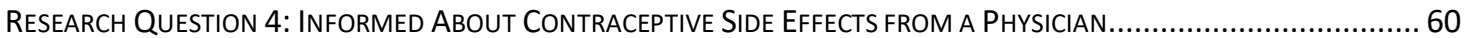

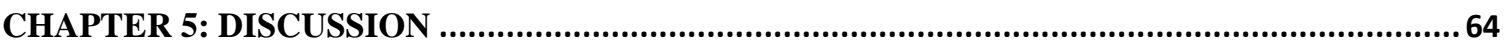

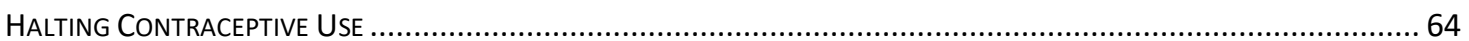

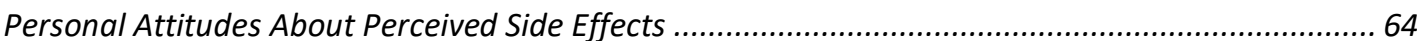

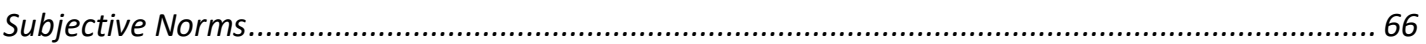

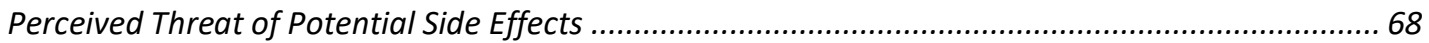

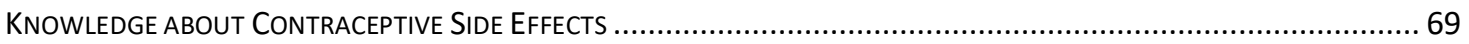

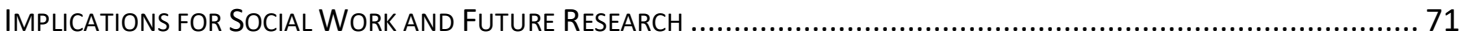

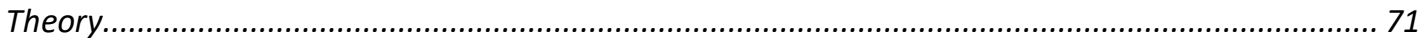

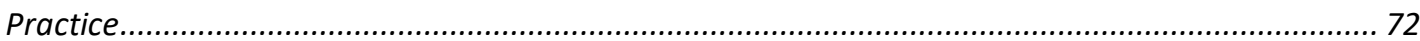

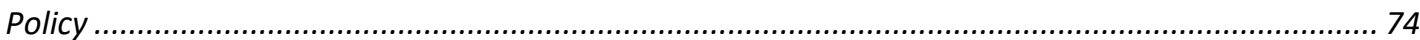

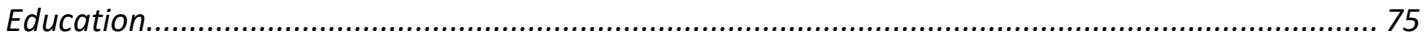

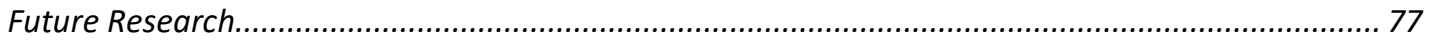

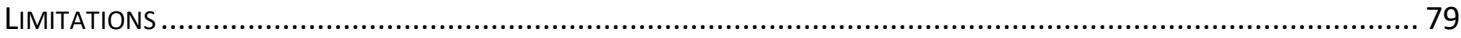

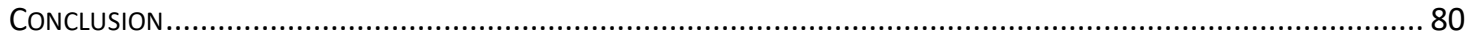

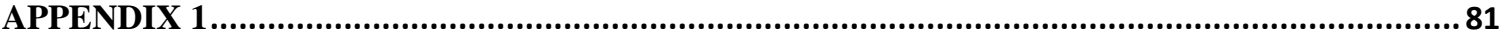

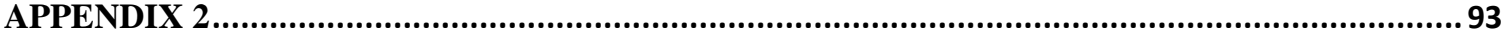

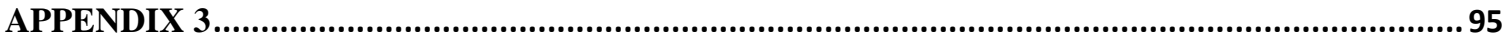

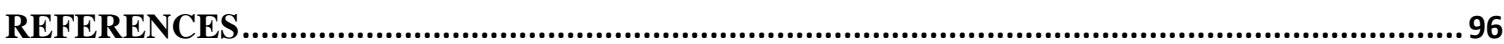

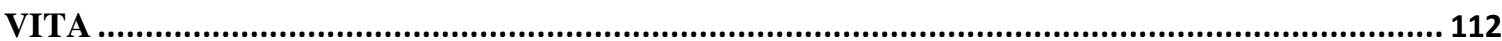




\section{LIST OF TABLES}

Table

Page

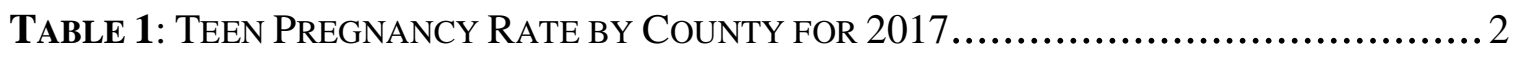

TABle 2: RequiRed Number OF GiRLS (USING A CONSERVATIVE ESTIMATE OF R2 = 0.20)

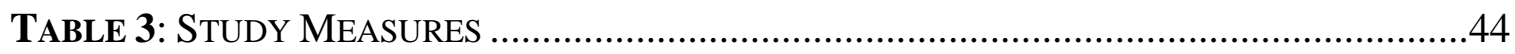

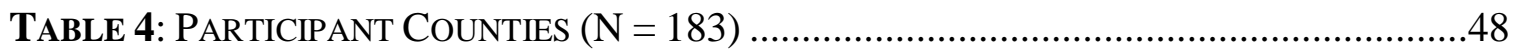

TABle 5: PARTiCIPANT Characteristics AND DesCriptive ANALySES $(\mathrm{N}=183) \ldots \ldots . . .49$

TABle 6: PARTICIPANT Characteristics And DesCriptive AnAlyses ( $\mathrm{N}=183)$..........50

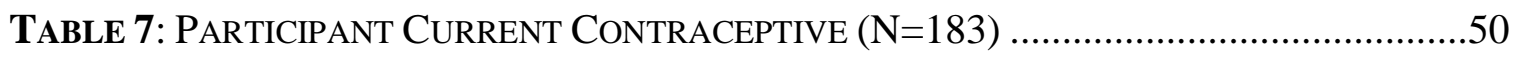

Table 8: Attitudes About Contraceptive Side Effects and Halting

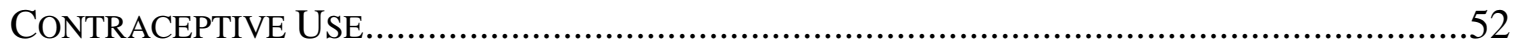

Table 9: Major and Minor Side EfFects and Halting Contraceptive Use.............53

Table 10: Subjective Norms and Halting Contraceptive Use ...............................55

TAble 11: Perceived Threat of Pregnancy Vs. Contraceptive Side EFFeCTS AND

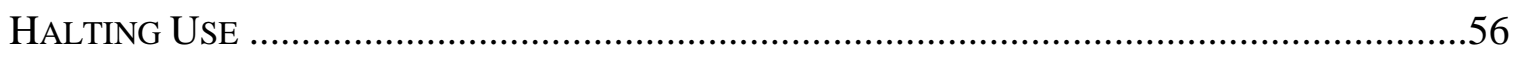

TABle 12: KNOWLedge of Side EfFects From a Physician And AtTitudes of Side

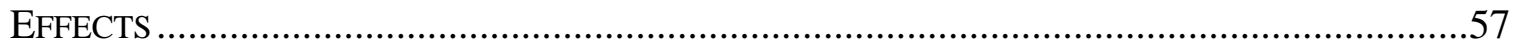

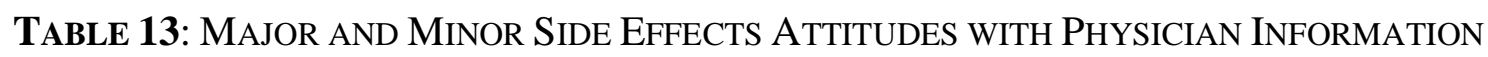
.58 


\section{LIST OF FIGURES}

Figure

Page

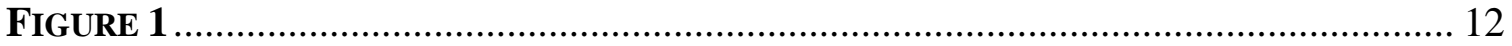

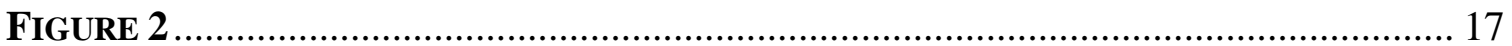

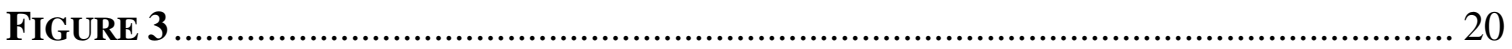

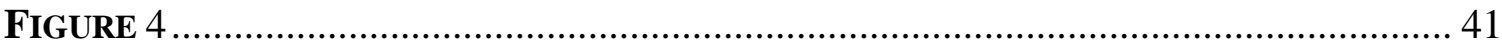

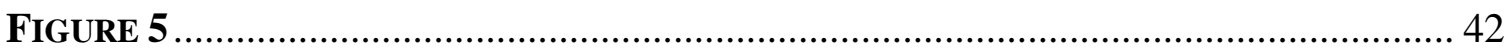




\title{
EXAMINING CONTRACEPTIVE USE AND PERCEIVED SIDE EFFECTS AMONG TEEN GIRLS IN RURAL MISSOURI
}

\author{
Mackenzie Cook Lee
}

Dr. Virginia Ramseyer Winter, Dissertation Supervisor

\begin{abstract}
In Missouri, there are 114 counties with 101 rural counties; 41 of these rural counties have teen pregnancy rates that vary from 42.4 to 90.1 per 1,000 (national rate is 43 per 1,000; Kost et al., 2017; TPPP, 2013). Nationally, teen pregnancy rates have been decreasing; however, some of the rural Missouri counties have seen an increase in pregnancy rates (e.g., Dunklin County saw an increase from 55.07 per 1,000 to 62.37 per 1,000 , and Pettis County saw an increase from 38.43 per 1,000 to 43.07 per 1,000 from 2015-2016). Most literature on teen pregnancy and pregnancy prevention has focused on urban populations. This is problematic because many rural communities have characteristics that result in disparately high teen pregnancy rates. The theory of planned behavior (Ajzen, 1991) and the health belief model (Kirscht, 1974) provide a theoretical framework for the current study. This study aimed to better understand teen girls' contraceptive use in rural Missouri specifically, how attitudes regarding perceived side effects, subjective norms about contraceptive use, and knowledge about contraceptive side effects relate to girls halting contraceptive use.

A convenience sample of 183 girls from the 41 rural Missouri counties participated in an online survey. The majority of the sample identified as White (72.6\%). Age and education levels varied; $10.9 \% 15$ years old, $24 \% 16$ years old, $23.5 \% 17$ years old, $25.7 \% 18$ years old, and $15.8 \% 19$ years old; $40.4 \%$ completed high school or GED, $11.5 \%$ completed $8^{\text {th }}$ grade, $24 \%$ completed some high school, $15.8 \%$ completed some
\end{abstract}


college, $3.8 \%$ completed trade/technical/vocational training, $1.6 \%$ completed an associate's degree, and $0.5 \%$ completed a bachelor's degree. About half the sample identified as religious (54.6\%). A series of logistic regression were performed in $\mathrm{R}$ version 3.4.1.

The results showed that girls who perceived birth control pills to have major side effects were more likely to have experienced a side effect from contraceptive use and halted use. The girls who had someone important to them who supported the use of condoms, IUD, and birth control pills were more likely to experience a side effect and halt use. The girls who had experienced a side effect from contraceptive use and halted use were more likely to believe that they would become pregnant in the next year if not using any form of contraception. The girls who had not been told about side effects associated with contraceptives were more likely to associate major side effects with IUDs and birth control pills.

This study greatly contributes to the literature regarding rural teens' contraceptive use and how their attitudes and knowledge about perceived side effects informs the girls' decision to use or halt contraceptive use. More research is needed to fully understand these factors and better improve intervention strategies as well as contraceptive counseling to reduce teen pregnancy rates in rural Missouri. 


\section{Chapter 1: Study Purpose}

\section{Statement of Problem}

Teen pregnancy rates in the United States have been declining for the past two decades (Power to Decide, 2019a; CDC, 2019), but this is not true for some areas of the country where disparate adolescent pregnancy rates have increased over the past two decades. Six of 114 counties in Missouri have a teen birth rate lower than the national rate, while 52 counties have a teen birth rate at least twice the national rate (County Health Rankings, 2019).

In Missouri there are 114 counties with 101 categorized as rural. There are 41 rural counties where teen pregnancy rates vary from 42.4 to 90.1 per 1,000 (national rate is 43 per 1,000; Kost et al., 2017; TPPP, 2013). Some of these counties do not follow the national trend of declining teen pregnancy rates, with some of these counties seeing an increase in teen pregnancy rates from 2015 to 2016 (TPPP, 2013). Refer to Table 1 for Missouri teen pregnancy rates by county. For example, Dunklin County saw an increase from 55.07 per 1,000 to 62.37 per 1,000 from 2015 to 2016, and Pettis County saw an increase from 38.43 per 1,000 to 43.07 per 1,000 from 2015-2016; however, these counties saw a decrease from 2016-2017 (Dunklin: 62.7 to 42.40; Pettis: 43.7 to 40.58).

Most existing literature on adolescent pregnancy and pregnancy prevention has focused on urban populations. This is problematic because many rural communities have characteristics that result in disparately high teen pregnancy rates including poverty and variability of socioeconomic status in the community. Further, religious beliefs, which have been reported as higher in rural areas than urban areas, have been shown to influence sexual debut and frequency of sexual activity among adolescents (Barral et al., 
2019; Billy et al., 1984). Rural communities are unique in that they are geographically isolated (i.e., rural counties are often hours from a city, and it is difficult to travel even from some rural towns to other rural towns because there are no direct or major roads to make the commute; Barral et al., 2019). These unique characteristics contribute to a lack of job opportunities and higher poverty rates, whereas urban youth may have more employment options. Rural youth also have less access to physicians, especially specialty physicians such as OB-GYNs, when compared to urban youth (Rowland \& Lyons, 1989). Further, rural areas often have a close-knit community with limited access to confidential reproductive health care (e.g., if a teen goes to the doctor for contraceptive counseling, they fear the risk of someone finding out and potentially getting in trouble; Barral et al., 2019).

\section{Table 1}

Teen Pregnancy Rate by Missouri County for 2017 (TPPP, 2019)

\begin{tabular}{|c|c|c|c|c|c|c|c|c|c|}
\hline County & Rate & County & Rate & County & Rate & County & Rate & County & Rate \\
\hline Adair & 13.43 & Clay & 23.50 & Iron & 32.47 & Montgomery & 26.32 & Schuyler & $\mathrm{x}$ \\
\hline Andrew & 17.61 & Clinton & 30.30 & Jackson & 36.44 & Morgan & 38.75 & Scotland & $\mathrm{x}$ \\
\hline Atchison & $x$ & Cole & 27.97 & Jasper & 39.31 & New Madrid & 59.76 & Scott & 45.95 \\
\hline Audrain & 28.29 & Cooper & 24.34 & Jefferson & 19.65 & Newton & 35.37 & Shannon & 32.39 \\
\hline Barry & 40.04 & Crawford & 34.19 & Johnson & 16.39 & Nodaway & 4.90 & Shelby & $x$ \\
\hline Barton & 39.58 & Dade & $\mathrm{x}$ & Knox & $x$ & Oregon & 18.93 & St. Charles & 9.81 \\
\hline Bates & 26.75 & Dallas & 22.77 & Laclede & 45.37 & Osage & $x$ & St. Clair & 32.65 \\
\hline Benton & 36.95 & Daviess & 16.61 & Lafayette & 36.89 & Ozark & 44.72 & St. Francois & 38.38 \\
\hline Bollinger & $x$ & DeKalb & 19.53 & Lawrence & 48.48 & Pemiscot & 45.22 & St. Louis City & 34.28 \\
\hline Boone & 14.36 & Dent & 24.66 & Lewis & 13.85 & Perry & 23.94 & St. Louis County & 18.88 \\
\hline Buchanan & 42.36 & Douglas & 26.71 & Lincoln & 23.23 & Pettis & 40.58 & Ste. Genevieve & 22.18 \\
\hline Butler & 40.73 & Dunklin & 42.40 & Linn & 32.00 & Phelps & 23.43 & Stoddard & 28.79 \\
\hline Caldwell & 47.30 & Franklin & 27.47 & Livingston & 40.82 & Pike & 34.21 & Stone & 35.35 \\
\hline Callaway & 22.10 & Gasconade & 35.71 & Macon & 37.86 & Platte & 15.19 & Sullivan & 34.68 \\
\hline Camden & 28.47 & Gentry & $x$ & Madison & 25.86 & Polk & 29.91 & Taney & 25.99 \\
\hline Cape Girardeau & 18.72 & Greene & 23.55 & Maries & $x$ & Pulaski & 27.04 & Texas & 32.81 \\
\hline Carroll & $x$ & Grundy & 29.76 & Marion & 25.41 & Putnam & $x$ & Vernon & 30.59 \\
\hline Carter & $x$ & Harrison & 24.39 & McDonald & 47.68 & Ralls & $x$ & Warren & 30.67 \\
\hline Cass & 23.58 & Henry & 41.87 & Mercer & $x$ & Randolph & 37.42 & Washington & 35.91 \\
\hline Cedar & 40.48 & Hickory & $x$ & Miller & 32.89 & Ray & 31.07 & Wayne & 43.01 \\
\hline Chariton & $x$ & Holt & $x$ & Mississippi & 52.78 & Reynolds & $x$ & Webster & 40.62 \\
\hline Christian & 20.84 & Howard & $x$ & Moniteau & 18.73 & Ripley & 40.43 & Worth & $\mathrm{x}$ \\
\hline Clark & $x$ & Howell & 46.03 & Monroe & $\mathrm{x}$ & Saline & 23.87 & Wright & 45.53 \\
\hline
\end{tabular}




\section{Precursors of Teen Pregnancy}

There is a plethora of correlates which can relate to higher likelihood of teen pregnancy. Some of the correlates include community disadvantage; family structure and economic disadvantage; family, peer, and partner attitudes and behaviors; and characteristics of teens themselves, such as attachment to school, sexual beliefs, attitudes and skills, and other behaviors that put young people at risk (Kirby, 2001). Some of the literature suggests that neighborhood disadvantage shapes teens' sexual attitudes and behaviors through group-level norms (e.g., Brewster 1994; Sucoff \& Upchurch, 1998). There is little research, with urban or rural populations, that uses schools as the community in which these norms influence sexual behaviors.

Two key data sources, The National Study of Adolescent Health (Add Health) and the National Longitudinal Survey of Youth (NLSY) are used in the studies discussed below. Both data sources contain information from youths living in areas across the United States collected in 1997 (NLSY) and 1994-5 (Add Health) (Harris, 2013; Moore et al., 2000). Add Health youths were in grades 7-12 and four in-home interviews were conducted. Add Health use a school-based design thus the school was the primary sampling unit (Harris, 2013) National Longitudinal Survey of Youth participants were ages 12-16 and they were recruited based on their home location (Moore et al., 2000).

One study using data from the National Longitudinal Study of Adolescent Heath (ADD Health; Harris, 2009; Harris et al., 2009), which was designed to examine health and health related behaviors among seventh through twelfth graders in the United States (Mollborn et al., 2014). Surveys were completed by 90,118 adolescents from 134 
schools, and 20,747 adolescents were interviewed in their homes after the survey was complete.

Mollborn and colleagues' analysis only included high school students (grades 912). Pregnancy norms were measured by asking, "If you got someone pregnant/got pregnant, it would be embarrassing for you." They also measure prevalence of pregnancy by girls self-reporting having ever been pregnant. They found that schools, as a community, with strong average norms against teen pregnancy and higher consensus about the norm had significantly lower rates of teen pregnancy (Mollborn et al., 2014). They also found that stronger school norms against pregnancy $(p=-.08 ; B=-0.63)$ were much more indicative of teen pregnancy outcomes than racial composition $(p=.06 ; B=$ 0.38; Mollborn et al., 2014). This is an important finding because much of the literature focused on urban settings has claimed race as a stronger predictor of risky sexual behavior and teen pregnancy than norms. There is a heightened risk of contracting STIs and unplanned pregnancies for adolescent racial minorities (Eitle \& Thorsen, 2018). Racial differences in sexual behavior do not entirely explain the heightened risk. Some research suggests that larger macrolevel factors such as socioeconomic environment may influence the epidemiological context and may help to understand these disparities (Eitle \& Thorsen, 2018; Eitle, et al., 2015; Ellen et al., 1998, Hallfors et al., 2007)

Another study focused on internal poverty (e.g., locus of control, education expectations, and confidence in graduating) and external poverty (e.g., parent's highest education; Young et al., 2004). Their sample included girls who completed the National Longitudinal Survey of Youth (NLSY) in $8^{\text {th }}, 10^{\text {th }}$, and $12^{\text {th }}$ grade (Young et al., 2004). The girls who were in $10^{\text {th }}$ and $12^{\text {th }}$ grade who reported having a child or current 
pregnancy or reported dropping out of school due to a pregnancy $(n=937)$ were matched on race, birth month, and birth year with girls who did not report a pregnancy or child ( $n$ =914; Young et al., 2004). Results of this study indicated that girls in $8^{\text {th }}$ grade who later became pregnant were more likely to have parents with lower occupational status and lower levels of education, more likely to report that their parents had lower educational expectations for them, and more likely to come from a lower socioeconomic quartile. Also, $8^{\text {th }}$ grade girls who later became pregnant/had a child before completing high school were more likely to expect a blue-collar occupation, had less confidence they would graduate high school, and lower overall educational expectations than those who did not become pregnant. Those who did not become pregnant had locus-of-control scores that were more internal than of those who became pregnant (Young et al., 2004).

It is possible that attitudes of the girls and those important to the girls regarding attitudes about contraception use and perceived side effects can serve as antecedents to teen pregnancy; however, literature regarding women's attitudes and satisfaction with contraception use is scant and even less is known about teens, especially teens in rural areas. Some of the studies, however, have shown that women are influenced by health professionals in their decision to begin and continue contraception (Roderique-Davies et al., 2016). Another study showed that women believe physicians are not willing to reveal potential negative aspects of contraceptive use, such as potentially experiencing a side effect (Dehlendorf et al., 2014). Further, Dehlendorf and colleagues (2012) found that women were particularly concerned about receiving information about side effects. Further, some women in their study stated they did not understand or did not receive any 
information regarding contraceptive side effects and that caused them to be unsure about starting or continuing a contraceptive method (Dehlendorf et al., 2014).

In a recent qualitative study taking place in 41 rural counties in Missouri, I conducted 15 interviews with teen moms (Cook, 2021). The majority of the girls in this study associated contraception use with an onset of negative mental and physical side effects (e.g., bipolar, endometriosis, anxiety, depression, abortion, infertility, and weight gain). One teen mom stated,

Well, from my experiences being friends with people on birth control, it does cause you to gain weight and it can have severe effects of your mental health. And my daughter's father's sister had gotten pregnant and she had an IUD and it had killed her baby.

In three interviews completed with the mothers of teen moms, two of the mothers also associated contraception use with negative mental and physical health outcomes (e.g., birth defects for their child, weight gain, anxiety, and depression). A prominent theme among the teen moms was to either never begin contraception or to halt their contraception use (Cook, 2021). It is important to understand attitudes and beliefs associated with contraception use, specifically associated with side effects, to reduce teen pregnancy rates in rural populations.

Existing literature focuses primarily on teen pregnancy as an outcome of poor resources (e.g., lack of sexual education and/or lack of access to contraception) and does not often consider that the teen pregnancies may be intentional. Rural youth in particular may see that there are few employment opportunities for them in their community and intentionally become pregnant to find purpose in the occupation of parenting (Bissell, 
2000; Domenic \& Jones, 2007; Yawn \& Yawn, 1993). Also, it may be that the rural teens have employment but see having a child as a way to attempt to secure a two-household income and intentionally become pregnant for financial security (Domenic \& Jones, 2007; Yawn \& Yawn, 1993). Temporary Assistance for Needy Families (TANF) which replaced Aid to Families with Dependent Children (AFDC) can be viewed as a safety net to help teen parents. However, in 2001-2002 only 18\% of teen mothers received any TANF benefits whereas before welfare reform $26 \%$ of teen mothers received AFDC support (Mollborn, 2017). Also, teen moms are more likely to be unmarried now. Teen moms are more likely to receive less support, financial and childcare, from the government, the child's father, and other family member (Mollborn, 2017) It is important to note that conversely, some studies have shown advantages for being a teen mother. In some cases, teen mothers during their mid-20s to early 30s are more likely to work more hours and have higher wages than females who have children later in life (Pandey, Tekin, \& Wallace, 2005). Also, in some cases teen moms expressed feeling positive and empowered to find a career now that they had someone else for whom they are responsible (Chambers \& Erausquin, 2018; Seamark, Lings, 2004).

It may also be that the pregnancy was not necessarily intended but no actions were taken to prevent pregnancy. There are a few studies which support this idea of teen pregnancies being “intentional” and not accidental nor unintended (Fortier \& Foster, 2017; Cashdollar, 2018). The reasons for not using contraceptives or preventing pregnancy varied. The girls in these studies were misinformed about their partner's fertility (i.e., their boyfriends said they were sterile; Cashdollar, 2018). Most of the teens 
in both studies reported feeling happy about becoming pregnant and thought it would strengthen their relationship (Cashdollar, 2018; Fortier \& Foster, 2017).

\section{Consequences of Teen Pregnancy}

Teen birth significantly impacts girls' financial wellbeing, mental health, and physical health. Teen births also contribute to lower education for teen mothers, higher likelihood of poverty throughout the mother's life, greater likelihood of depression and substance abuse for teen moms, and greater likelihood of single-parent home for the child because eight out of ten teen fathers do not remain in relationships with the mother (Bissell, 2000; National Campaign, 2013; Walker \& Holtdreter, 2021). This is significant because children of parents experiencing poverty are more likely to experience poverty themselves as adults, thus perpetuating the cycle of poverty. Also, teen pregnancy has negative consequences for the children born to adolescent parents, as children who experience poverty and single-mother homes are more likely to experience feelings of unhappiness, anxiety, and dependence (Gossens et al., 2015; McLeod \& Shanahan, 1993).

\section{Study Purpose}

To explore the rising teen birth rate in rural Missouri, this study aimed to better understand teen girls' contraceptive use in rural Missouri. Specifically, this study examined how knowledge obtained from physicians about side effects and how other's (e.g., friends, family, religious leaders) beliefs about contraceptive use, in addition to the girls' own attitudes about contraceptive use, influence their use of contraceptives. Also, how their use differs based on their belief of perceived side effects from contraceptive information they received or if they had personally experienced a side effect from 
contraceptive use. This information will aid in understanding what factors influence the use or halting of contraceptives among girls in rural areas in Missouri.

The research questions for this study, among a sample of rural teen girls (15-19), include:

1. Do attitudes regarding contraceptive side effects relate to the girls' decision to halt contraceptive use?

H1. Girls with higher negative attitudes regarding contraceptive side effects will be more likely to halt use of contraceptives.

2. Are decisions to halt contraceptive use related to social network members' attitudes toward contraceptive use?

H2. Girls who have people close to them who have negative attitudes regarding contraceptive use will be more likely to halt contraceptive use due to perceived side effects.

3. Is the threat of the likelihood of becoming pregnant without using contraceptives influenced by experiencing side effects from contraceptive use and deciding to halt?

H3. Girls who experience side effects from contraceptive use and halt use will perceive the threat of the likelihood of becoming pregnant in the next year if not using any form of contraception to be low.

4. Are girls' attitudes about contraceptive side effects influenced by being told about contraceptive side effects by a physician? 
H4. Girls who perceive contraceptives to have associated side effects will be more likely to have been told about contraceptive side effects by a physician.

\section{Summary}

This chapter discussed the significance of teen pregnancy and its potential harmful effects. The next four chapters will discuss the theories which were used in this study, current literature regarding the topics of contraceptive knowledge and attitudes regarding contraceptive side effects, the methods for the proposed study, the results, and

finally a discussion of the results as well as implications, future research, and limitations. 


\section{Chapter 2: Review of Literature}

\section{Theoretical Framework}

This section will provide an overview of the health belief model and theory of planned behavior, which serve as theoretical underpinnings for the proposed study. The constructs associated with both theories will be defined and how these constructs relate to contraceptive use for girls will be discussed. A critique of each theory will be included as evidence for why both theories are needed to underscore the current study.

\section{Health Belief Model}

The health belief model (HBM) was born in the discipline of public health (Janz \& Becker, 1984). It was developed by social psychologists in the early 1950 s in an attempt to understand the failure of individuals to participate in disease prevention and/or screenings for early disease detection (Kirscht, 1974). Later the HBM was applied to individuals' responses to disease symptoms and compliance to medical instructions (Becker, 1974). Most of the researchers in the early development of HBM exhibited a phenomenological orientation, which posits that it is the world of the perceiver, not the physical environment, that dictates one's behavior unless the physical environment comes to be represented in the mind of the individual (Rosenstock, 1974). The HBM was derived from psychological and behavioral theory which hypothesize that behavior depends on two main variables: (1) the value placed by an individual on a particular goal, and (2) the individual's estimate of the likelihood that a given action will achieve that goal (Maiman \& Becker, 1974). When these variables were adapted to the context of health-related behavior, these two variables became (1) the desire to avoid illness (or if 
ill, to get well), and (2) the belief that a specific health action will prevent illness (Maiman \& Becker, 1974). Refer to Figure 1 for a conceptual model of the HBM.

\section{Figure 1}

\section{Health Belief Model}

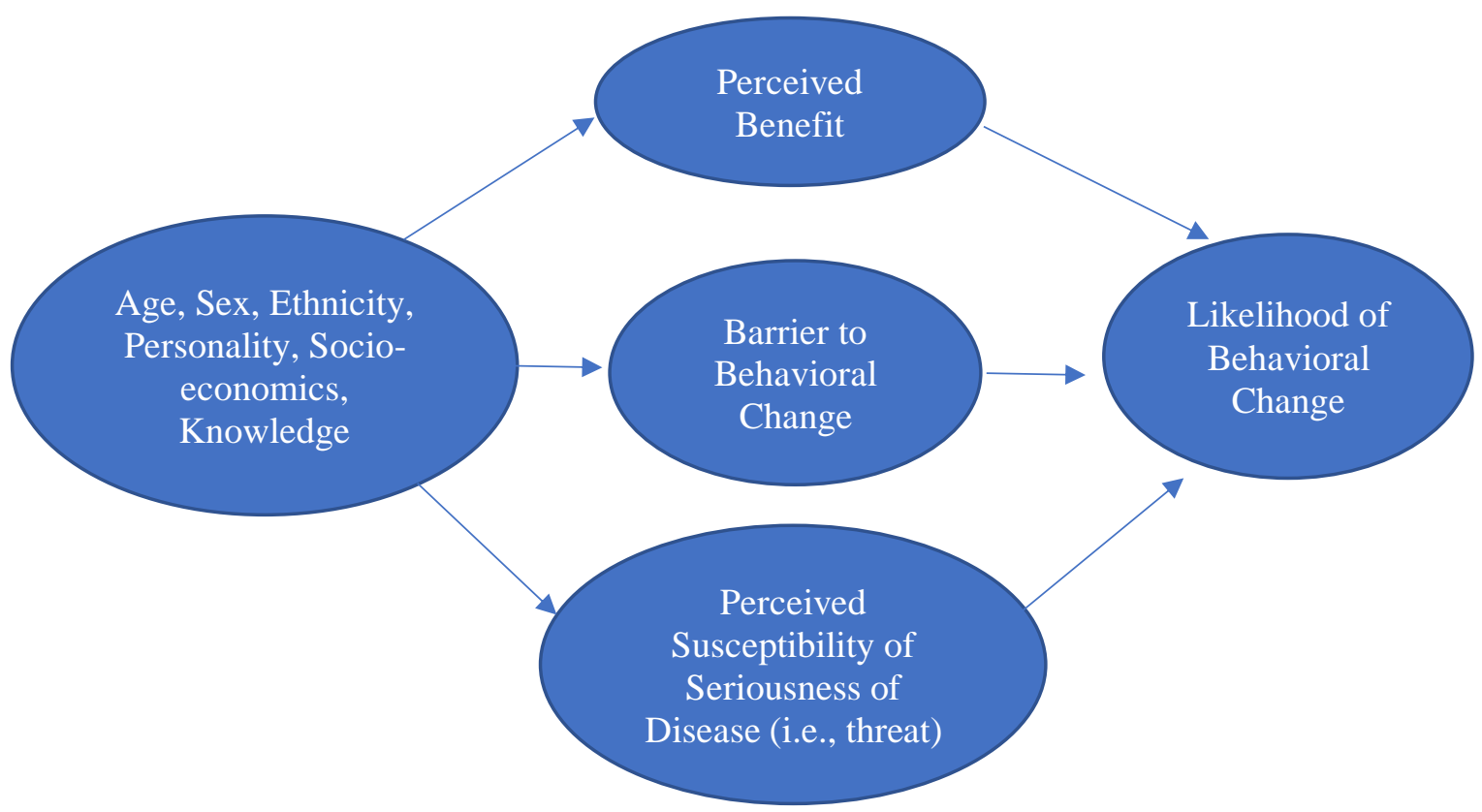

Also, in the formation of the HBM, the founders specifically adapted the idea that an individual exists in a life space which contains regions or situations, some positively valued and some negatively valued, and some regions which remain relatively neutral (Rosenstock, 1974). For example, diseases, if present in an individual's life, would be in the negative regions and were seen to influence the individual to move away from that region unless doing so required them to enter a region of even greater negativity (Rosenstock, 1974). In the context of teen pregnancy, accessing contraception and potentially getting in trouble by a parent can be a negative region; however, not accessing 
contraception and becoming pregnant would cause them to enter a region of greater negativity.

The earliest characteristics of the HBM included certain beliefs that needed to be held by the individual to act to avoid a disease. The individual would need to believe that they were personally susceptible to the disease, that the occurrence of the disease would have at least moderate severity on some component of their life, that taking a particular action would in fact be beneficial by reducing its severity, and that it would not entail overcoming important psychological barriers such as cost, convenience, pain, or embarrassment (Janz \& Becker, 1984). For example, a teen may want to act to avoid pregnancy; however, they may be faced with fear of parental consequences if they access contraception, they may be nervous of side effects and not know which benefits outweigh the others, have financial barriers, barriers to accessing providers to prescribe the contraception, and other factors which may play into their decision-making process to avoid pregnancy.

\section{Perceived Susceptibility}

The HBM includes the individual's subjective risks of contracting a disease. Perceived susceptibility is a continuum and varies widely between individuals (Rosenstock, 1974). Relating this to teen pregnancy, at one end of the continuum, the individual might deny any possibility of becoming pregnant. The more moderate position is the individual may admit to the "statistical" possibility of pregnancy. The other end of the continuum may be an individual who expresses a feeling of being at severe risk of becoming pregnant (Rosenstock, 1974). If a girl denies the possibility of becoming

pregnant entirely, she may not obtain contraception to prevent pregnancy. Whereas a girl 
may believe pregnancy is a certainty with intercourse, and if pregnancy is not their desired outcome, she may obtain contraception and use barrier methods or choose abstinence.

\section{Perceived Seriousness}

The perceived seriousness of a given health outcome also varies widely between individuals. According to the HBM, the degree to which the seriousness of the health outcome may be perceived can be affected by both the degree of emotions triggered by the thought of a disease as well as the perceived difficulties the individual believes the given health outcome will create (Rosenstock, 1974). An individual may see a health problem in terms of the medical consequence; however, they may also see it and the perceived seriousness in a broader context, such as how it will affect their job, family, and friendships (Rosenstock, 1974). In other words, a teen girl may not see pregnancy as having major medical consequences but may see pregnancy as being very serious and potentially harmful regarding her relationships with family, friends, and partner as well as effecting her job, education, and long-term goals.

\section{Perceived Benefits}

The personal susceptibility to a condition and believed seriousness does influence a behavior; however, it does not dictate what that course of action will look like. According to the HBM, this is hypothesized to depend on the beliefs of the individual regarding effectiveness of the various actions to reduce the threat of the disease (Rosenstock, 1974). In other words, just because the individual feels threatened by the health problem, it would not be expected for them to accept recommended medical action unless that action seemed feasible and efficacious by the individual (Rosenstock, 1974). 
For example, just because a girl feels threatened by the possibility of an unplanned pregnancy does not mean the girl would necessarily choose to use a contraceptive method to reduce their risk of an unplanned pregnancy. The girl would need to believe the contraceptive method will work and feel the contraceptive method aligned with their other health beliefs and other aspects of their life, such as their finances, insurance, and access.

\section{Perceived Barriers}

Potential negative factors of a medical action may act as barriers to the uptake of the recommended behaviors (Janz \& Becker, 1984). Individuals may weigh the action's effectiveness with other factors of the action, such as cost, danger (e.g., risk of side effects), pain (physical and mental), and convenience of the action (e.g., it may be timeconsuming; Rosenstock, 1974). The susceptibility and severity set in motion the need to act, and the perception of benefits help dictate the preferred path of action. However, the theory states that something needs to trigger the decision-making process (Rosenstock, 1974). This trigger could be internal, such as symptoms, or external, such as reminders or check-ins via phone and mail from a provider (Janz \& Becker, 1984). Even with this trigger, the barriers to the recommended medical action may be too great to set the process in motion. For example, if the teen girl uses one form of contraception and experiences negative side effects, she may halt usage and be hesitant to try another form of contraception and, therefore, cease contraception use completely.

\section{Critique of the $\mathrm{HBM}$}

While the constructs of the HBM account for several factors that could influence a woman's decision to use contraception, it does not account for all factors that could 
affect this behavior. For instance, the HBM does not account for the social environment and how external factors influence the individuals' decision-making process or ability to perform or not perform a behavior. For example, if a teen girls' parent(s) or an influential person in their life has had a negative experience with contraception or does not support contraceptive use, this could influence the teen to not use contraception. The HBM also does not account for the individual's sense of control of the situation. In other words, the HBM states that the individual may be at risk for a potential health outcome, in this case pregnancy, and the individual's reaction or prevention will depend on their feelings or attitudes about the outcome. Further, this model does not account for the individual's motivation to engage in preventive measures, nor does the model take into account the individual's feelings of perceived control to access contraception from medical providers, accessibility due to family (e.g., parents will not allow their minor daughter to access contraception), and accessibility due to partner barriers (e.g., their partner does not want the girl taking contraception and is a barrier to access), or ability to comply with prevention tasks.

These limitations with the HBM illuminate the need for an additional theory to support the proposed research. The theory of planned behavior was selected because of its ability to complement the HBM and simultaneously address the HBM's aforementioned limitations. The following sections will provide an overview of the theory of planned behavior as well as justification for its use.

\section{Theory of Planned Behavior}

The theory of planned behavior (TPB) was developed in 1988 to use behavioral dispositions, specifically cognitive self-regulation, to predict behavior (Ajzen, 1991). 
This theory consists of four primary constructs that predict if an individual will perform a behavior: (1) attitudes toward a behavior, (2) subjective norms, (3) intention, and (4) perceived behavioral control (Ajzen, 1991). The TPB also includes an individual's intention to perform a given behavior and states that intention captures motivation or how willing or how much effort an individual will place in engaging in the behavior (Ajzen, 1991). See Figure 2 for a visual representation of the TPB.

\section{Figure 2}

\section{Theory of Planned Behavior}

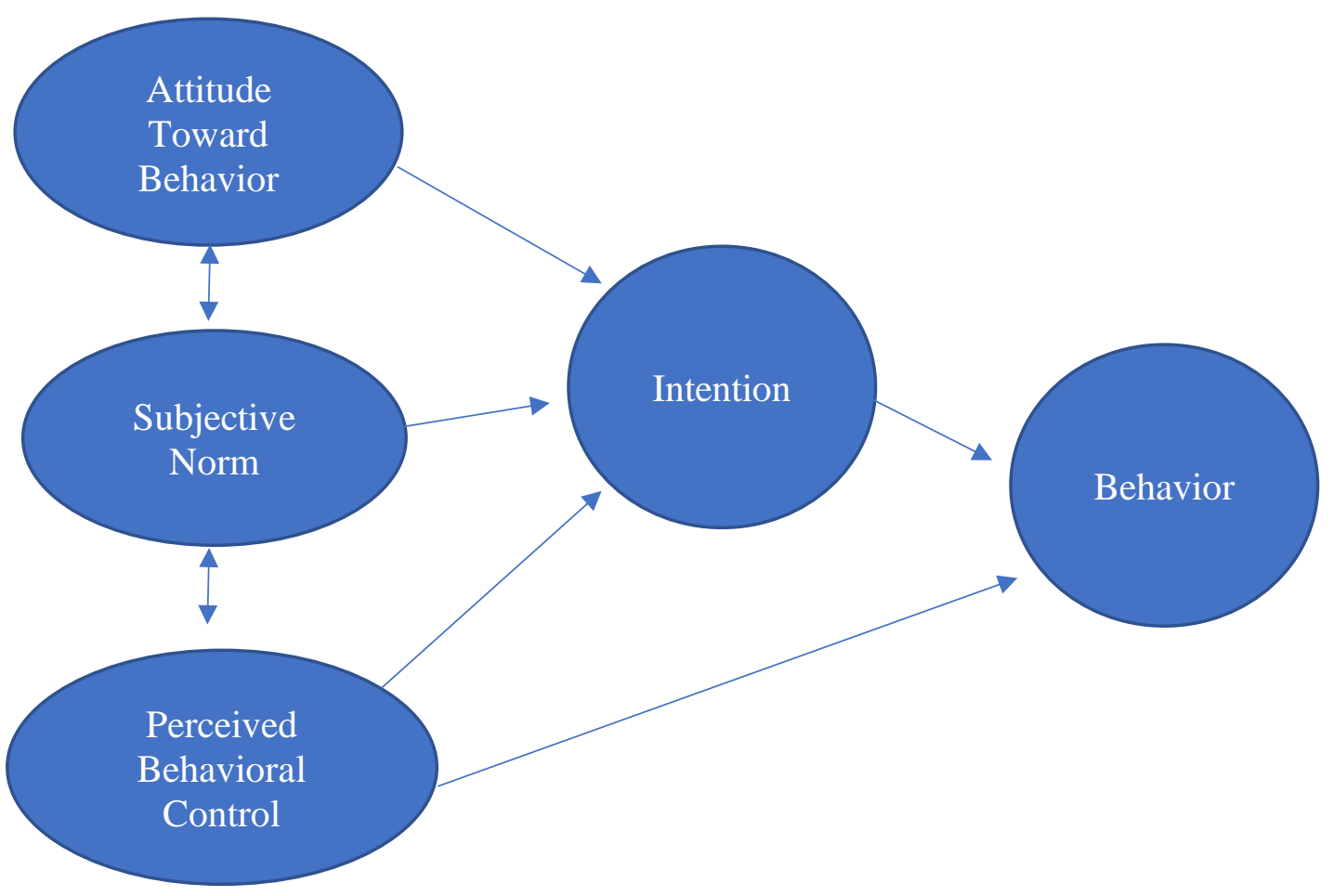

\section{Attitudes Toward a Behavior}

According to the TPB, an individual's attitudes toward a behavior are defined as the degree to which the individual has a favorable or unfavorable evaluation of the behavior in question (Ajzen, 1991). For example, a girl may have a favorable attitude towards one form of contraception (i.e., IUD) over another (i.e., the pill) for various reasons, such as convenience (e.g., not taking the pill at the same time every day), 
maintenance (e.g., only having to have the IUD changed every 3-5+ years), and possibility of effectiveness and/or perceived side effects (e.g., the girl may believe the pill is more likely to result in negative side effects than another form of contraceptive).

\section{Subjective Norms}

The TPB defines subjective norms as an individual's perceived social pressure to perform or not perform a behavior (Ajzen, 1991). Normative beliefs (i.e., what behaviors, influences, or persons of power in a group approve or disapprove) greatly influence an individual's perception of behaviors they should or should not perform. In other words, if a girl's parents, pastor, or someone they view as important in their life has positive or negative beliefs about her using contraception, it could influence the woman's beliefs and actions regarding contraceptive use.

\section{Perceived Behavioral Control}

One's perceived behavioral control refers to the perception one has on the ease or difficulty of performing the behavior of interest (Ajzen, 1991). This construct is often viewed as similar to Bandura's $(1977,1982)$ concept of self-efficacy, which focuses on how well an individual can execute a task required in prospective situations. Self-efficacy is conceptualized as the choice of activity, preparation for the activity, effort during performance of the activity, thought patterns, and emotional responses. Perceived behavioral control, conversely, is conceptualized in a more general framework of relations among beliefs, attitudes, intentions, and behavior. Perceived behavior control can be influenced by the individuals' internal choice to engage in a behavior and the availability or access to resources that are necessary to complete the action (Ajzen, 1991). For example, one of the teens in a qualitative research study that explored rural teen 
pregnancy disclosed that her primary physician did not believe in contraception and would not prescribe it, so the teen had to go to another provider to obtain contraception (Cook, 2021). This situation became a barrier to access and effected the teen's perceived behavioral control because it made it more difficult for her to access what the teen believed would help prevent an unwanted negative health outcome.

\section{Intention}

According to the TPB, intentions are the motivational factors that influence a behavior (Ajzen, 1991). Intentions indicate how much effort one is willing to exert to perform a behavior (Ajzen, 1991). The theory suggests that the stronger the intention to engage in a behavior, the more likely it is the behavior will take place as long as it is up to the individual to make that decision (i.e., the individual is not being coerced; Ajzen, 1991). It is important to note that the other three constructs (i.e., attitude toward the behavior, subjective norm, and perceived behavioral control) have an effect on one's intention and ultimately the performance of a behavior (Ajzen, 1991), according to the TPB. In other words, intention is influenced by attitudes, previous experiences, and knowledge, and is a mediator between those constructs and the behavior itself (see Figure $3)$.

\section{Critique of TPB}

While the TPB accounts for the constructs involved in the decision-making process and intention to perform behaviors, it does not account for the specific factors influencing a medical decision. The TPB also focuses solely on the individuals' decisionmaking process. The HBM is, therefore, warranted to account for the specific nature of making a decision that could not only prevent pregnancy, in this case, but may have other 
negative and positive implications. Also, the HBM accounts for some of the macro-level institutional factors, such as perceived barriers and the teen not being able to access contraception because of institutional barriers (e.g., provider will not prescribe, lack of health insurance, financial constraints to travel to access contraception, etc.). The decision to begin a contraceptive method and retain that method is complex, involving external and internal influences. Thus, constructs from both the HBM and the TPB have been used to create a theory of change for this project which investigated how perceived threat of side effects verses perceived threat of pregnancy, knowledge of side effects, and attitudes regarding contraceptive use of those close to the girls, influence teens' decision to halt the use contraceptives. See Figure 3 for the theoretical model of change for the current study.

\section{Figure 3}

\section{Theory of Change}

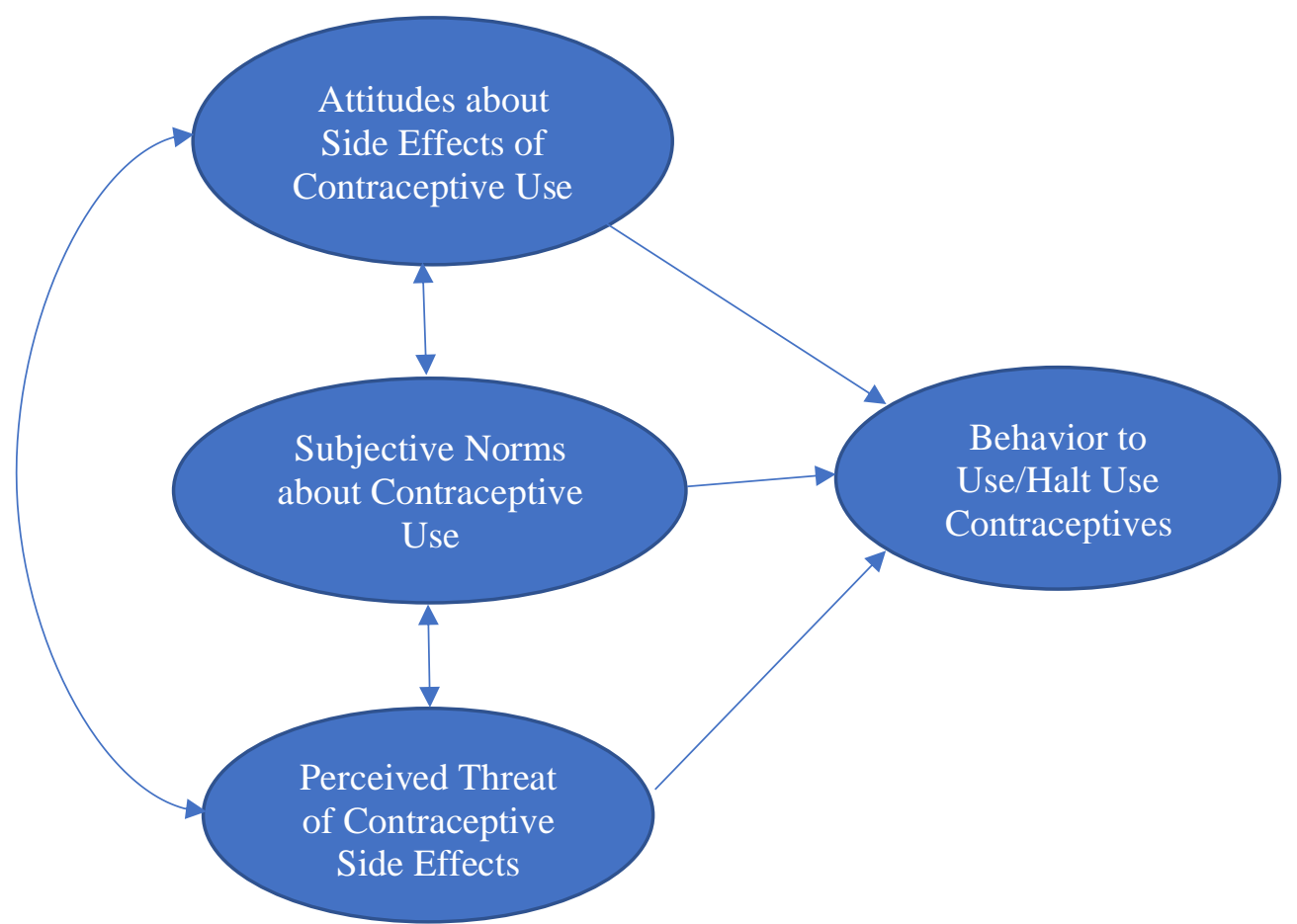

Note. Covariates: Age, race, education, religiosity 


\section{Review of Existing Literature: Teen Contraceptive Use}

There is a dearth of research examining contraceptive use and teen pregnancy in the context of these theories. However, there are a few studies that examine contraception use and health outcomes or side effects and how those factors impact the decisionmaking process to begin and/or continue contraception use, especially among teens. The following sections contain a review of the literature focusing on contraceptive health outcomes, beliefs about contraceptive side effects, attitudes about contraceptives of people close to the girls, and physician providing information regarding contraceptive side effects and how these may relate to one's decision to use contraception.

\section{Contraceptive Health Outcomes}

There are several factors with may influence girls' decisions to continue or halt contraception use. One of those factors may be subjective norms, or attitudes regarding contraceptive use of those or are important to the girls. Another factor may be perceived threat of experiencing a side effect verses threat of becoming pregnant without contraceptive use and understanding which threat is greater to the girls will provide a better understanding of how to approach contraceptive counseling with teens specifically in rural Missouri. This section will provide an overview of existing literature on the aforementioned factors or constructs.

Several studies have examined factors that influence women's and girls' contraceptive use. One study recently looked at what factors influenced women to use long-acting reversible contraception (LARC; e.g., intrauterine device, implants; see section "Perceived Side Effects and Attitudes Regarding Perceived Side Effects" for detailed 
description) using the HBM and the TBP (Roderique-Davies et al., 2016). This study took place in the United Kingdom, specifically Southeast Wales, and recruited from eight community contraception and sexual health clinics. These clinics were sought out by the participants because the women were at risk for pregnancy but did not want to become pregnant (Roderique-Davies et al., 2016). The study focused on self-efficacy and intention to use a LARC as their constructs for the HBM and the TPB. The sample was comprised of 128 women with a mean age of 26.12 years. They determined that constructs of the TPB and the HBM accounted for $73 \%$ of the variance in intention to use a LARC, and the construct with the strongest predictive power was perceived benefits ( $ß$ $=0.798, \mathrm{p}<.001)$. The next strongest predictor variable was subjective norms $(B=0.275$, $\mathrm{p}<.001$ ), which determined that the beliefs of others do impact a woman's intention to use a LARC (Roderique-Davies et al., 2016). Cues to action, defined as the stimulus needed to trigger the decision-making process to accept and act on a recommended health action (e.g. to begin a form of contraceptives) and health motivation also predicted intention to use a LARC (Roderique-Davies et al., 2016). Intention was a significant predictor of LARC use until variables of the HBM were introduced (perceived barriers and health motivation) in the analysis and those were associated with not using a LARC. Perceived barriers to using a LARC ( $<<.01 ;$ OR: 0.664) was the strongest predictor to women not obtaining LARC (Roderique-Davies et al., 2016). In sum, this study suggests that how women perceive the benefits of contraception use outweighs the risks of becoming pregnant; however, perceived barriers and perceived control may influence the use of them regardless of the benefits. Also, this study supports that others' 
attitudes/beliefs (i.e., subjective norms) may influence a woman's decision to use contraception.

The HBM has been used as a theoretical framework to examine contraceptive use in other studies as well. One study examined social and attitudinal determinates of contraceptive choice between birth control pills and diaphragm use (Condelli, 1986). A convenience sample of women who visited a suburban family planning clinic completed a survey $(N=632)$. They found that women who chose birth control pills were more likely to perceive greater support from others using the pill (Coefficient $=-.48, p<.001)$. They also found that the participants who chose birth control reported that diaphragm use was more inconvenient $($ Coefficient $=0.47, p<.001)$, there was less concern about the birth control pill's side effects (Coefficient $=0.28, p<.001$ ), birth control pills provide more protection against pregnancy $($ Coefficient $=0.22, p<.001)$, and the participants knew less about contraceptives in general than those who chose to use diaphragms $($ Coefficient $=0.13, p<.001 ;$ Condelli, 1986). Similarly, a survey based off the constructs of HBM was administered to a convenience sample of patients at high risk for unintended pregnancy based on income filling prescriptions at a federal clinic. The majority of the sample were female (76\%), White (75\%), and 18-35 years old (64\%). Results showed the most important reason for current contraceptive choice was effectiveness $(p=.043)$ and ease of use was the most important for patients with higher education levels $(p=.001$; Brown et al., 2011). Also, as household income increased, worries of potential side effects lessened.

The TPB has also been used as a theoretical framework to examine contraceptive use. A study found that the TPB explained between $23.5 \%$ and $45.8 \%$ of the variance in 
intentions to use contraceptives (Craig et al., 2000). This sample consisted of 711 male and female students (53.8\% and 46.2\%) in grades 9-13 from an Ontario city. The results also suggested that the TPB is a good model to use when examining teen contraceptive use intentions because the external variables (e.g., age, race, past use of contraceptives) affect intentions to use indirectly through their influence on attitudes, subjective norms, or perceived behavioral control (Craig et al., 2000). Attitudes were consistently positive predictors of intentions to use condoms and birth control pills for both male and female participants (Craig et al., 2000). Another study found that TPB constructs related to contraceptive use among African American teen girls (age range 14-19, mean age = 17.35 years; Marcinkowski et al., 2021). This study is a secondary data analysis using data obtained from 2GETHER-The Dual Protection Project, which was a randomized control trial aiming to decrease STIs/pregnancy among African American adolescents (Ewing et al., 2017; Marcinkowski et al., 2021). The data included in this secondary analysis were from participants who engaged in vaginal sex in the past 3 months and finished the baseline survey $(N=697)$. Results showed that anti-pregnancy attitudes $(p<$ $0.001)$ and subjective norms $(p=.031)$ were associated with increased intentions to use contraception (Marcinkowski et al., 2021). Higher perceived behavioral control ( $p<$ $.010)$, anti-pregnancy attitudes $(p=.010)$, and intentions to use contraceptives $(p<.001)$ were associated with using contraceptives (Marcinkowski et al., 2021).

A qualitative study focused on teens' perceptions of their mother's approval of contraception related to the teens' decisions to use contraception (Jaccard \& Dittus, 2000). This study conducted two waves of interviews with 10,000 adolescents in grades 7 to 12 in urban and suburban areas (Jaccard \& Dittus, 2000). Overall, they found if the 
adolescents perceived their mother's approval of them using contraception, they were more likely to access and use contraception methods (Jaccard \& Dittus, 2000). This study also found that the adolescents' perception of their mother's approval was more important in the decision-making process than the maternal attitudes regarding contraception use (Jaccard \& Dittus, 2000). These findings are important for this project because they suggest that subjective norms can impact one's decision to begin and/or halt contraception use among teen girls in urban and suburban areas. The mother's approval could also limit the teen's access and perceived behavioral control.

However, another qualitative study examining family communication and teen contraceptive use found contradicting results to the Jaccard and Dittus (2000) study. This study interviewed teens $(<15-17$ years old, $N=290)$ from urban, suburban, and semirural areas in Southeastern Pennsylvania at three points in time: the first time was when they first accessed one of the six family planning facilities selected, then six months post first access, and again 15 months post access (Furstenberg, 1984). The results indicated that neither communication about sex and contraception nor the mothers' knowledge of the teens' visit to the clinic was strongly related to the use of contraceptives by the teens (Furstenberg, 1984). This study is older than the Jaccard and Dittus (2000) study, which causes concern for comparison of results; however, the Furstenberg (1984) results are important to note as these teens were accessing and using contraception with little influence from their mothers, which could be in support of a hypothesis that mothers, or people of importance to the teens, influence the teens' decision-making process (i.e., subjective norms). In other words, if the mothers are not talking about contraception or their opinions regarding contraception, it may not influence the teens' opinions and 
decisions regarding contraceptive use. Alternatively, if the mother expresses her opinions regarding contraception use, it may influence the teen's opinion and decision-making process (i.e., if the mothers express negative opinions about contraceptives, the teens may adopt these beliefs). These study's conflicting results indicate more research is needed to fully understand factors that influence girls to use and continue to use contraceptives. These findings are important to consider for this research on the relationship between perceived side effects and continuation or halting of contraception use because knowing more about how the constructs of these theories are associated with perceived side effects and contraceptive use could contribute to intervention development.

\section{Perceived Side Effects and Attitudes Regarding Perceived Side Effects}

Side effects are a risk with any medication and contraceptives are no different, but the prevalence of these side effects is low. Known side effects of an IUD include, bacterial infection, and infiltrating the wall of the uterus both are very rare (Planned Parenthood, 2021). Side effects associated with birth control pills mostly happens in conjunction with another behavior such as smoking. Smoking and birth control use has been shown to increase the risk of stroke especially in women over 35 (Gillum, Mamidipudi, \& Johnston, 2000). The arm implant (Implanon) again has low prevalence of side effects. Side effects associated with the arm implant include, bleeding, pus, redness, or pain that does not go away in the arm where the implant was inserted, yellowing of the eyes and/or skin, heavier and/or longer than normal bleeding from your vagina (Planned Parenthood, 2021). However, there may be other factors contributing to the girls perceiving or believing in side effects that are not associated with contraceptive use or that the prevalence rate is greater than reported. Some of these factors may be 
misinformation from social sources (e.g. friends, family members, and social media). It may also be that they already had the medical condition, but it was undiagnosed until after they began contraceptive use (i.e. the girl had an anxiety disorder but it was not diagnosed until after beginning contraceptive use and therefore the girl assumes the anxiety disorder is a side effect of contraceptive use). There are several studies on the topic of side effects and contraceptive use few of these are with teen populations and almost none of rural U.S. populations. The rest of the section will focus on a review of existing literature and provide a better understanding of this construct as it relates to the theory of change for this project.

A recent study focused on understanding if the use of hormonal contraception was related to the use of antidepressants and a diagnosis of depression (Skovlund et al., 2016). The population for this study came from the Danish Sex Hormone Register Study, which is an ongoing nationwide study that includes all teen girls and women living in Denmark. The study's sample focused on girls and women 15-34 years old during the years of 2000-2013 $(N=6,832,938)$. Contraception was categorized based on estrogen type and dose, progestin type, and route of administration (Skovlund et al., 2016). The reference group consisted of girls and women who have never used hormonal contraceptives and former contraceptive users. The depression variables were redeemed prescription of an antidepressant and a first discharge diagnosis of depression from the Psychiatric Central Research Register (Skovlund et al., 2016). They found that all types of contraception were positively associated with the use of antidepressants and a depression diagnosis. Incidence rate ratio $(\mathrm{RR})$ for antidepressant use when using oral contraceptives was 1.2, and for progestin-only contraceptives, $R R=1.3$. For first diagnosis of depression, $R R=$ 
1.0 for all oral contraceptives and $\mathrm{RR}=1.1$ for all progestin-only contraceptives. The study also found that 2.2 per 100 girls and women who were using contraception had a first use of anti-depressants, whereas in the control group (not using contraception), 1.7 per 100 girls and women had a first use of anti-depressants (Skovlund et al., 2016). Adolescent girls using contraception experienced higher risks of depression diagnoses and first use of anti-depressants than adult women (Skovlund et al., 2016). This could be a direct result of the contraception; however, developmental stages and the age of the girls and women should be considered. It may be that the adolescent girls were just beginning to experience depressive symptoms, whereas the adult women may have experienced symptoms in younger years and not been formally diagnosed. More evidence is needed to determine if there is an effect of contraceptive use on onset of depression.

Another qualitative study was interested in understanding the decision to halt contraception from a social perspective rather than the more traditional medical perspective. These authors were interested in the link between cultural messages about gender and women's contraception use, and the author argues that the gendered emphasis on women's appearance and emotionality shapes how the women perceive the seriousness of contraception side effects, such as weight gain and mental health problems (Littlejohn, 2013). The data were from the College and Personal Life Study, which consisted of 103 in-depth interviews with women to understand why women who do not wish to become pregnant do not always consistently use contraception. They found that women who halted contraception use because of weight gain still wanted to avoid pregnancy, but the weight gain caused enough discomfort and challenges that they discontinued contraception use. Women who experienced negative mental health side 
effects discontinued contraception because they said it made them feel irrational (Littlejohn, 2013). When the women felt the contraceptive use was making them more emotional, they associated words like "crazy" and other negative emotions with their response (Littlejohn, 2013). The author mentioned that cultural messages about women's emotions frame the women as emotional beings and that particular emotions are irrational and negative for women (Littlejohn, 2013). This study is important to consider for the current study because subjective norms, especially those specific to rural communities, may influence the teens' use of contraceptives. Subjective norms are determined by perceived social pressure from others for an individual to behave in a certain manner and their motivation to comply with those people's views (Ajzen, 1991). If the girls feel that there is societal pressure from people important to them to look a certain way (e.g., not gain weight) and act a certain way (e.g., not act "crazy") and they perceive that using contraceptives is not helping them meet this agenda, they may halt contraceptive use.

One randomized control trial examining perceived side effects from oral contraceptives found that the group that received oral contraceptives and the placebo group reported similar perceived side effects (O’Connell et al., 2007). The sample consisted of 76 participants and 57 (77\%) of participants reported side effects (O'Connell et al., 2007). The test group and placebo group both had a median of two side effects complaints (O’Connell et al., 2007). Side effects included headache, nausea, acne, abdominal pain, back pain, vomiting, breast tenderness, breast enlargement, mood swings, weight gain, premenstrual syndrome, and irregular bleeding (O'Connell et al., 2007). These results support the proposed hypothesis in this study that perceiving experiencing side effects, whether they are actually experiencing side effects or not, may 
contribute to their attitudes about contraceptive use and ultimately lead to them halting contraceptive use.

Another study with a sample of 1,716 women under the age of 25 from three family planning clinics in Atlanta, New York, and Dallas who requested oral contraceptives from their provider were randomly assigned to Quick Start (QS) or Conventional Start (CS) of oral contraception (Westhoff et al., 2007). Participants engaged in a three-month and six-month telephone interview. The majority of participants were Hispanic (58.7\%). Based on results of a focus group carried out prior to this study, the side effects selected to be measured were weight change, headaches, moodiness, and sexual satisfaction (Westhoff et al., 2007). Fifty-seven percent of participants had discontinued oral contraceptive use by the six-month interview (Westhoff et al., 2007). At the three-month interview, the majority had not complained of any of the pre-determined side effects. Those who did complain, especially of headaches (increased due to pill use, $30.6 \%$ ) or moodiness (increased due to pill use, $27.0 \%$ ), were more likely to halt contraceptive use (Westhoff et al., 2007). Similar results were reported in another study (Hall et al., 2012). The majority of women in the study identified as Hispanic $(n=324,92 \%)$. This sample is part of a larger randomized trial conducted in New York City. Women ages 13-24 $(n=354)$ were randomized into three or sevenmonth pill pack supply groups and were interviewed at six months to determine if perceived side effects had occurred (Hall et al., 2012). At six-months, only $38 \%$ of participants were still using oral contraceptives. Results showed that perceived depressed $\operatorname{mood}(p=.05)$, stress increase $(p=.03)$, and weight gain $(p=.04)$ were causes for discontinuing oral contraception among young ethnic minority women (Hall et al., 2012). 


\section{Physician Influence on Perceived Side Effects of Contraceptives}

Physicians can influence their patients' decision-making processes (Bailo, et al., 2019; Fridman, et al., 2018). Patients often have their decisions influenced by mistaken judgement (e.g. they have been misinformed about side effects of a type of contraceptive). There may be patient concerns that the physician will not be forthcoming or honest about side effects and/or the prevalence of side effects. Also, people are more likely to trust those close to them and their information more than a physician. However, physicians should have the knowledge and the contraceptive counseling skills to inform and support their patients to make the best decision for the patients desired results. The physician influence on teens beliefs of contraceptive side effects has not been explored among teens in rural America however, previous literature has studied this relationship among other populations.

One study reviewed what is known about contraceptive counseling (e.g., how it is performed, what works, and what does not work; Dehlendorf et al., 2014). This study emphasized relational communication, defined as "interpersonal communication that contributes to the formation of a positive therapeutic relationship between the provider and the patient," as a very important component of contraceptive counseling (Dehlendorf et al., 2014). They found that relational communication, as seen in other studies, has often been provider-dominated with minimal engagement between women and their providers in the process of selecting a contraceptive method (Dehlendorf et al., 2014). They also found that providers were not tailoring their contraceptive counseling to the needs or wants of their patients (i.e., they were using a "cookie-cutter" approach to contraceptive counseling for all females). Another very important point from this study is 
that women believe physicians are not willing to reveal potential negative aspects of contraceptive use, providers frequently have inaccurate knowledge about contraceptive methods, and report providers using scare tactics to influence their choice of contraception (Dehlendorf et al., 2014). A qualitative study had similar results in that women were particularly concerned about receiving information about side effects (Dehlendorf et al., 2013). The sample consisted of 42 women (10 non-Hispanic White, 10 Black, 13 Latina Spanish-speaking, 9 Latina English-speaking), and semi-structured interviews were conducted to better understand women's interactions with family planning providers in the decision-making process about using contraceptives (Dehlendorf et al., 2013). The transcripts were coded using modified grounded theory (Dehlendorf et al., 2013). Some women stated they did not understand or did not receive any information regarding side effects of contraceptive use and that caused them to be unsure about starting or continuing a contraceptive method (Dehlendorf et al., 2013).

\section{Rural Communities}

This review of the literature provides evidence that the HBM and the TPB are appropriate theoretical frameworks for understanding girls' behavior to continue or halt contraception use. It can also be seen from the previous literature that internal and external factors impact this process and solidify this is as a multi-faceted process. However, this literature review also illuminates a large gap in our knowledge about contraceptive use among teens in rural communities. As such, a qualitative study aimed to understand factors related to teen pregnancy in 41 rural counties in Missouri, some of which have pregnancy rates twice the national average (Cook, 2021). The aims of this project were to: (1) identify factors associated with unintended teen pregnancy in rural 
Missouri; (2) investigate how religion influences sexual debut, condom use, and contraception use; and (3) investigate how parental/generational ideals influence sexual debut, condom use, and contraception use.

Cook (2021) completed 15 interviews with teen moms. In 11 of the 15 interviews, the girls stated that they either did not begin contraception or halted contraception (and did not begin again) prior to or just after becoming pregnant with their first child because of perceived negative health outcomes. Perceived negative health outcomes associated with the girls' contraception use, in this sample, consisted of endometriosis, bipolar disorder, anxiety, depression, weight gain, and negative health outcomes for the child, such as deafness and mental developmental delays. For example, one teen mom stated, "I was on the depo shot for three years and then it caused me to get endometriosis."

The forms of contraception used by the individuals included oral contraceptives, the Depo Provera shot, Implanon/Explanon (arm implant), and intrauterine devices (IUD). The majority of the girls stated that stopping the contraception was the best decision for them because of the perceived negative outcomes they associated with the contraception use, regardless of the increased likelihood of becoming pregnant. It is important to note that none of the girls who stopped contraception used any other form of barrier method (i.e., condoms, diaphragm, etc.) after halting their contraceptive use. Some of the girls also discussed not ever beginning contraception or halting their contraception use because of the negative outcomes they were told by friends and family (i.e., subjective norms). The negative outcomes they discussed included miscarriage, infertility, and mental illness. One teen mom stated, "Birth control is like just something a lot of the girls in my family say not to do because it can cause infertility and make it 
even worse and like harder to have a kid." This study informs the proposed project as it suggests subjective norms, attitudes toward contraceptive use, and perceived seriousness (i.e., the risk of side effects from contraceptive vs. the risk of becoming pregnant) are all potential factors in understanding girls' use of contraceptives. This is very important to understand given the high rates of teen pregnancy in these rural areas.

There are no known studies regarding perceived side effects influencing girls' decision to use contraceptives in rural areas in the United States. However, there are a few in rural areas of other countries. A qualitative study conducted in the southern region of Malawi held 60 focus groups (20 with adolescents 15-19 years, 20 with young adults 20-34 years, and 20 with adults 35-65 years). They found that oral contraceptive use was popular; however, most women stated they do not like using them because they were told by health workers that birth control pills cause damage to organs (Chipeta et al., 2010). Another qualitative study conducted in Vhembe District in Limpopo Province, South Africa held six focus groups with teens (13-19 years old; 23 boys and 34 girls; Lebese et al., 2013). The results indicated that adolescents viewed barriers in accessing contraception services in health care settings (Lebese et al., 2013). Specifically, they identified cultural barriers related to communication about sex-related matters, lack of contraceptive education through school-based sex education courses, lack of access to medically factual information, and peers being their main form of contraceptive information but that information was mostly untrustworthy or distorted (Lebese et al., 2013).

\section{Current Climate and Why This is Important}


It is important to note the climate in the United States when this research took place, specifically regarding COVID-19 and sexual health. Prior to COVID-19, girls and women in rural areas have less access to sex education, specialty doctors (e.g., OBGYN), and it is more difficult for them to access contraceptives, as well as contraceptive counseling (Barral et al., 2019; Rowland \& Lyons, 1989). However, it is unclear if the medical attention directed toward COVID-19 has made sexual health resources even more scarce for girls and women in these rural areas.

A few sources have expressed anticipating a surge in unwanted/unplanned pregnancies among teens and women globally. Researchers estimate there will be 49 million women with an unmet need for contraception, 15 million unintended pregnancies, 28,000 maternal deaths, 168,000 newborn deaths, and three million unsafe abortions in low and middle-income countries (Riley et al., 2020). Also, school closings in the past have shown to be harmful for girls, leading to an increase in gender-based violence and unintended pregnancy (Ahmed, 2020). The COVID-19 pandemic has strained public health systems globally (UNFPA, 2020). The World Health Organization (WHO) conducted a recent survey and found that family planning and contraception were some of the most frequently disrupted health services, with 7 in 10 countries experiencing disruptions (UNFPA, 2020). Family planning services were disrupted in $68 \%$ of countries, and $9 \%$ of countries reported severe or complete disruption (World Health Organization, 2020). A survey conducted by the Guttmacher Institute examining reproductive health services among women in the United States found that $33 \%$ of women had to delay or cancel visiting a health care provider for sexual reproductive health (SRH) care due to the pandemic (Lindberg et al., 2020). Also, 27\% of women 
reported being more worried about their ability to afford or obtain contraception due to the pandemic (Lindberg et al., 2020). Again, while it is unclear the impact COVID-19 will have on reproductive health in rural areas in America, or specifically Missouri, these anticipated surges in unwanted/unplanned pregnancies are of great concern. It is critical that researchers continue to focus on the effects COVID-19 has on sexual health among girls and women so we can work quickly and effectively to correct these issues.

Given a general lack of knowledge about rural girls' experiences, it is critical to understand how and why girls in rural Missouri are experiencing teen pregnancy at disparate rates and where they are receiving information to inform health behaviors that may lead to teen pregnancy (e.g., contraceptive use). There is overwhelming evidence that teen pregnancy leads to adverse health, financial, and social outcomes for teen mothers and their children (National Campaign, 2013; TPPP, 2013). However, the teenagers in Cook's (2021) study felt supported by their community and physically and financially stable, at least in the early stages of motherhood. One teen mom stated, My family had this little rinky-dink trailer, so we fixed it up with $\$ 7,000$ we got from my grandparents. And we live on my aunt and uncle's land. And someone my dad knows got my boyfriend a job and we were able to buy a car, so I just feel like we're doing good for how young we are.

Also, several of the teen moms stated that their church communities were supportive and let them host their gender reveal and/or baby showers at the church. It is unclear how this sense of support impacts further decisions regarding family planning/prevention. Too little is known about the decision to use contraceptives among teens in rural Missouri and in order to best foster interventions and education, further research is warranted. It is 
critical for researchers and social workers to understand all aspects of the contraceptive use decision-making process in order to develop and deliver effective interventions for reducing teenage pregnancy.

Thus, this project was completed with girls in rural Missouri to understand how perceived side effects, societal norms, knowledge, and attitudes relate to their use of contraceptives.

\section{Conclusion}

This chapter provided an overview of the health belief model and theory of planned behavior. The literature review portion of this chapter provides support for the selected theories and illuminates the gaps in this area of research, which provides support for the current study. The next chapter discusses this study's methods. 


\section{Chapter 3: Methods}

\section{Research Design}

The primary goal of the proposed study is to explore whether constructs from the HBM and the TPB (e.g., attitudes toward behavior, subjective norms, and perceived threat) influence contraceptive use among girls in rural Missouri. Specifically, this study is inquiring how people close to the girls' attitudes about contraceptive use and the girls' own attitudes about contraceptive use, specifically potential side effects, influence their decision to halt use of contraceptives. Also, this study examines how information they received about side effects associated with contraceptives or perceived experience of side effects caused by contraceptive use is related to their decision to use or halt contraceptives. This chapter will cover the research questions, methodology, and analytic plan for the proposed study.

\section{Research Questions}

1. Do attitudes regarding contraceptive side effects relate to the girls' decision to halt contraceptive use?

H1. Girls with higher negative attitudes regarding contraceptive side effects will be more likely to halt use of contraceptives.

2. Are decisions to halt contraceptive use related to social network members' attitudes toward contraceptive use?

H2. Girls who have people close to them who have negative attitudes regarding contraceptive use will be more likely to halt contraceptive use due to perceived side effects. 
3. Is the threat of the likelihood of becoming pregnant without using contraceptives influenced by experiencing side effects from contraceptive use and deciding to halt?

H3. Girls who perceive experiencing potential side effects from contraceptive use as a greater threat will think the likelihood of becoming pregnant in the next year if not using any form of contraception to be low.

4. Are girls' attitudes about contraceptive side effects influenced by being told about contraceptive side effects by a physician?

H4. Girls who perceive contraceptives to have associated side effects will be more likely to have been told about contraceptive side effects by a physician.

\section{Sample and Recruitment}

This study uses a nonexperimental, cross-sectional research design using a convenience sample. Girls ages 15-19 in the 41 rural Missouri counties with higher teen pregnancy rates than the national average, were recruited for the proposed study. I used Facebook advertisements to advertise the Qualtrics survey and recruit teen girls into the study. The Facebook advertisements targeted the 41 rural Missouri counties with teen pregnancy rates higher than the national average (see Figure 4 for a map of Missouri highlighting these counties in green). I posed Facebook advertisements on July 20, 2020 (\$100 for 18 days), and the post was "boosted" (i.e., paid to have the advertisement show more times a day on people's Facebook pages in the counties) on July 22, 2020 (added $\$ 13$ for one day) and July 24, 2020 (added \$30 for one day). The advertisement ran for a total of 18 days, reached 16,273 people. The advertisement had 1,601 post engagements (i.e., people clicked on the advertisement; 174 people viewed the ad, 437 people clicked 
on the link, and 941 "other clicks"). There were also 26 "likes," three "loves," four "laughs," one "sad," two "angry," 10 comments, and two shares of the advertisement. The advertisements targeted one city in each county +25 -mile radius (e.g., New Madrid, Missouri $+25 \mathrm{mi})$. The majority of people reached $(84.9 \%)$ were girls ages $13-17$. This recruitment strategy was selected because it has proven effective for this population; this strategy was used for recruitment for the qualitative study that informed this research (Cook, 2021). The target sample size, based on a power analysis in G*Power 3.1 (Faul et al., 2009), was originally 340 to achieve a statistical power of $80 \%$. The total sample size included in analyses was 183 , short of the target sample due to missing data. 


\section{Figure 4}

\section{Missouri Counties for Recruitment}

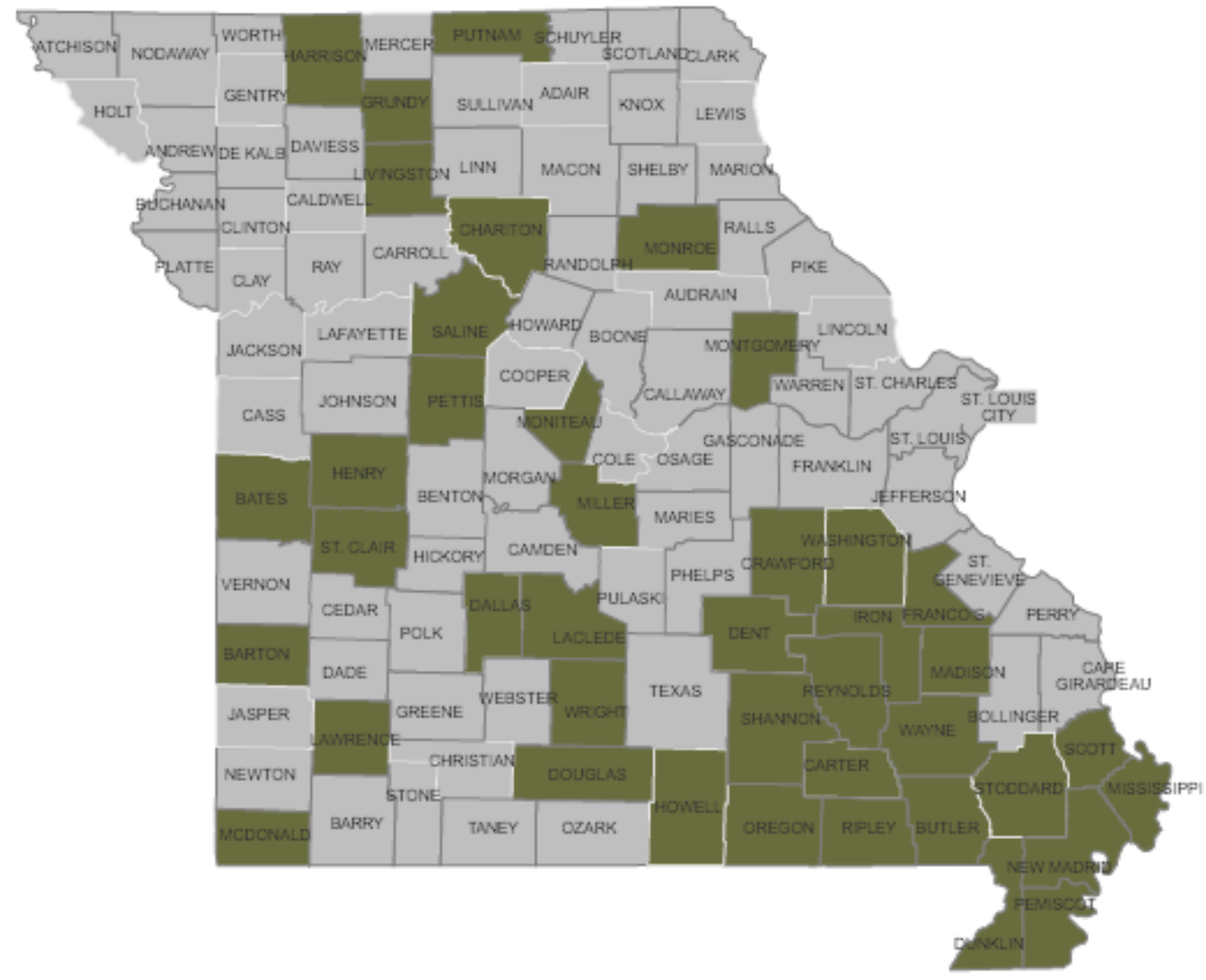

\section{Power Analysis}

A power analysis framework for a logistic regression was used. The power analysis to determine the number of girls needed in the sample was completed using G*Power 3.1 software (Faul et al., 2009). An odds ratio of OR = 1.71 was determined [Pr $(\mathrm{Y}=1 \mathrm{X}=1) \mathrm{H} 1 ; \operatorname{Pr}(\mathrm{Y}=1 \mathrm{X}=1) \mathrm{H} 0$ ] using probabilities of $30 \%$ for the alternative hypothesis and $20 \%$ for the null hypothesis. Also, an effect size of $8 \%$ was selected based on previous research (Roderique-Davies et al., 2016; Skovlund et al., 2016). These 
parameters, as well as a statistical power of $80 \%$, provided a sample size calculation of 340.

\section{Figure 5}

Power Analysis

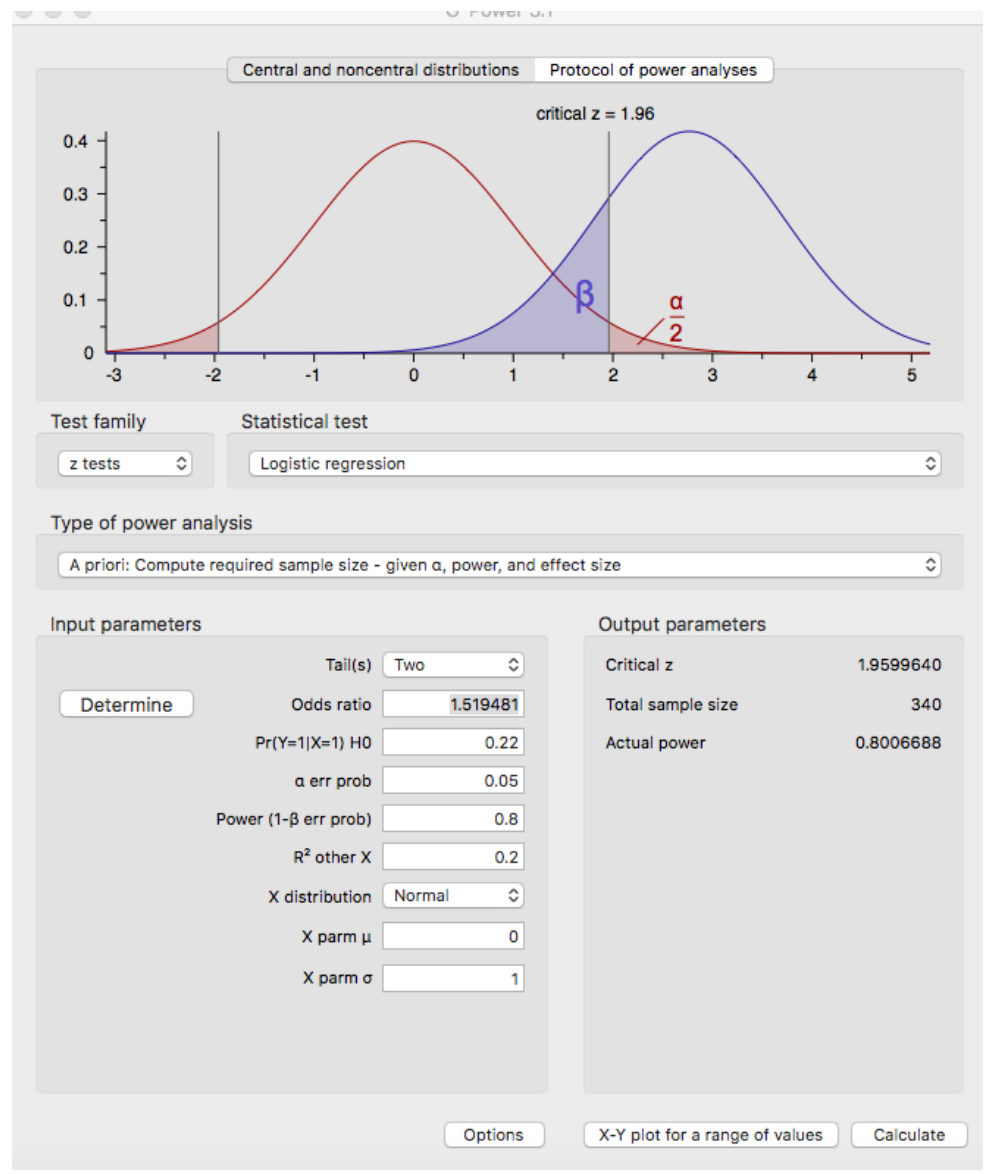

Table 2

Required Number of Girls (using a conservative estimate of $R 2=0.20$ )

\begin{tabular}{ccc}
\hline \multicolumn{3}{c}{ Effect Sizes } \\
\hline $8 \%$ & $10 \%$ & $12 \%$ \\
\hline 340 & 223 & 166 \\
\hline
\end{tabular}

\section{Procedures}

All data collection procedures underwent review and approval through the University of Missouri Institutional Review Board (IRB) prior to data collection. Final 
IRB approval was received on March 18, 2020. I created the survey in Qualtrics and distributed it to participants directly through that platform. The participants completed the survey and received a $\$ 10$ electronic gift card within three days of completion. The eligibility criteria for participants were: cisgender (as cisgender girls are more likely to take hormonal contraceptives than transgender girls as transgender girls do not have the risk of pregnancy), aged 15-19 (the majority of teen pregnancy research/statistics use this age range (Maddow-Zimet \& Kost, 2021), fluent in English (this is necessary because the teens need to be able to read and understand the survey questions), and living and have lived for a minimum of 5 years in one of the 41 Missouri counties identified. This decision was made because the average age most girls begin contraceptive use is age 16 in the United States. Therefore, it was decided that the girls taking the survey had most likely not experienced urban/suburban ideals and accessed contraceptive use (Guttmacher, 2020) in one of the 41 Missouri counties identified. The eligibility criteria were screened for at the beginning of the survey. If the participant did not meet the eligibility criteria, they did not complete the survey and were directed to the end screen of the survey. If the participant did meet the eligibility criteria, they were directed to the consent page. If the participant consented, they were directed to the beginning of the survey. A total of 1,690 people started the survey and 685 participated in the survey after meeting the eligibility criteria.

Bots are a known issue for online data collection (Godinho et al., 2020). Bots was an unanticipated problem; however, quickly discovered due to the location of the IP addresses being outside of Missouri and often outside of the United States. Also, bots were detected by the time it took to complete the survey. For example, I determined the 
survey was completed by a bot if it took under 5-minutes to complete the survey that should take approximately 15 minutes to complete. I added a security measure requiring the IP address to be in Missouri for people to be able to participate in the survey and the survey was relaunched after two days. Those who had an IP address that was not in the

state of Missouri, prior to the survey being relaunched, were not paid and their responses were deleted. Of the 685 surveys, I determined 425 were completed by bots thus, paying 260 participants compensation. The total number of surveys started after meeting eligibility criteria was 401 however, 218 of those surveys had no questions answered and I deleted those participants leaving a total sample size of 183.

\section{Study Measures}

\section{The Contraceptive Utilities, Intention, and Knowledge Scale}

Contraceptives for this study are defined as a device or drug serving to prevent pregnancy. The Contraceptive Utilities, Intention, and Knowledge Scale (CUIKS) has three subscales: perceived likelihood of becoming pregnant, attitudes regarding major and minor side effects of contraceptives, and the knowledge survey (Condelli, 1998). The scale was tested on over 600 women of varying ages and educational backgrounds (Condelli, 1998). Reliability for the major and minor side effects scale in the current study was $\alpha=0.85$. A sample item is, "Different forms of contraception vary in terms of how likely they are to have side effects. Some side effects may be minor, such as irritation of or skin problems, which others may be major, such as increasing risk of serious illness. For each method of contraception below, please rate how concerned you would be about the occurrence of both minor and major side effects. Circle the number from 1-5 that best represents your feelings (1=Not at all concerned, 5=Very concerned)." 
Forms of contraception that were listed include foams/condoms, diaphragm, and IUD (Condelli, 1998). The scale was modified to include contraception pills, the "Depo" shot, the patch, Implanon (the arm implant), and NuvaRing.

\section{Contraceptive Avoidance or Discontinuation}

There were six survey items aimed to understand if the severity of the potential side effects of contraception use were a reason for avoiding or halting contraception use. There is not a validated scale for this area, so questions were developed for the purpose of this study. Those items were: "Did information you learned about side effects of contraception result in you never or no longer taking contraception?" "Did you personally experience a negative side effect from contraception use that led you to halt the contraception use?" "Had you been told about side effects associated with contraception? If yes, did this information about side effects of contraception lead to the decision to avoid or halt contraception use? If yes, what side effects were you told about and by whom?” The item "Did you personally experience a negative side effect from contraception use that led you to halt the contraception use?" was used in the model for research questions one, two, and three.

\section{Pregnancy Variables}

Questions were asked regarding pregnancy demographics. These items include: "Have you ever been pregnant?" (yes/no) "How old were you when the pregnancy(ies) occurred?" (fill in responses) "Were you using a form of contraception when the pregnancy(ies) occurred? If yes, what method of contraception?" (select all that apply with different forms of contraception listed) "Were the pregnancy(ies) planned?" (yes/no)

\section{Subjective Norms}


For this study, subjective norms are defined as the belief that an important person will approve and support a particular behavior (i.e., contraceptive use). The girls were asked how those who are most important to them would feel about them using different forms of contraceptives. A Likert scale of 1-5 was used with 1 being "very much opposed (would discourage me)" and 5 being "very in favor (would encourage me)." Again, there is not a validated scale, so eight questions were developed for the purpose of this study, such as, "Please indicate how the people who are most important to you would feel about you using condoms/IUD/etc."

\section{Perceived Threat}

This study defines perceived threat as a situation that would be difficult or troubling to the girls (i.e., pregnancy or experiencing a side effect). Girls were asked a two questions that were measured using a Likert scale with 1 being "very likely" and 5 "very unlikely." They include: "What is the likelihood you would become pregnant if engaging in sex while not using any form of contraception or barrier method?" "What is the likelihood you would become pregnant if engaging in sex while using your current contraception method?" These items were influenced by a qualitative study completed with adolescents in Northern California (Rosengard et al., 2004).

\section{Covariates}

Covariates included age, race, education, and religiosity. These were selected because the HBM suggests that age, race, SES, and gender affect perceived barriers to behavioral change, perceived benefits, and perceived threat of a "disease," or in this case side effects and/or pregnancy. See Table 3 for a detailed description of all study measures. 


\section{Table 3}

Study Measures

\begin{tabular}{|c|c|c|c|}
\hline Construct & Measure/Scoring & Sample Item & $\begin{array}{l}\text { Cronbach's } \\
\text { Alpha }\end{array}$ \\
\hline $\begin{array}{l}\text { Attitudes } \\
\text { about } \\
\text { contraceptive } \\
\text { side effects }\end{array}$ & $\begin{array}{l}\text { The Contraceptive } \\
\text { Utilities, Intention, and } \\
\text { Knowledge Scale } \\
\text { (Condelli, 1998). } \\
8 \text { out of } 16 \text { items used, } \\
\text { each used as single items } \\
\text { (i.e. scale not summed or } \\
\text { scored otherwise) } \\
\text { 5-point Likert scale } \\
\text { Circle the number from 1-5 } \\
\text { that best represents your } \\
\text { feelings (1=Not at all } \\
\text { concerned 5=Very } \\
\text { concerned) }\end{array}$ & $\begin{array}{l}\text { "Different forms of } \\
\text { contraception vary in } \\
\text { terms of how likely they } \\
\text { are to have side effects. } \\
\text { Some side effects may be } \\
\text { minor, such as irritation of } \\
\text { or skin problems, which } \\
\text { others may be major, such } \\
\text { as increasing risk of } \\
\text { serious illness. For each } \\
\text { method of contraception } \\
\text { below, please rate how } \\
\text { concerned you would be } \\
\text { about the occurrence of } \\
\text { both minor and major side } \\
\text { effects." }\end{array}$ & 0.85 \\
\hline $\begin{array}{l}\text { Subjective } \\
\text { norms about } \\
\text { contraceptive } \\
\text { use }\end{array}$ & $\begin{array}{l}\text { The Contraceptive } \\
\text { Utilities, Intention, and } \\
\text { Knowledge Scale } \\
\text { (Condelli, 1998). } \\
4 \text { single-items used out of } \\
14 \text { items, each used as } \\
\text { single items (i.e. scale not } \\
\text { summed or scored } \\
\text { otherwise) } \\
5 \text {-point Likert scale } \\
\text { Circle the number from } 1 \\
\text { to } 5 \text { that best represents } \\
\text { their feelings (1= very } \\
\text { much opposed, 5= very } \\
\text { much in favor) }\end{array}$ & $\begin{array}{l}\text { "People who are } \\
\text { important to you may } \\
\text { have feelings about the } \\
\text { type of birth control you } \\
\text { might use. For each birth } \\
\text { control method below, } \\
\text { please indicate how the } \\
\text { people who are most } \\
\text { important to you would } \\
\text { feel about your using that } \\
\text { form of contraception." }\end{array}$ & \\
\hline $\begin{array}{l}\text { Perceived } \\
\text { threat of } \\
\text { pregnancy }\end{array}$ & $\begin{array}{l}\text { The Contraceptive } \\
\text { Utilities, Intention, and } \\
\text { Knowledge Scale } \\
\text { (Condelli, 1998). }\end{array}$ & $\begin{array}{l}\text { "What is the likelihood } \\
\text { they would become } \\
\text { pregnant if engaging in } \\
\text { sex while not using any }\end{array}$ & \\
\hline
\end{tabular}




\begin{tabular}{|c|c|c|}
\hline & $\begin{array}{l}1 \text { single-item used out of } 4 \text {, } \\
\text { used as single items (i.e. } \\
\text { scale not summed or } \\
\text { scored otherwise) } \\
\text { 5-point Likert scale (1= } \\
\text { very unlikely } \\
5 \text { = very likely) }\end{array}$ & $\begin{array}{l}\text { form of contraception or } \\
\text { barrier method?" }\end{array}$ \\
\hline $\begin{array}{l}\text { Behavior to } \\
\text { halt } \\
\text { contraceptives }\end{array}$ & $\begin{array}{l}\text { Contraceptive } \\
\text { discontinuation } \\
\text { Single-item } \\
\text { Yes/no answer }\end{array}$ & $\begin{array}{l}\text { "Did you personally } \\
\text { experience a negative side } \\
\text { effect from contraception } \\
\text { use that led to you halting } \\
\text { the contraception use?" }\end{array}$ \\
\hline $\begin{array}{l}\text { Told about } \\
\text { Contraceptive } \\
\text { Side Effects } \\
\text { from a } \\
\text { Physician }\end{array}$ & $\begin{array}{l}\text { Physician influence of } \\
\text { contraceptive side effects } \\
\text { Single-item } \\
\text { Yes/no answer }\end{array}$ & $\begin{array}{l}\text { "Had you been told about } \\
\text { side effects associated } \\
\text { with birth control from a } \\
\text { physician?" }\end{array}$ \\
\hline Age & $\begin{array}{l}\text { Single-item } \\
\text { Select one } 15-19 \text { years } \\
\text { Dichotomized as } 17 \text { and } \\
\text { younger or } 18 \text { and older }\end{array}$ & $\begin{array}{l}\text { "What is your age (in } \\
\text { years)?" }\end{array}$ \\
\hline Race & $\begin{array}{l}\text { Single-item } \\
\text { Select all that apply: Asian, } \\
\text { Black/African American, } \\
\text { White/Caucasian, Native } \\
\text { American or Other Pacific } \\
\text { Islander, American Indian } \\
\text { or Alaska Native, Other, } \\
\text { please describe } \\
\text { Dichotomized as White } \\
\text { and People of Color }\end{array}$ & $\begin{array}{l}\text { "Please identify your } \\
\text { race." }\end{array}$ \\
\hline Religion & $\begin{array}{l}\text { Single-item } \\
\text { Yes/No answer }\end{array}$ & $\begin{array}{l}\text { "Do you identify as } \\
\text { religious?" }\end{array}$ \\
\hline Education & $\begin{array}{l}\text { Single-item } \\
\text { Select one: } 8^{\text {th }} \text { grade, Some } \\
\text { high school, High } \\
\text { school/GED, Some }\end{array}$ & $\begin{array}{l}\text { "Please identify your } \\
\text { highest level of education } \\
\text { completed." }\end{array}$ \\
\hline
\end{tabular}




\begin{tabular}{|l|l|l|l|}
\hline $\begin{array}{l}\text { college, } \\
\text { Trade/technical/vocational } \\
\text { training, Associate's } \\
\text { degree, Bachelor's degree, } \\
\text { Master's degree, } \\
\text { Professional degree }\end{array}$ & & \\
$\begin{array}{l}\text { Dichotomized as high } \\
\text { school and some college } \\
\text { and up }\end{array}$ & & \\
\hline
\end{tabular}




\section{Analytic Plan}

The data was analyzed through a series of logistic regressions. Analyses were completed using $\mathrm{R}$ version 3.4.1. In logistic regressions, the linear predictor of the outcome variable, also known as the $\operatorname{logit}(\log [\mathrm{p} /(1-\mathrm{p})]$ with $\mathrm{p}$ being the probability of $y$ $=1$ ), holds similar assumptions to that of linear regression and general linear models that are based on ordinary least squares algorithms (Hosmer \& Lemeshow, 2000), particularly regarding linearity, normality, homoscedasticity, and measurement level (Hosmer \& Lemeshow, 2000). Regression diagnostics were performed to detect potential assumption violations, assumptions were met, and to determine model fit. Hierarchical regressions were performed for research questions one and four where minor side effects were added to demographics and then major side effects were added to demographics and minor side effects. Likelihood ratio tests were performed to determine the overall effect of minor and major side effects on both the outcome variables of perception of experiencing a side effect and halting contraceptive use as well as, if the physician told the girls about side effects associated with various forms of contraceptives.

Variables were treated in the following way for logistic regressions. Age: recoded as $15-17=0,18-19=1$; Race: recoded as People of Color $=0$, White $=1$; Religious: recoded as $\mathrm{No}=0$, Yes $=1$; Education: recoded as high school $=0$, some college and up $=1$; Side effects experienced and halted contraceptive use coded as $0=$ did not halt due to perceived side effect, 1 = did halt due to perceived side effect; Physician told girl about side effects associated with contraceptives recoded as $0=$ yes, told, $1=$ no, not told. Race and education were dichotomized in this way because there were few responses for race 
categories other than White and education levels above high school completion. Age was dichotomized this way because the age of consent is 18 in the United States.

\section{Sample}

This study used a convenience sample of 183 girls from 41 rural Missouri counties. The majority of the sample identified as White $(n=122,72.6 \%)$. For the ages, $10.9 \%(n=20)$ of the sample was 15 years old, $24 \%(n=44) 16$ years old, $23.5 \%(n=$ 43) 17 years old, $25.7 \%(n=47) 18$ years old, and 15.8\% $(n=29) 19$ years old.

Education varied as well; however, the majority reported completing high school or GED $(40.4 \%, n=74), 11.5 \%(n=21)$ completed $8^{\text {th }}$ grade, $24 \%(n=44)$ completed some high school, $15.8 \%(n=29)$ completed some college, $3.8 \%(n=7)$ completed trade/technical/ vocational training, 1.6\% $(n=3)$ completed an associate's degree, and $0.5 \%(n=1)$ completed a bachelor's degree. About half the sample identified as religious (54.6\%). The total sample size for, "Did you personally experience a negative side effect from contraception use that led you to halt the contraception use?" was 182 with $25 \%(n=45)$ reporting "yes" and 75\% $(\mathrm{n}=137)$ reporting "no." Tables 3-6 provide an overview of the sample. Table 4 shows a breakdown of the participants by county. Participant demographics (age, race, religion, education) can be found in Table 5. Table 6 shows demographics related to pregnancy variables. Table 7 shows participants' current form of contraception. Based on these results and research that suggests Depo-Provera (i.e., the shot), oral contraceptives (i.e., the pill), IUD, and Nuva ring have the greatest number of side effects associated with them, in decreasing order, we have included birth control pills, condoms, IUD, and Implanon (arm implant) in further analyses (Lindberg, 2018; Planned Parenthood, 2021). 


\section{Table 4}

Participant Counties (N=183)

\begin{tabular}{|c|c|c|}
\hline \multirow[t]{2}{*}{ County } & \multicolumn{2}{|c|}{ Entire Sample } \\
\hline & $n$ & $\%$ \\
\hline Grundy & 21 & 11.5 \\
\hline Montgomery & 20 & 10.9 \\
\hline Bates & 12 & 6.6 \\
\hline Washington & 12 & 6.6 \\
\hline Dent & 6 & 3.3 \\
\hline Laclede & 4 & 2.2 \\
\hline Lawrence & 13 & 7.1 \\
\hline Wright & 7 & 3.8 \\
\hline Douglas & 6 & 3.3 \\
\hline Howell & 5 & 2.7 \\
\hline Shannon & 3 & 1.6 \\
\hline Oregon & 3 & 1.6 \\
\hline Carter & 7 & 3.8 \\
\hline Ripley & 3 & 1.6 \\
\hline Wayne & 1 & 0.5 \\
\hline Scott & 4 & 2.2 \\
\hline Mississippi & 18 & 9.8 \\
\hline New Madrid & 4 & 2.2 \\
\hline Butler & 4 & 2.2 \\
\hline Stoddard & 3 & 1.6 \\
\hline Pemiscot & 1 & 0.5 \\
\hline Dunklin & 2 & 1.1 \\
\hline Marion & 1 & 0.5 \\
\hline Saline & 2 & 1.1 \\
\hline Pettis & 1 & 0.5 \\
\hline Moniteau & 1 & 0.5 \\
\hline St. Clair & 1 & 0.5 \\
\hline McDonald & 7 & 3.8 \\
\hline Crawford & 2 & 1.1 \\
\hline Iron & 1 & 0.5 \\
\hline St. Francois & 7 & 3.8 \\
\hline Madison & 1 & 0.5 \\
\hline
\end{tabular}


Table 5

Participant Characteristics and Descriptive Analyses ( $N=183)$

\begin{tabular}{|c|c|c|}
\hline \multirow[t]{2}{*}{ Characteristic } & \multicolumn{2}{|c|}{ Entire Sample } \\
\hline & $n$ & $\%$ \\
\hline \multicolumn{3}{|l|}{ Race } \\
\hline White & 122 & 72.6 \\
\hline Black & 22 & 13.1 \\
\hline Asian & 5 & 3.0 \\
\hline Native American/Pacific Islander & 12 & 7.7 \\
\hline American Indian/Alaska Native & 3 & 1.8 \\
\hline Multiracial & 3 & 1.8 \\
\hline \multicolumn{3}{|l|}{ Age } \\
\hline 15 & 20 & 10.9 \\
\hline 16 & 44 & 24 \\
\hline 17 & 43 & 23.5 \\
\hline 18 & 47 & 25.7 \\
\hline 19 & 29 & 15.8 \\
\hline \multicolumn{3}{|l|}{ Sexual Orientation } \\
\hline Heterosexual & 165 & 90.2 \\
\hline Gay & 10 & 5.5 \\
\hline Lesbian & 1 & .5 \\
\hline Bisexual & 7 & 3.8 \\
\hline \multicolumn{3}{|l|}{ Education level } \\
\hline $8^{\text {th }}$ grade & 21 & 11.5 \\
\hline Some high school & 44 & 24.0 \\
\hline High school graduate or GED & 74 & 40.4 \\
\hline Some college & 29 & 15.8 \\
\hline Trade/technical/vocational training & 7 & 3.8 \\
\hline Associate's degree & 3 & 1.6 \\
\hline Bachelor's degree & 1 & .5 \\
\hline \multicolumn{3}{|l|}{ Do you identify as religious? } \\
\hline Yes & 100 & 54.6 \\
\hline No & 82 & 44.8 \\
\hline
\end{tabular}




\section{Table 6}

Participant Characteristics and Descriptive Analyses $(N=183)$

\begin{tabular}{lcc}
\hline Characteristic & \multicolumn{2}{c}{ Entire Sample } \\
& $n$ & $\%$ \\
\hline & & \\
& & \\
Have you ever been pregnant? & 17 & 9.3 \\
$\quad$ Yes & 129 & 70.5 \\
No & & \\
How old were you when the & & \\
pregnancy(ies) occurred? & 2 & 11.8 \\
13 & 1 & 6.0 \\
14 & 1 & 6.0 \\
$14-16$ & 2 & 11.8 \\
15 & 2 & 11.8 \\
16 & 1 & 11.8 \\
17 & 4 & 23.5 \\
18 & 2 & 11.8 \\
19 & & \\
Was the pregnancy(ies) planned? & 6 & 35.3 \\
Yes & 11 & 64.7 \\
No &
\end{tabular}

Note. Numbers do not all add up to the final sample size due to missing data

Table 7

Participant Current Contraceptive $(N=183)$

\begin{tabular}{lcc}
\hline Contraceptive & \multicolumn{2}{c}{ Entire Sample } \\
& $n$ & $\%$ \\
\hline Condom & 37 & 20.2 \\
Diaphragm & 1 & 0.5 \\
IUD & 2 & 1.1 \\
Pill & 31 & 16.9 \\
Arm Implant (Implanon) & 3 & 1.6 \\
None & 21 & 11.5 \\
Multiple & 25 & 13.7 \\
Condom/pill & 51 & 27.9 \\
Condom/diaphragm & 9 & 4.9 \\
Diaphragm/pill & 3 & 1.6
\end{tabular}




\section{Chapter 4: Results}

This study explored if perceived contraceptive side effects influenced girls' decision to use contraceptives. The research questions and methodology were informed by the theory of planned behavior and the health belief model (Ajzen, 1991; Rosenstock, 1974). All data were collected through online surveys using Qualtrics. If participants had more than $50 \%$ of the survey unanswered, their responses were deleted, leaving the total sample number at 183 . This chapter will provide a description of the sample as well as the results from the logistic regression analyses. Missing data of greater than 5\% only occurred in the demographic variables (age, race, education, and religiosity). Percent of missing values ranged from 0.5 to $8.2 \%$. To evaluate the potential impact of missing values on study outcomes, a missing value analysis was performed. Surveys with missing demographic data were recoded as " 0 " and those that did not have any missing data were recoded as " 1. ." A logistic regression was performed. The outcome variables for the research question were the predictor variables and the recoded demographics were the outcome variable. There was no significance (expsehalt: OR: 2.24, CI: 0.57-14.93, $\mathrm{p}=0.309$, physsetold: OR: 2.272 , CI: $0.83-12.35, \mathrm{p}=0.134)$; the reference groups were did not experience side effects and were not told about side effects from a physician. Potential adverse effects of missing values on outcomes is likely to be low. In addition, none of the outcome or predictor variables were missing more than $5 \%$ of data, so imputation was not necessary (Saunders et al., 2006).

\section{Research Question 1: Attitudes Regarding Contraceptive Side Effects}

Prior to adjustment, those who perceived that condoms and IUD (OR: 1.33, CI: 1.01-1.79, $p=.049 ;$ OR:1.50, CI:1.04-2.23, $p=.036$ ) had a greater risk of perceived 
minor side effects were at a greater risk to have experienced a side effect from contraceptive use and halt use. Again, prior to adjustment, those who perceived condoms and birth control pills (OR: 1.43, CI:1.07-1.93, $p=.016$; OR: 1.96, OR: 1.30-3.13, $p$ $=.002)$ to have major side effects were at greater risk to have experienced a side effect from contraceptive use and halt use. The only one of these predictor variables that remained significant after adjustment was birth control pills (OR:1.85, CI:1.09-3.35, $p=$ .031). See Table 8 for full results of Question 1.

\section{Table 8}

Attitudes About Contraceptive Side Effects and Halting Contraceptive Use

Univariate model
$95 \% \mathrm{CI}$

\begin{tabular}{lcccccccc} 
Source & OR & lower & upper & $p$-value & OR & lower & upper & $p$-value \\
\hline Age & 0.76 & 0.27 & 1.90 & 0.3584 & 1.32 & 0.37 & 4.27 & 0.650 \\
Race & 0.72 & 0.34 & 1.56 & 0.394 & 0.86 & 0.34 & 2.27 & 0.757 \\
Religious & 1.46 & 0.74 & 2.96 & 0.279 & 1.32 & 0.60 & 2.97 & 0.493 \\
Educ & 2.00 & 0.69 & 1.28 & 0.156 & 1.87 & 0.52 & 6.55 & 0.327 \\
MinorCondoms & 1.33 & 1.01 & 1.79 & $0.049^{*}$ & 1.29 & 0.74 & 2.29 & 0.363 \\
MinorIUD & 1.50 & 1.04 & 2.23 & $0.036^{*}$ & 1.63 & 0.98 & 2.82 & 0.066 \\
MinorBCP & 1.17 & 0.83 & 1.71 & 0.386 & 0.63 & 0.36 & 1.07 & 0.089 \\
MinorArm & 1.11 & 0.80 & 1.56 & 0.523 & 0.93 & 0.57 & 1.51 & 0.774 \\
MajorCondom & 1.43 & 1.07 & 1.93 & $0.016^{*}$ & 1.00 & 0.56 & 1.78 & 0.991 \\
MajorIUD & 1.23 & 0.87 & 1.79 & 0.246 & 0.86 & 0.50 & 1.46 & 0.578 \\
MajorBCP & 1.96 & 1.30 & 3.13 & $0.002^{*}$ & 1.85 & 1.09 & 3.35 & $0.031^{*}$ \\
MajorArm & 1.13 & 0.80 & 1.61 & 0.495 & 0.96 & 0.55 & 1.63 & 0.863
\end{tabular}

Note. $\mathrm{OR}=$ Odds Ratio, $\mathrm{CI}=$ confidence interval 
Table 9 represents girls' perception of minor and major side effects associated with forms of contraceptives and if the girls experienced a side effect they perceived to be from contraceptive use, which caused them to halt use. The predictor variables were entered in a hierarchical manner. Using a likelihood ratio (LR) test, it was concluded that newly entered effects (e.g., minor side effects in addition to demographics and major side effects in addition to demographics and minor side effects) did not significantly contribute to explain the outcome variable. The addition of minor side effects did not lead to a significantly better model fit, $\operatorname{LR} \chi^{2}(d f=4)=6.36, p=.174$. Similarly, the addition of major side effects to demographics and minor side effects proved non-significant, $\operatorname{LR} \chi^{2}(d f=4)=5.46, p=.243$. Based on these models, the hypothesis that girls with more negative attitudes regarding contraceptive side effects will be more likely to halt contraceptive use was supported. Therefore, attitudes regarding contraceptive side effects do relate to the girls' decisions to halt contraceptive use.

\section{Table 9}

Major and Minor Side Effects and Halting Contraceptive Use

\begin{tabular}{|c|c|c|c|c|c|c|c|c|c|}
\hline & \multicolumn{3}{|c|}{ Demographics } & \multicolumn{3}{|c|}{$\begin{array}{l}\text { Demographics + } \\
\text { Minor Side Effects }\end{array}$} & \multicolumn{3}{|c|}{$\begin{array}{l}\text { Demographics + } \\
\text { Minor Side Effects + } \\
\text { Major Side Effect }\end{array}$} \\
\hline & OR & $\mathrm{CI}$ & $\begin{array}{l}\mathrm{p}- \\
\text { value }\end{array}$ & OR & $\mathrm{CI}$ & $\begin{array}{l}\mathrm{p}- \\
\text { value }\end{array}$ & OR & $\mathrm{CI}$ & $\begin{array}{l}\mathrm{p}- \\
\text { value }\end{array}$ \\
\hline Age & 1.10 & $\begin{array}{l}0.33- \\
3.21\end{array}$ & 0.873 & 1.15 & $\begin{array}{l}0.33- \\
3.48\end{array}$ & 0.811 & 1.39 & $\begin{array}{l}0.38- \\
4.48\end{array}$ & 0.594 \\
\hline Race & 0.82 & $\begin{array}{l}0.34- \\
2.07\end{array}$ & 0.661 & 0.84 & $\begin{array}{l}0.33- \\
2.22\end{array}$ & 0.715 & 0.92 & $\begin{array}{l}0.35- \\
2.53\end{array}$ & 0.875 \\
\hline Religious & 1.32 & $\begin{array}{l}0.63- \\
2.84\end{array}$ & 0.469 & 1.34 & $\begin{array}{l}0.63- \\
2.95\end{array}$ & 0.454 & 1.34 & $\begin{array}{l}0.60- \\
3.05\end{array}$ & 0.483 \\
\hline
\end{tabular}




\begin{tabular}{|c|c|c|c|c|c|c|c|c|c|}
\hline Education & 1.58 & $\begin{array}{l}0.48- \\
4.97\end{array}$ & 0.434 & 1.67 & $\begin{array}{l}0.48- \\
5.66\end{array}$ & 0.409 & 2.03 & $\begin{array}{l}0.55- \\
7.26\end{array}$ & 0.276 \\
\hline MinorCon & & & & 1.37 & $\begin{array}{l}0.96- \\
1.99\end{array}$ & 0.086 & 1.25 & $\begin{array}{l}0.71- \\
2.22\end{array}$ & 0.448 \\
\hline MinorIUD & & & & 1.45 & $\begin{array}{l}0.94- \\
2.30\end{array}$ & 0.100 & 1.55 & $\begin{array}{l}0.93- \\
2.69\end{array}$ & 0.102 \\
\hline MinorBCP & & & & 0.83 & $\begin{array}{l}0.53- \\
1.32\end{array}$ & 0.428 & 0.62 & $\begin{array}{l}0.36- \\
1.06\end{array}$ & 0.085 \\
\hline $\begin{array}{l}\text { Minor } \\
\text { Arm }\end{array}$ & & & & 0.91 & $\begin{array}{l}0.60- \\
1.37\end{array}$ & 0.633 & 0.95 & $\begin{array}{l}0.59- \\
1.55\end{array}$ & 0.847 \\
\hline MajorCon & & & & & & & 1.08 & $\begin{array}{l}0.60- \\
1.94\end{array}$ & 0.801 \\
\hline MajorIUD & & & & & & & 0.86 & $\begin{array}{l}0.50- \\
1.46\end{array}$ & 0.569 \\
\hline MajorBCP & & & & & & & $1.74 *$ & $\begin{array}{l}1.02- \\
3.14\end{array}$ & 0.053 \\
\hline MajorArm & & & & & & & 0.95 & $\begin{array}{l}0.55- \\
1.64\end{array}$ & 0.865 \\
\hline
\end{tabular}

\section{Research Question 2: Subjective Norms Attitudes about Contraceptive Use}

Those who had someone important to them who supported the use of condoms, IUDs, and birth control pills were at greater risk to experience a side effect and halt use (OR:1.52, CI: 1.06-2.28, $p=.029$; OR:0.62, CI: 0.42-0.91, $p=.014$; OR: 0.58, CI: 0.42$0.80, p=.001)$. All predictor variables that were significant in the univariate models remained significant after adjustment (OR:1.69, CI: 1.11-2.69, $p=.020$; OR: 0.60, CI:0.35-0.99, $p=.048$; OR:0.61, CI: 0.42-0.88, $p=.010$ ). All results for Question 2 can be seen in Table 10. Based on this model, the hypothesis that girls who have people close to them who have negative attitudes regarding contraceptive use will be more likely to halt contraceptive use due to perceived side effects was not supported. The girls social network members had positive attitudes regarding contraceptive use and yet the girls still perceived side effects of contraceptive use 
as a risk and halted use. Therefore, the girls' decision to halt contraceptive use due to perceived side effects was not related to the girls' social network members' attitudes toward contraceptive use.

\section{Table 10}

Subjective Norms and Halting Contraceptive Use

\begin{tabular}{|c|c|c|c|c|c|c|c|c|}
\hline \multirow[b]{2}{*}{ Source } & \multicolumn{3}{|c|}{$\begin{array}{c}\text { Univariate models } \\
\frac{95 \% \mathrm{CI}}{}\end{array}$} & \multirow[b]{2}{*}{$p$-value } & \multicolumn{4}{|c|}{$\begin{array}{c}\text { Multivariable Model } \\
95 \% \mathrm{CI}\end{array}$} \\
\hline & OR & lower & upper & & OR & lower & upper & $p$-value \\
\hline Age & 0.76 & 0.27 & 1.90 & 0.584 & 1.04 & 0.37 & 3.08 & 0.947 \\
\hline Race & 0.72 & 0.34 & 1.56 & 0.394 & 1.02 & 0.40 & 2.69 & 0.973 \\
\hline religious & 1.46 & 0.74 & 2.96 & 0.279 & 1.50 & 0.67 & 3.45 & 0.328 \\
\hline Educ & 2.00 & 0.69 & 1.28 & 0.156 & 0.95 & 0.25 & 3.26 & 0.935 \\
\hline PFCondoms & 1.52 & 1.06 & 2.28 & $0.029^{*}$ & 1.69 & 1.11 & 2.69 & $0.020^{*}$ \\
\hline PFIUD & 0.62 & 0.42 & 0.91 & $0.014^{*}$ & 0.60 & 0.35 & 0.99 & $0.048^{*}$ \\
\hline PFBCP & 0.58 & 0.42 & 0.80 & $0.001 * *$ & 0.61 & 0.42 & 0.88 & $0.010^{*}$ \\
\hline PFArm & 1.04 & 0.74 & 1.45 & 0.834 & 1.34 & 0.87 & 2.09 & 0.190 \\
\hline
\end{tabular}

Note $. \mathrm{OR}=$ Odds Ratio, $\mathrm{CI}=$ confidence interval

\section{Research Question 3: Perceived Threat of Pregnancy or Contraceptive Side Effects}

Table 11 shows the results for Question 3. Those who had experienced a side effect from contraceptive use and halted use were at a greater probability of thinking that they would become pregnant in the next year if not using any form of contraception (OR: 2.09, CI: 1.04-4.37, $p=.044)$. This effect remained significant after adjustment (OR: 2.30, CI: $1.10-5.05, p=.031)$. Based on this model, the hypothesis that girls who perceive experiencing potential side effects as a greater threat than becoming pregnant in the next year without using any form of contraceptive was not supported. The girls perceived potential side effects of contraceptives to be a 
threat however, they also believe the likelihood of them becoming pregnant without using contraceptives would be a great threat as well, in other words, while the threat of pregnancy was high but the threat of potential sides effects from contraceptive use was viewed as a more severe threat to the girls.

\section{Table 11}

Perceived Threat of Pregnancy vs. Contraceptive Side Effects and Halting Use

\begin{tabular}{|c|c|c|c|c|c|c|c|c|}
\hline \multirow[b]{3}{*}{ Source } & \multicolumn{4}{|c|}{ Univariate mor } & \multicolumn{4}{|c|}{ Multivariable Model } \\
\hline & \multirow[b]{2}{*}{ OR } & \multicolumn{2}{|c|}{$95 \% \mathrm{CI}$} & \multirow[b]{2}{*}{$p$-value } & \multicolumn{4}{|c|}{$95 \% \mathrm{CI}$} \\
\hline & & lower & upper & & OR & lower & upper & $p$-value \\
\hline Age & 0.93 & 0.43 & 2.16 & 0.918 & 1.10 & 0.42 & 2.99 & 0.845 \\
\hline Race & 0.68 & 0.33 & 1.36 & 0.279 & 0.57 & 0.24 & 1.26 & 0.172 \\
\hline Religious & 0.78 & 0.43 & 1.40 & 0.400 & 0.77 & 0.40 & 1.49 & 0.445 \\
\hline Educ. & 0.83 & 0.33 & 2.10 & 0.691 & 0.45 & 0.14 & 1.36 & 0.161 \\
\hline $\begin{array}{l}\text { Side } \\
\text { Effect }\end{array}$ & 2.09 & 1.04 & 4.37 & $0.044 *$ & 2.30 & 1.10 & 5.05 & $0.031 *$ \\
\hline
\end{tabular}

Note. OR $=$ Odds Ratio, $\mathrm{CI}=$ confidence interval

\section{Research Question 4: Informed About Contraceptive Side Effects from a Physician}

The girls who perceived IUDs and birth control pills (OR: 1.61, CI:1.15-2.31, $p=$ $.007, \mathrm{OR}: 1.50, \mathrm{CI}: 1.07-2.17, p=.022)$ to have greater risk of major side effects were at greater risk of not being told about side effects of contraceptives from a physician. The risk predictor variable that remained significant after adjustment was IUD (OR: 1.87, CI:1.13-3.28, $p=.020$ ). Also, the risk predictor of minor side effects from arm implant (Implanon) was a greater risk if not told about side effects of contraceptives was significant in the adjusted model (OR:1.02, CI:0.65-1.61, $p=.005)$. All the results for Question 4 may be seen in Table 12. 


\section{Table 12}

Knowledge of Side Effects from a Physician and Attitudes of Side Effects

Univariate model

Multivariable Model

\begin{tabular}{lcccccccc} 
& & \multicolumn{3}{c}{$95 \% \mathrm{CI}$} & & \multicolumn{3}{c}{$95 \% \mathrm{CI}$} \\
\cline { 7 - 9 } Source & OR & lower & upper & $p$-value & OR & lower & upper & $p$-value \\
\hline Age & 1.43 & 0.62 & 3.20 & 0.392 & 1.99 & 0.69 & 5.93 & 0.208 \\
Race & 1.24 & 0.61 & 2.60 & 0.554 & 1.65 & 0.66 & 4.33 & 0.293 \\
Religious & 1.45 & 0.78 & 2.74 & 0.242 & 1.17 & 0.55 & 2.49 & 0.688 \\
Educ & 1.22 & 0.46 & 3.08 & 0.68 & 3.00 & 0.84 & 11.07 & 0.090 \\
MinorCondoms & 1.15 & 0.89 & 1.49 & 0.300 & 0.93 & 0.54 & 1.58 & 0.780 \\
MinorIUD & 1.23 & 0.89 & 1.73 & 0.24 & 1.05 & 0.66 & 1.68 & 0.841 \\
MinorBCP & 0.99 & 0.73 & 1.37 & 0.967 & 0.45 & 0.25 & 0.76 & 0.089 \\
MinorArm & 1.14 & 0.85 & 1.56 & 0.382 & 1.02 & 0.65 & 1.61 & $0.005^{* *}$ \\
MajorCondom & 1.26 & 0.97 & 1.64 & 0.085 & 1.41 & 0.81 & 2.48 & 0.923 \\
MajorIUD & 1.61 & 1.15 & 2.31 & $0.007 * *$ & 1.45 & 0.89 & 2.44 & 0.227 \\
MajorBCP & 1.50 & 1.07 & 2.16 & $0.022^{*}$ & 1.87 & 1.13 & 3.28 & $0.020^{*}$ \\
MajorArm & 1.24 & 0.90 & 1.72 & 0.200 & 0.93 & 0.55 & 1.55 & 0.773
\end{tabular}

Note. $\mathrm{OR}=$ Odds Ratio, $\mathrm{CI}=$ confidence interval

Table 13 represents the overall effect of girls' beliefs of minor and major side effects of various forms of contraception if the physician told the girls about side effects associated with contraceptives. The variables were entered in a hierarchical manner. Using a likelihood ratio (LR) test, it was concluded that as newly entered effects (i.e., major side effects in addition to demographics and minor side effects) did significantly contribute to explain the outcome variable. The addition of major side effects to demographics and minor side effects significantly improved model fit, $\operatorname{LR} \chi^{2}(d f=4)=13.08, p=.011$. The addition of 
just minor side effects to demographics did not significantly contribute to explaining the outcome variable, $\operatorname{LR} \chi^{2}(d f=4)=5.30, p=.258$. Based on these models, the hypothesis that girls perceive contraceptives to have associated side effects were more likely to be told about contraceptive side effects from a physician was not supported. The girl's belief of side effects associated with contraceptives were not influenced by being told about contraceptive side effects from a physician.

\section{Table 13}

Major and Minor Side Effects Attitudes with Physician Information

\begin{tabular}{|c|c|c|c|c|c|c|c|c|c|}
\hline & \multicolumn{3}{|c|}{ Demographics } & \multicolumn{3}{|c|}{$\begin{array}{l}\text { Demographics }+ \\
\text { Minor Side Effects }\end{array}$} & \multicolumn{3}{|c|}{$\begin{array}{l}\text { Demographics + } \\
\text { Minor Side Effects + } \\
\text { Major Side Effect }\end{array}$} \\
\hline & OR & $\mathrm{CI}$ & $\begin{array}{l}\mathrm{P}- \\
\text { value }\end{array}$ & OR & $\mathrm{CI}$ & $\begin{array}{l}\mathrm{p}- \\
\text { value }\end{array}$ & OR & CI & p-value \\
\hline Age & 2.10 & $\begin{array}{l}0.77- \\
5.76\end{array}$ & 0.144 & 2.04 & $\begin{array}{l}0.74- \\
5.23\end{array}$ & 0.167 & 1.99 & $\begin{array}{l}0.68- \\
5.93\end{array}$ & 0.208 \\
\hline Race & 1.14 & $\begin{array}{l}0.50- \\
2.70\end{array}$ & 0.763 & 1.19 & $\begin{array}{l}0.50- \\
2.97\end{array}$ & 0.703 & 1.65 & $\begin{array}{l}0.66- \\
4.33\end{array}$ & 0.293 \\
\hline Religious & 1.24 & $\begin{array}{l}0.63- \\
2.47\end{array}$ & 0.528 & 1.24 & $\begin{array}{l}0.62- \\
2.50\end{array}$ & 0.540 & 1.17 & $\begin{array}{l}0.55- \\
2.49\end{array}$ & 0.688 \\
\hline Education & 1.51 & $\begin{array}{l}0.49- \\
4.61\end{array}$ & 0.463 & 1.93 & $\begin{array}{l}0.59- \\
6.39\end{array}$ & 0.272 & 3.00 & $\begin{array}{l}0.84- \\
11.07\end{array}$ & 0.091 \\
\hline MinorCon & & & & 1.20 & $\begin{array}{l}0.88- \\
1.67\end{array}$ & 0.257 & 0.93 & $\begin{array}{l}0.54- \\
1.58\end{array}$ & 0.780 \\
\hline MinorIUD & & & & 1.28 & $\begin{array}{l}0.87- \\
1.91\end{array}$ & 0.222 & 1.05 & $\begin{array}{l}0.66- \\
1.68\end{array}$ & 0.841 \\
\hline MinorBCP & & & & 0.69 & $\begin{array}{l}0.45- \\
1.03\end{array}$ & 0.070 & 0.45 & $\begin{array}{l}0.25- \\
0.76\end{array}$ & $0.005^{* *}$ \\
\hline $\begin{array}{l}\text { Minor } \\
\text { Arm }\end{array}$ & & & & 1.04 & $\begin{array}{l}0.72- \\
1.51\end{array}$ & 0.830 & 1.02 & $\begin{array}{l}0.65- \\
1.61\end{array}$ & 0.923 \\
\hline MajorCon & & & & & & & 1.41 & $\begin{array}{l}0.81- \\
2.47\end{array}$ & 0.227 \\
\hline MajorIUD & & & & & & & 1.45 & $\begin{array}{l}0.89- \\
2.44\end{array}$ & 0.143 \\
\hline
\end{tabular}




\begin{tabular}{|l|l|l|l|l|l|l|}
\hline MajorBCP & & & 1.87 & $1.13-$ & $0.020^{*}$ \\
\hline MajorArm & & & & 3.27 & \\
\hline
\end{tabular}




\section{Chapter 5: Discussion}

This study aimed to understand what factors, specifically associated with side effects, are related to teen girls' decision to use contraceptives. There are several significant results which will be discussed in this chapter. This chapter will then discuss implications of the results, recommendations for future research, and limitations of this study.

This is the first known study to examine contraceptive use behavior due to perceived side effects among teen girls in rural America. Research on teen contraceptive use in America suggests that teens are more likely to use condoms and birth control pills than other forms of contraceptives (Guttmacher Institute, 2020). Also, health department statistics show this is accurate for Missouri (Douglas-Hall et al., 2018). The current contraceptive use for this study's sample was as anticipated based on the information available, with $27.9 \%(n=51)$ using birth control pills and condoms, $20.2 \%(n=37)$ using condoms, $16.9 \%(n=31)$ using birth control pills, and $11.5 \%$ currently not using any form of contraceptive.

\section{Halting Contraceptive Use}

\section{Personal Attitudes About Perceived Side Effects}

Girls' attitudes regarding contraceptive side effects were examined to determine whether attitudes toward contraceptive side effects influenced the decisions of girls in rural Missouri to halt contraceptive use due to perceived side effects. It was hypothesized that girls with higher negative attitudes regarding contraceptive side effects would be more likely to halt use of contraceptives. 
In the adjusted model, girls who perceived birth control pills to have major side effects (e.g., increased risk for serious illness) were more likely to report having experienced a side effect from contraceptive use and halt use. In the unadjusted or univariate model, girls who perceived condoms and IUDs to have minor side effects (e.g., irritation or skin problems) and condoms and birth control pills to have major side effects were more likely to experience a side effect from contraceptive use and halt use. These results are important, though not surprising, because the majority of teens are more likely to use birth control pills over other forms of contraception (Martinez \& Abma, 2020). Previous research supports these findings of girls perceiving side effects from oral contraceptives and deciding to halt use (Gilliam, 2004; Guendelman, 2000; Hall, 2012; Westhoff, 2007). While the populations are different, the previous literature shows that the results support those found in the current study, which contributes rural areas to existing literature that supports the hypothesis of halting contraceptives use due to perceived side effects.

A few studies examining side effects with oral contraception saw that women who reported increased headaches, moodiness, depressed mood, stress increase, nausea, acne, abdominal pain, back pain, vomiting, breast tenderness, breast enlargement, premenstrual syndrome, and irregular bleeding and/or weight gain in the early months of using oral contraceptives were more likely to discontinue use (Hall et al., 2012; O’Connell \& Kerns, 2007; Westhoff et al., 2007). These findings are important to note because the results of this study do not determine if the side effects were in fact experienced or just perceived. It may be that the girls have heard of potential side effects through a variety of platforms (e.g., friends, family, physicians, media) and are more susceptible to believing they are 
experiencing side effects. Future research should focus on this distinction between perceived verses actual side effects and where and from whom their knowledge regarding contraceptive use is obtained. Also, more research is needed specifically with rural populations to determine this; however, literature supports that perceived side effects are enough of an incentive to halt contraceptive use (Littlejohn, 2013; Skovlund et al., 2016; Westhoff et al., 2007).

\section{Subjective Norms}

Subjective norms, or the attitudes regarding contraceptive use of those close to the girls, were examined to see if they were related to the girls' halting contraceptive use due to perceived side effects. It was hypothesized that those close to the girls who had negative attitudes about contraceptive use would be related to girls being more likely to halt contraceptive use due to perceived side effects.

Those who had someone important to them who supported the use of condoms, IUD, and birth control pills were more likely to experience a side effect and halt use. The subjective norm attitudes were positive (i.e., supportive of using contraceptives), yet the girls still associated side effects with contraceptive use and chose to halt use. Previous research suggests that parental support, specifically mother support, of contraceptive use plays a large role in girls' deciding to use contraceptives (Commendador, 2010). Another study showed similar results that girls who were older (grades 10-11) who perceived parent approval of contraceptive use were more likely to use contraceptives and younger girls (7-9 grade) who perceived father approval of birth control use were more likely to use contraceptives (Sieving et al., 2007). 
The literature supports that parent approval increases girls' decision to use contraceptives; however, in this study, parent approval is not related to girls' halting contraception use after perceived side effects were experienced. One reason for this could be that previous literature asked if parents' support or approval contributed to them using contraceptives but did not ask if parent approval/support influenced their decision to stop use. Cook's (2021) results showed that the majority of the girls in the rural Missouri counties did not have a father figure in their life. Not having a father figure to influence the girl's contraceptive use or knowledge about contraceptive side effects could impact their decision to halt birth control, which could explain the difference as seen with the results in Sieving et al., (2007).

Another possibility for why the current study results are different is that subjective norms did not just include parents but also other people who are important to the girls. One study examining subjective norms (e.g., "people who are important to me believe that I should/would wish that I/would not like me to use contraception if I have sexual intercourse in the forthcoming 3 months") and contraceptive use found that willingness to have unsafe sex (i.e., not using any form of contraceptive) was significantly correlated with subjective norms among girls in the sample (Myklestad \& Rise, 2007). These results are more consistent with the current study in that subjective norm had an opposite effect than anticipated on girls' contraceptive use (i.e., those important to the girls supported the girls using contraceptives but the girls still did not use or in the current study actually halted use due to perceived side effects). These results may also be more consistent with the current study because of the way subjective norm is measured in that it states someone who is important to the girls and not just parents. This 
may be because the girls view others (e.g., boyfriend and friends) as more important than their parents, especially during adolescence. More research is needed to fully understand this relationship.

\section{Perceived Threat of Potential Side Effects}

Next it was aimed to understand if the perceived threat of becoming pregnant without using contraceptives is a greater threat than experiencing potential side effects from contraceptive use and halting use. It was hypothesized that girls who perceive potential side effects as a greater threat than becoming pregnant will be more likely to halt contraceptive use.

The girls who had experienced a side effect from contraceptive use and halted use were more likely to believe that they would become pregnant in the next year if not using any form of contraception. This is as hypothesized and suggests that the threat of perceived side effects the girls are experiencing are viewed as a greater threat than becoming pregnant in the next year. There is very little research on this decision-making process. One study measured pregnancy attitudes and classified participants as propregnancy, anti-pregnancy, and ambivalent (defined as could not form an opinion about becoming pregnant; Bruckner et al., 2004). This study found that those who identified as ambivalent were less likely than those anti-pregnancy to use contraception (Bruckner et al., 2004). Also, those who used contraceptives consistently were more likely to have positive attitudes regarding contraceptives (Bruckner et al., 2004). However, this study

did not find that ambivalence indicated the teens to be more likely to become pregnant in the next year (Bruckner et al., 2004). Another study showed that teen girls with ambivalent attitudes about pregnancy were more likely to become pregnant in the next 
year (Jaccard et al., 2003). The current literature focuses on general contraceptive attitudes rather than side effects specifically, as well as general attitudes about pregnancy, which may be one reason this study's results do not align with current evidence. The current study specifically examined if potential side effects were a great enough threat to halt use and increase the risk of pregnancy or if the risk of pregnancy was a greater threat than the potential perceived side effects. The inconclusive results from previous research and this study and the lack of research in this area implies a need for more research to better understand these factors. It would be important to know, in more detail, the girls' likelihood of becoming pregnant as there are many factors that could impact this (i.e., the girls are no longer having intercourse, their partner is sterile, etc.) or if they really do fear the potential side effects more than the increased risk of pregnancy.

\section{Knowledge about Contraceptive Side Effects}

Not being told about contraceptive side effects by a physician was related to girls' associating side effects with contraceptives. It was hypothesized that girls who had been told about side effects associated with contraceptive use from a physician would be more likely to believe in potential side effects of contraceptives.

The girls who had not been told about side effects associated with contraceptives were more likely to associate major side effects with IUDs and birth control pills. Also, girls who had not been told about side effects associated with contraceptive were more likely to associate minor side effects with the arm implant (Implanon). This is again different than what was originally hypothesized. The girls are more likely to believe that side effects are possibilities of contraceptives if not told about them from a physician. Previous literature supports these results in that women who were not told about side 
effects are more likely to believe in contraceptive side effects; however, previous literature measured this outcome variable differently. One study found that women often have concerns and misconceptions about the safety of contraceptive methods and potential side effects and they have doubts about their providers' willingness to reveal potential negative aspects of contraceptive use (Dehlendorf et al., 2014). Another qualitative study had similar results in that women were particularly concerned about receiving information about side effects (Dehlendorf et al., 2012). Some women stated they did not understand or did not receive any information regarding side effects of contraceptive use and that caused them to be unsure about starting or continuing a contraceptive method (Dehlendorf et al., 2012). Thus, previous research did not measure if the women were told about side effects associated with contraceptives by a physician but rather examined if they were not told about side effects how did that influence their contraceptive use decision-making. The current study did ask if they had been told about side effects associated with contraceptive use from a physician, which is why it was hypothesized that if they had been informed of side effects, they would be more likely to believe in accurate contraceptive side effects. However, it is possible that the girls who were told about side effects were misinformed (i.e., a physician may have said there are no known side effects associated with contraceptives or only minor side effects that were not listed on the measurement for this survey). Another possibility is that the girls were accurately informed about side effects with the occurrence rate being very rare, which could have influenced their belief of side effects associated with contraceptives. Effective medically accurate contraceptive counseling is a crucial part in girls' continued and proper use of contraceptives. Future research should focus on the physicians', in rural 
areas, level of knowledge regarding various forms of contraceptives and side effects associated with them as well as their form of contraceptive counseling.

\section{Implications for Social Work and Future Research}

\section{Theory}

Research on this study's population is scant, especially in the context of theory of planned behavior and the health belief model (Ajzen, 1991; Kirscht, 1974). This study provides new evidence to support these theories with an under researched topic and population. The girls' negative attitudes, a construct from TPB, toward contraceptive side effects were correlated to their behavior to halt contraceptive use. However, the TPB construct, subjective norm results did not fall in line with the theory's suggested progression. Those who were important to the girls had positive attitudes about the girls' use of contraceptives however the girls still chose to halt due to perceived side effects. This may be because the way the construct was measured, it would be interesting to see if the same results are produced if asked about specific people who are important to the girls' attitudes. For example, does you mom support you using contraceptives vs. does a friend or partner support the use of you using contraceptives. Peers and romantic partners often influence teens behaviors and attitudes greater than parents. It may be that the peers and having a negative effect on their attitudes regarding side effects of contraceptive use even though their parents support the use of contraceptives.

The results regarding the construct of perceived threat, from HBM, support the theory. Perceived threat contributes to the likelihood of behavioral change. In this study the likelihood of the threat of experiencing a side effect verse not using contraception and likelihood of becoming pregnant then correlate with the girls' behavior to halt 
contraceptive use. The girls believed that experiencing a side effect from contraceptive use to be a greater threat than the threat of becoming pregnant without using contraceptive even though they viewed the threat of becoming pregnant as great. While these results support the theory, it does raise more questions. The behavior change should be to help the person reach their desired health outcome. These results imply the girls were choosing the lesser of two evil in their opinion and beliefs. This could have been influenced by peers and others who hold similar beliefs. For example, if a friend had told the girl contraceptive use had made her infertile and the girl desires to carry a child at some point, she may see the threat of becoming pregnant earlier than desired as less of a risk than potentially never being able to become pregnant.

The results from this study support and contribute to the Theory of Planned Behavior and the Health Belief Model. More research is needed to better understand how these theories constructs work within this population of rural Missouri teen girls. Also, it is necessary to see if results still support the theories with a more diverse rural sample.

\section{Practice}

Three of the 12 Grand Challenges directly pertain to the challenges faced by teen parents, especially teen mothers: 1) ensure healthy development for all youth, 2) build financial capability for all, and 3) achieve equal opportunity and justice (Grand Challenges for Social Work, 2019). The results of this study have direct implications for social work practice as well as other fields (e.g., medicine). Results showed that physician information did not influence girls' decisions to halt contraceptive use due to side effects. These results are surprising however, in an era of social media and disinformation it may be that the girls are believing the opinions of friends, family, and 
potentially complete strangers who disclose similar experiences of side effects not factually associated with contraceptives. Girls need to be told about medically accurate potential side effects and prevalence rates for all forms of contraceptives in order to be able to make a well-informed decision about if they want to use contraceptives and what form. Though this recommendation is contrary to the results of this study I do think that misinformation and group think could be affecting the girls' decision to halt contraceptive use. Undoing or correcting the misinformation through contraceptive counseling with someone the girl(s) trust may be the most effective way to fulfill the Grand Challenge of ensuring healthy development for all youth. Teen parents, mothers especially, face many physical and mental health barriers. Being accurately informed of their contraceptive choices will potentially aid in delaying parenthood until they are adults, which in turn could help with the other Grand Challenge of building financial capability for all as teen moms since their children are more likely to live in poverty (Bissell, 2000; National Campaign, 2013; Walker \& Holtdreter, 2021). Also, the girls potentially face side effects from contraceptives that could impact their healthy development and, therefore, they should have all the information to be able to choose the safest method for their situation.

All people deserve transparency about the risks and benefits, as well as the prevalence rates for both, when making a medical decision, including adolescent girls when making decisions about contraception. Social workers as well as physicians can help achieve the grand challenge of achieving equal opportunity and justice by utilizing effective contraceptive counseling. Social workers in rural areas should be prepared to provide this information in clinical settings. The need for interventions among this 
population is great; however, the research to support interventions is lagging. The factors identified in this study from TPB and HBM correlated with the girls' behavior to halt contraceptive use and could contribute to pilot interventions. More information regarding how these factors influence girls' halting contraceptive use due to perceived side effects is needed before moving to complete interventions.

\section{Policy}

Missouri does not require public schools to teach sex education. Public schools can choose to teach sex education or not offer sex education courses at all. In 2011 the Missouri sex education statue 1.70.015 subsection 3 was revised to read,

Present students with the latest medically factual information regarding both the possible side effects and health benefits of all forms of contraception, including the success and failure rates for the prevention of pregnancy and sexually transmitted diseases or shall present students with information on contraceptives and pregnancy in a manner consistent with the provisions of the federal abstinence education law, 42 U.S.C. Section 710.

It previously read, "Present students with the latest medically factual information regarding both the possible side effects and health benefits of all forms of contraception, including the success and failure rates for the prevention of pregnancy and sexually transmitted diseases." Federal abstinence education guidelines do not require the teaching of possible side effects as well as health benefits of all forms of contraception. This could have huge implications based of the results of this study. Girls' who attend abstinenceonly schools are not being provided medically factual information regarding 
contraceptives, which could be influencing their beliefs regarding contraceptive side effects as well as their decision to use and/or halt contraceptives at all or certain types. I have written previously in support of the proposed change to amend the Missouri sex education statute to remove the "... or shall present students with information on contraceptives and pregnancy in a manner consistent with the provisions of the federal abstinence education law, 42 U.S.C. Section 710" (Cook, 2019). This will aid in supporting the three social work grand challenges mentioned in the previous section.

\section{Education}

These results show that girls in rural Missouri perceive side effects of contraceptive to be a risk great enough that they are halting contraceptive use. Results from this project also reveal that girls are more likely to believe in contraceptive side effects if they are not informed about known contraceptive side effects and prevalence risks by physicians. Also, the opinions regarding contraceptive use of those who were important to the girls did not affect the girls' decision to halt contraceptive use. These results are surprising as subjective norms typically have a positive correlation with the behavior (i.e. those who are important to the girls favor contraceptive use and therefore the girls would continue to use contraceptives). These results are not definitive however, they pose that the constructs of the TPB and HBM are functioning differently with this population (i.e. teen girls in rural Missouri). Rumors regarding contraceptive side effects have influenced decisions to halt use (DeClerque, 1986). This is an era of disinformation as seen with vaccine reluctance first because of the false information causation related to autism and more recently persons being hesitant about the COVID-19 vaccine. This is also an era of social media and people are trusting of information the read on these 
platforms (Wang et al., 2019). It may be that the rumors are having more influence than the opinions of those close to the girls. Professional information may not be enough to influence behavior and the misinformation from friends, family, and potentially complete strangers may have more influence. Especially, with people being able to share their experiences in real time via posts, reddit boards, tweets. Group think can be powerful and if people are sharing similar experiences with side effects of contraceptives it will validate the individual's feelings and impact their behavior.

Also, sex education is optional in Missouri and there are no credentials necessary to teach sex education. It may be that those who are teaching are misinformed about known contraceptive side effects and potentially contributing to the false contraceptive rumors. More research is needed to first see if these results are similar in other rural areas in the United States and to better understand what factors are influencing the behavior to halt use.

It was not measured why the physicians were not sharing this contraceptive information with the girls. It may be that the physicians are uncomfortable or unprepared to enter contraceptive counseling with girls. Societal and possibly religious ideals may be influencing the physicians' hesitancy with contraceptive counseling. It may also be that that most physicians in rural areas are primary care providers and not specialty physicians (e.g. OBGYN) and may not have accurate contraceptive knowledge themselves making it difficult for them to provide contraceptive counseling. Next steps may include medically accurate sex education curriculum required for medical school and social work students. Medical school sexual health education is limited to 3-10 hours of lectures and covers topics such as sexual dysfunction, altered sexual identification, and issues of sexuality in 
illness or disability (Solursh et al., 2003). These topics are important; however, physicians should also be educated on topics such as contraceptive counseling or contraceptive types and the risks and benefits associated with the various types. This is crucial for the implications of this study as physicians in rural areas are typically general practitioners and not specialized (i.e., OB-GYN). It is also important to have a better understanding of external factors (e.g. societal and religious ideals) that may impede the physicians from being able to effectively provide contraceptive counseling.

Similar barriers to contraceptive counseling for physicians present for social workers. There is currently no requirement for human sexuality education to be taught within graduate-level social work education (McKay, 2015). However, there are some Masters of Social Work (MSW) programs that are teaching sex education (McKay, 2015). The majority of MSW programs do not have a sexuality-related stand-alone course (60.6\%; McKay, 2015; Ramseyer Winter et al., 2016). However, it could be argued that the majority of practicing social workers will need to be prepared to address sexuality-based issues and be adequately prepared to support their clients (Begun et al., 2016; McKay, 2015). Social workers may be more likely to have to enter contraceptive counseling than physicians because of the rapport built with their clients.

\section{Future Research}

To date, contraceptive attitudes and behavior research—domestic and abroad— primarily focused on urban populations or populations with specific medical issues (i.e., breast cancer; Aldelman et al., 2019; Combs et al., 2018; Machiyama et al., 2018). This study adds uniquely to the existing literature in better understanding factors associated with teens' use or halting use of contraceptives due to perceived side effects. This is a 
specific population; however, given the lack of research on teens' contraceptive use in any rural area in America, these results provide important insight as to what factors should be focused on in future research.

There are several areas of this study upon which future research should expand. The first is generalizability to girls in rural areas through the United States. It is important to see if perceived side effects are related to girls halting contraceptive use or not beginning contraceptives in other rural areas in America. It could be that the Missouri sex education statute, rural community values, and/or provider influence are affecting rural Missouri girls' perception of perceived side effect. A factor that more research is needed to better understand is knowledge of contraceptives (e.g., benefits and risks) and how knowledge is obtained. This is a huge gap in this study as well as other literature on this topic. Little is known about the physicians' level of knowledge of known side effects of contraceptives; it may be possible that they are misinforming the girls or those close to the girls, which then could be influencing the girls' attitudes about different forms of contraceptives. Also, having a base level of the girls' knowledge of different forms of contraceptives is critical for future research and, eventually, intervention development.

It was difficult to identify scales that measure the constructs in the current study. The scales used were not tested with this population or used crude measurements (e.g., a single-item variable to measure perceived threat). Future research should devote attention to scale development or further additions and revisions to existing scales to be able to better understand the factors of interest (e.g., having sub-scales rather than a single item). Lastly, it is unclear from this study if the girls had experienced the side effect prior to beginning contraceptive use and went undiagnosed or if the side effect was directly 
related to the contraceptive use. This was a theme among the girls in the qualitative study that inspired this study (Cook, 2021). Future research should focus on better understanding the series of events to be able to provide better interventions and potentially earlier diagnoses. This may be possible through a longitudinal randomized control trial in which mental and physical health are evaluated at multiple timepoints and the experiment group prior to and during contraceptive use among teen girls in rural areas.

\section{Limitations}

There are limitations to this study. First, all outcome variables used were singleitem variables. This makes it problematic to fully understand the construct and the relationship between the predictor variables and the outcome. It also makes it difficult to understand if this measure has true predictive power (i.e., is this single-item variable reliable and valid for what is trying to be measured; Heuckmann et al., 2019). Uncertainty in predictive power makes informing or developing an intervention challenging (Heuckmann et al., 2019). Also, dichotomizing the covariates is a limitation as it decreases the statistical power making it more difficult to detect a relationship between the covariates and the outcome variable. Another limitation is not accounting for intention to halt contraceptive use, a key construct in the theory of planned behavior (Ajzen, 1991). Importantly, causality cannot be inferred with any of the results as this is a cross-sectional study and more research is needed to see if similar results are found.

Generalizability also cannot be determined because it was a very specific sample recruited from certain counties that met the criteria for the current study. Also, the sample size was smaller than anticipated, which affected the power and potentially impacted 
results by either not being able to detect other significant results or that significant results were seen due to such a homogenous sample. During recruitment, there were problems with "bots" taking the survey. Further security measures were taken and the survey was relaunched (e.g., the IP address had to be located in Missouri). Also, a convenience sample was used and there was a lot of data thrown out due to more than half the survey not being completed. The majority of this sample identified as White, which is another limitation and contributed to generalizability not being determined. This study supports current evidence; future research can focus on if these results are generalizable to other rural U.S. populations and if these factors also influence the intention to use contraceptives among girls in rural areas.

\section{Conclusion}

This study aimed to understand if perceived side effects relate to girls' contraceptive use in rural Missouri where, in some cases, teen pregnancy rates are double the national rate. Subjective norms regarding contraceptive use, perceived threat (of pregnancy and of side effects), and knowledge of side effects (through physician information) were also factors examined in this study. Results showed that subjective norms, physician information, and the threat of pregnancy did not deter girls from halting contraceptive use due to perceived side effects. This study greatly contributes to the literature regarding rural teens' contraceptive use and how their beliefs about perceived side effects informs the girls' decision to use or halt contraceptive use. More research is needed to fully understand these factors and better improve intervention strategies as well as contraceptive counseling to reduce teen pregnancy rates in rural Missouri. 


\section{Appendix 1}

\section{Eligibility Criteria}

1. Do you identify as cis-gender (your gender assigned at birth is the same as the gender you currently identify as)?

a. Yes

b. No

2. Do you live in the United States?

a. Yes

b. No

3. Are you a native English speaker?

a. Yes

b. No

4. Do you live (and have lived for a minimum of five years) in one of the following counties? (Grundy, Montgomery, Bates, Washington, Dent, Laclede, Lawrence, Wright, Douglas, Howell, Shannon, Oregon, Carter, Ripley, Wayne, Scott, Mississippi, New Madrid, Butler, Stoddard, Pemiscot, Dunklin)

5. How old are you? (15-19)
a. 15
b. 16
c. 17
d. 18
e. 19

\section{Demographics}

1. Please identify your race. (please check all that apply)
Asian
Black/African American
White/Caucasian
Native American or Other Pacific Islander
American Indian or Alaska Native
Other, please describe

2. Please identify your ethnicity.

Hispanic or Latino/a

Not Hispanic or Latino/a

3. Please identify your sexual orientation.

Straight/heterosexual

Gay 
Lesbian

Bisexual

Pansexual

Queer

Other, please describe

4. Please identify your highest level of education completed.

$8^{\text {th }}$ grade

Some high school

High school/GED

Some college

Trade/technical/vocational training

Associate's degree

Bachelor's degree

Master's degree

Professional degree

5. What is your age (in years)?

6. Please indicate whether the following are very true, a little true, or not true about your current situation. (Hamby, Turner, \& Finkelhor, 2011).

1. You don't have enough money to buy the clothes or household items that you or your family need.

2. You are behind one month or more on your rent or mortgage payment.

3. You don't have enough money to pay your regular bills.

4. You don't have enough money to go out to dinner, or pay for entertainment or recreational activities.

5. It would be hard for you to find the money to cover an unexpected expense, such as a medical bill or repair that was $\$ 500$ or more.

7. Please identify your household income.
a. Less than $\$ 25,000$
b. $\$ 25,00-\$ 34,000$
c. $\$ 35,000-\$ 49,000$
d. $\$ 50,000-\$ 74,000$
e. $\$ 75,000-\$ 99,000$
f. $\$ 100,000-\$ 150,000$
g. Above $\$ 150,000$

8. Do you identify as religious?
a. Yes
b. No 
Contraceptive Rumors (DeClerque et al., 1986)

1. Have you ever heard anyone say using contraceptives causes side effects?

If yes: What form(s) of contraceptives

Condoms

Diaphragms

IUD

Birth control pills

The shot (Depo)

The patch

Arm Implant (Implanon)

NuvaRing

What side effect(s)?

Who did you hear that from?

Did you talk to or mention this to someone else?

If yes: Who did you mention it to?

2. Do you believe that contraceptives cause side effects?

If yes: What form(s) of contraceptives?

Condoms

Diaphragms

IUD

Birth control pills

The shot (Depo)

The patch

Arm Implant (Implanon)

NuvaRing

What side effects?

3. In your neighborhood or community, do you know of anyone who actually complained of side effects from birth control?

If yes: Who?

From what form of contraceptive?

Condoms

Diaphragms

IUD

Birth control pills

The shot (Depo)

The patch 
Arm Implant (Implanon)

NuvaRing

What side effects did they describe?

\section{Contraceptive Avoidance/Discontinuation}

1. Did information you learned about side effects of contraception result in you never or no longer taking contraception?

2. Did you personally experience a negative side effect from contraception use that led to you halting the contraception use?

3. Had you been told about side effects associated with contraception?

a. If yes, did this information about side effects of contraception lead to the decision to avoid or halt contraception use?

b. If yes, what side effects were you told about and by who?

\section{Pregnancy}

1. Have you ever been pregnant?

2. How old were you when the pregnancy(ies) occurred?

3. Were you using a form of contraceptives when you got pregnant?

a. If yes, what method of contraception?

4. Were you using condoms when the pregnancy(ies) occurred?

5. Were the pregnancy(ies) planned?

\section{First Sexual Experience}

1. How old were you when you had your first intercourse (vaginal penetration with a penis)?

2. Was your first sexual experience consensual (meaning did you give your partner permission to have sex with you/did you say yes to your first sexual experience)?

3. How old was your partner during your first intercourse?

4. Did you use contraceptive and/or barrier methods during your first intercourse?

a. If yes, what method(s).

\section{Subjective Norms}

1. People who are important to you may have feelings about the type of birth control you might use. For each birth control method below, please indicate how the people who are most important to you would feel about your using that form of contraception (Circle the number from 1 to 5 that best represents their feelings).

They would be:

$1=$ Very much opposed (would discourage me) 
$2=$ Somewhat opposed

$3=$ Neither opposed nor in favor (neutral)

$4=$ Somewhat in favor

$5=$ Very much in favor (would encourage use)

Condoms

Diaphragms

IUD

Birth control pills

The shot (Depo)

The patch

Arm Implant (Implanon)

NuvaRing

2. How would your mom react if you were to use contraceptives?

Very supportive

Supportive

Neutral

Unsupportive

Very unsupportive

N/A

3. How would your dad react if you were to use contraceptives?

Very supportive

Supportive

Neutral

Unsupportive

Very unsupportive

N/A

4. How would your siblings react if you were to use contraceptives?

Very supportive

Supportive

Neutral

Unsupportive

Very unsupportive

N/A

5. How would your friends react if you were to use contraceptives? 
Very supportive

Supportive

Neutral

Unsupportive

Very unsupportive

N/A

6. How would your religious leader (e.g., pastor) react if you were to use contraceptives?

Very supportive

Supportive

Neutral

Unsupportive

Very unsupportive

N/A

7. How would your religious community react if you were to use contraceptives?

Very supportive

Supportive

Neutral

Unsupportive

Very unsupportive

N/A

Attitudes Towards Contraceptive Use (Condelli, 1998).

1. If you were not to use birth control, how likely do you think it is that you would become pregnant during the next year?

Very unlikely

Somewhat unlikely

Neutral, neither likely not unlikely

Somewhat likely

Very likely

2. What form of birth control have you chosen to use?

3. How likely do you think it is that you will use the above method every time you have intercourse over the next year?

Very unlikely 
Somewhat unlikely

Neutral, neither likely not unlikely

Somewhat likely

Very likely

4. If you were to continue using this form of birth control, how likely do you think it is that you would become pregnant during the next year?

Very unlikely

Somewhat unlikely

Neutral, neither likely not unlikely

Somewhat likely

Very likely

5. Below are a number of statements about how you might feel about becoming pregnant within the next year. Please select the one that best represents how you feel (Check only one).

It would be the worst thing that could happen to me

It would be very bad

It would be sort of bad but not terrible

It would be O.K.

It would be be sort of good but not terrific

It would be very good

It would be the best thing that could happen to me

6. Different birth control methods vary in how effective or ineffective they are in preventing pregnancy. They also vary in how convenient they are to use. For each birth control method listed below, please rate how effective you think they would be in preventing you from becoming pregnant and how convenient or inconvenient they would be for you to use. (Click the number from 1 to 5 that best represents your feelings).

$1=$ Very effective (definitely prevents pregnancy)

$2=$ Pretty effective

$3=$ Unsure

$4=$ Pretty ineffective

$5=$ Ineffective (would not prevent pregnancy)

$1=$ Very convenient (no trouble at all)

$2=$ Pretty convenient

3=Unsure

$4=$ Pretty inconvenient

$5=$ Very inconvenient (too much trouble to use) 


\begin{tabular}{|l|l|l|}
\hline & Effectiveness & Convenience \\
\hline Condoms & & \\
\hline Diaphragm & & \\
\hline IUD & & \\
\hline Birth Control Pills & & \\
\hline The Shot (Depo) & & \\
\hline The patch & & \\
\hline Arm Implant (Implanon) & & \\
\hline NuvaRing & & \\
\hline
\end{tabular}

7. Different forms of birth control can vary in terms of how likely they are to have side effects. Some side effects may be minor, such as irritation or skin problems, while other may be major, such as increasing risk of serious illness. For each method of birth control below, please rate how concerned you would be about the occurrence of both minor and major side effects. (Click the number from 1 to 5 that best represents your feelings.

$$
\begin{aligned}
& 1=\text { Not at all concerned } \\
& 2=\text { Slightly unconcerned } \\
& 3=\text { Unsure } \\
& 4=\text { Pretty concerned } \\
& 5=\text { Very concerned }
\end{aligned}
$$

\begin{tabular}{|l|l|l|}
\hline & Minor Side Effects & Major Side Effects \\
\hline Condoms & & \\
\hline Diaphragm & & \\
\hline IUD & & \\
\hline Birth Control Pills & & \\
\hline The Shot (Depo) & & \\
\hline The patch & & \\
\hline Arm Implant (Implanon) & & \\
\hline NuvaRing & & \\
\hline
\end{tabular}

\section{Instructions for Scales:}

These are directions for filling out the 7-point scales used in the study. A 7-point scale is one with adjectives at both ends, and 7 points between them. See the example below, and 
read them carefully. If your feelings seem very closely described by the adjective at one end of the scale or the other, you should select as follows (Kelley, 1998).

Positive 1234567 negative

Positive 1234567 negative

If your feelings seem to quite closely describe one or the other end of the scale (but not extremely), you should place you check mark as follows:

Positive 1234567 negative

Positive 1234567 negative

If your feelings seem only slightly described by one side as opposed to the other (but not really neutral), then you should select as follows:

Positive 1234567 Negative

Positive 1234567 Negative

The direction toward which you check, of course, depends on which of the two ends of the scale seem most characteristic of your feelings.

If you consider your feelings neutral on the scale, both sides of the scale equally associated with your feelings, or if the scale is completely irrelevant, unrelated in any way to your feelings, then you should select the middle space as shown here:

Positive 1234567 Negative

1. How would you feel about doing the following thing?

a. Asking a doctor for a contraceptive

i. (Positive) 1234567 (Negative)

ii. (Disgusted) 1234567 (Not at all disgusted)

How would you feel about doing the following things?

A. Take a contraceptive pill

B. Having an IUD (intrauterine device) inserted into your uterus

C. Wearing an IUD (intrauterine device) in your uterus

D. Inserting contraceptive foam into your vagina

E. Inserting a diaphragm into your vagina

F. Having an abortion

G. Asking for contraceptive foam 
H. Buying contraceptive foam

I. Asking for birth control pills

J. Using birth control pills

K. Using the shot (e.g., Depo)

L. Using the patch

M. Using the arm implant (Implanon)

N. Using NuvaRing (a ring inserted into the vagina)

\section{Perceived Threat}

1. What is the likelihood they would become pregnant if engaging in sex while not using any form of contraception or barrier method?

Very unlikely

Somewhat unlikely

Neutral, neither likely not unlikely

Somewhat likely

Very likely

2. What is the likelihood they would become pregnant if engaging in sex while using only barrier methods (e.g., condoms)?

Very unlikely

Somewhat unlikely

Neutral, neither likely not unlikely

Somewhat likely

Very likely

3. What is the likelihood they would become pregnant if engaging in sex while only using contraception?

Very unlikely

Somewhat unlikely

Neutral, neither likely not unlikely

Somewhat likely

Very likely

4. What is the likelihood they would become pregnant if engaging in sex while using contraception and barrier methods (e.g., condoms)?

Very unlikely

Somewhat unlikely

Neutral, neither likely not unlikely

Somewhat likely

Very likely

6. One of these vignettes will randomly pop up in each of the participant's survey. 
Molly is a 15-year-old girl. Molly's sister uses birth control and told Molly it caused her to have some side effects. Molly is using the depo shot for birth control currently. Molly smokes about half a pack of cigarettes a day ( 10 cigarettes).

Molly is a 15-year-old girl. Molly's sister uses birth control and told Molly she has not had any side effects. Molly is using the depo shot for birth control currently. Molly smokes about half a pack of cigarettes a day ( 10 cigarettes).

Molly is a 15-year-old girl. Molly's sister uses birth control and told Molly it caused her to have some side effects. Molly is using birth control pills currently for birth control. Molly smokes about half a pack of cigarettes a day ( 10 cigarettes $)$.

Molly is a 15-year-old girl. Molly's sister uses birth control and told Molly it caused her to have some side effects. Molly is using the depo shot for birth control currently. Molly does not smoke or chew tobacco.

Molly is a 15-year-old girl. Molly's sister uses birth control and told Molly she has not had any side effects. Molly is using birth control pills for birth control currently. Molly does not smoke or chew tobacco.

Molly is a 15-year-old girl. Molly's sister uses birth control and told Molly she has not had any side effects. Molly is using birth control pills for birth control currently. Molly smokes about half a pack of cigarettes a day ( 10 cigarettes).

Molly is a 15-year-old girl. Molly's sister uses birth control and told Molly it caused her to have some side effects. Molly is using birth control pills for birth control currently. Molly does not smoke or chew tobacco.

Molly is a 15-year-old girl. Molly's sister uses birth control and told Molly she has not had any side effects. Molly is using the depo shot for birth control currently. Molly does not smoke or chew tobacco.

Molly is a 19-year-old girl. Molly's sister uses birth control and told Molly it caused her to have some side effects. Molly is using the depo shot for birth control currently. Molly smokes about half a pack of cigarettes a day $(\sim 10$ cigarettes).

Molly is a 19-year-old girl. Molly's sister uses birth control and told Molly she has not had any side effects. Molly is using the depo shot for birth control currently. Molly smokes about half a pack of cigarettes a day ( 10 cigarettes).

Molly is a 19-year-old girl. Molly's sister uses birth control and told Molly it caused her to have some side effects. Molly is using birth control pills 
currently for birth control. Molly smokes about half a pack of cigarettes a day ( 10 cigarettes).

Molly is a 19-year-old girl. Molly's sister uses birth control and told Molly it caused her to have some side effects. Molly is using the depo shot for birth control currently. Molly does not smoke or chew tobacco.

Molly is a 19-year-old girl. Molly's sister uses birth control and told Molly she has not had any side effects. Molly is using birth control pills for birth control currently. Molly does not smoke or chew tobacco.

Molly is a 19-year-old girl. Molly's sister uses birth control and told Molly she has not had any side effects. Molly is using birth control pills for birth control currently. Molly smokes about half a pack of cigarettes a day $(\sim 10$ cigarettes).

Molly is a 19-year-old girl. Molly's sister uses birth control and told Molly it caused her to have some side effects. Molly is using birth control pills for birth control currently. Molly does not smoke or chew tobacco.

Molly is a 19-year-old girl. Molly's sister uses birth control and told Molly she has not had any side effects. Molly is using the depo shot for birth control currently. Molly does not smoke or chew tobacco.

After the vignette the participant will be prompted randomly with one of the following:

How many out of 100 girls who are exactly like Molly are likely to experience anxiety as a side effects from birth control: out of 100 girls

How many out of 100 girls who are exactly like Molly are likely to experience depression as a side effects from birth control: out of 100 girls

How many out of 100 girls who are exactly like Molly are likely to experience bipolar as a side effects from birth control: out of 100 girls

How many out of 100 girls who are exactly like Molly are likely to experience endometriosis as a side effects from birth control: out of 100 girls

How many out of 100 girls who are exactly like Molly are likely to experience weight gain as a side effects from birth control: out of 100 girls

How many out of 100 girls who are exactly like Molly are likely to experience infertility as a side effects from birth control: out of 100 girls 


\section{Appendix 2}

Institutional Review Board

482 McReynolds Hall

University of Missouri-Columbia

Columbia, MO 65211

FWA Number: 00002876

573-882-3181

IRB Registration Numbers: 00000731,

irb@missouri.edu 00009014

March 18, 2020

Principal Investigator: Mackenzie Anne Cook

Department: Social Work

Your IRB Application to project entitled EXAMINING INTENTION TO USE CONTRACEPTIVES

AMONG TEEN GIRLS IN RURAL MISSOURI was reviewed and approved by the MU Institutional

Review Board according to the terms and conditions described below:

IRB Project Number 2020030

IRB Review Number 260121

Funding Source Society of Family Planning Research Fund (SFPRF)

Initial Application Approval Date March 17, 2020

IRB Expiration Date March 17, 2021

Level of Review Expedited

Application Status Approved

Project Status Active - Open to Enrollment

Expedited Categories 45 CFR 46.110.a(f)(7)

Risk Level Minimal Risk

Child Category 46.404/50.51

Type of Consent

Consent with Waiver of Documentation

Child Assent without Documentation

Waiver of Parental Consent

HIPAA Category No HIPAA

External Funding External Grant (ex. Federal funding, foundation funding)

Approved Documents

IRB Approved Assent Document - Children 15-17

IRB Approved Consent Document - Subjects 18-19

protocol_3.12.20.docx

survey_diss.docx

eligibility_screener_script_diss..docx

teen_birth_control_use_research_study-5.pdf

eligibility_criteria_diss..docx

fact_sheet_diss..docx

The principal investigator (PI) is responsible for all aspects and conduct of this study. The PI must comply with the following conditions of the approval:

1. No subjects may be involved in any study procedure prior to the IRB approval date or after the expiration date.

2. All unanticipated problems must be reported to the IRB on the Event Report within 5 business days of becoming aware of the problem. Unanticipated problems are defined as events that are unexpected, related or possibly related to the research, and suggests the research places subjects or others at a greater risk of harm than was previously known or recognized. If the unanticipated problem was a death, this is reportable to the IRB within 24 hours on the Death Report. 
3. On-site deaths that are not unanticipated problems must be reported within 5 days of awareness on the Death Report, unless the study is such that you have no way of knowing a death has occurred, or an individual dies more than 30 days after s/he has stopped or completed all study procedures/interventions and required follow-up.

4. All deviations (non-compliance) must be reported to the IRB on the Event Report within 5 business days of becoming aware of the deviation.

5. All changes must be IRB approved prior to implementation unless they are intended to reduce immediate risk. All changes must be submitted on the Amendment Form.

6. All recruitment materials and methods must be approved by the IRB prior to being used.

7. The project-generated annual report must be submitted to the IRB for review and approval at least 30 days prior to the project expiration date. If the study is complete, the Completion/ Withdrawal Form may be submitted in lieu of the annual report.

8. Securely maintain all research records for a period of seven years from the project completion date or longer depending on the sponsor's record keeping requirements.

9. Utilize the IRB stamped consent documents and other approved research documents located within the document storage section of eCompliance. These documents are highlighted green.

If you are offering subject payments and would like more information about research participant payments, please click here to view the MU Business Policy and Procedure: http:// bppm.missouri.edu/chapter2/2_250.html

If you have any questions, please contact the IRB Office at 573-882-3181 or muresearchirb@missouri.edu.

Thank you,

MU Institutional Review Board 
Appendix 3

\section{TEEN BIRTH CONTROL USE: RESEARCH STUDY}

LIVE IN RURAL MISSOURI?

15-19 YEAR-0LD GIRL?

COMPLETE A BRIEF SURVEY AND RECEIVE \$10 WALMART GIFT CARD
CONTRACEPTION
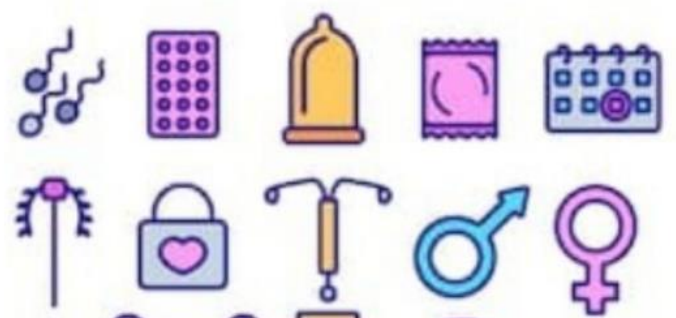

$\Theta$ क्षि<smiles>O=C1CCCCC1</smiles><smiles></smiles>
$\theta$<smiles>C1=CCCC1</smiles>
I管 $\theta \cong$
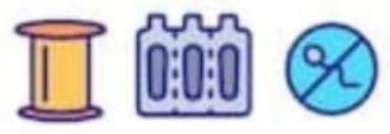

shutterstock.com • 1385714102

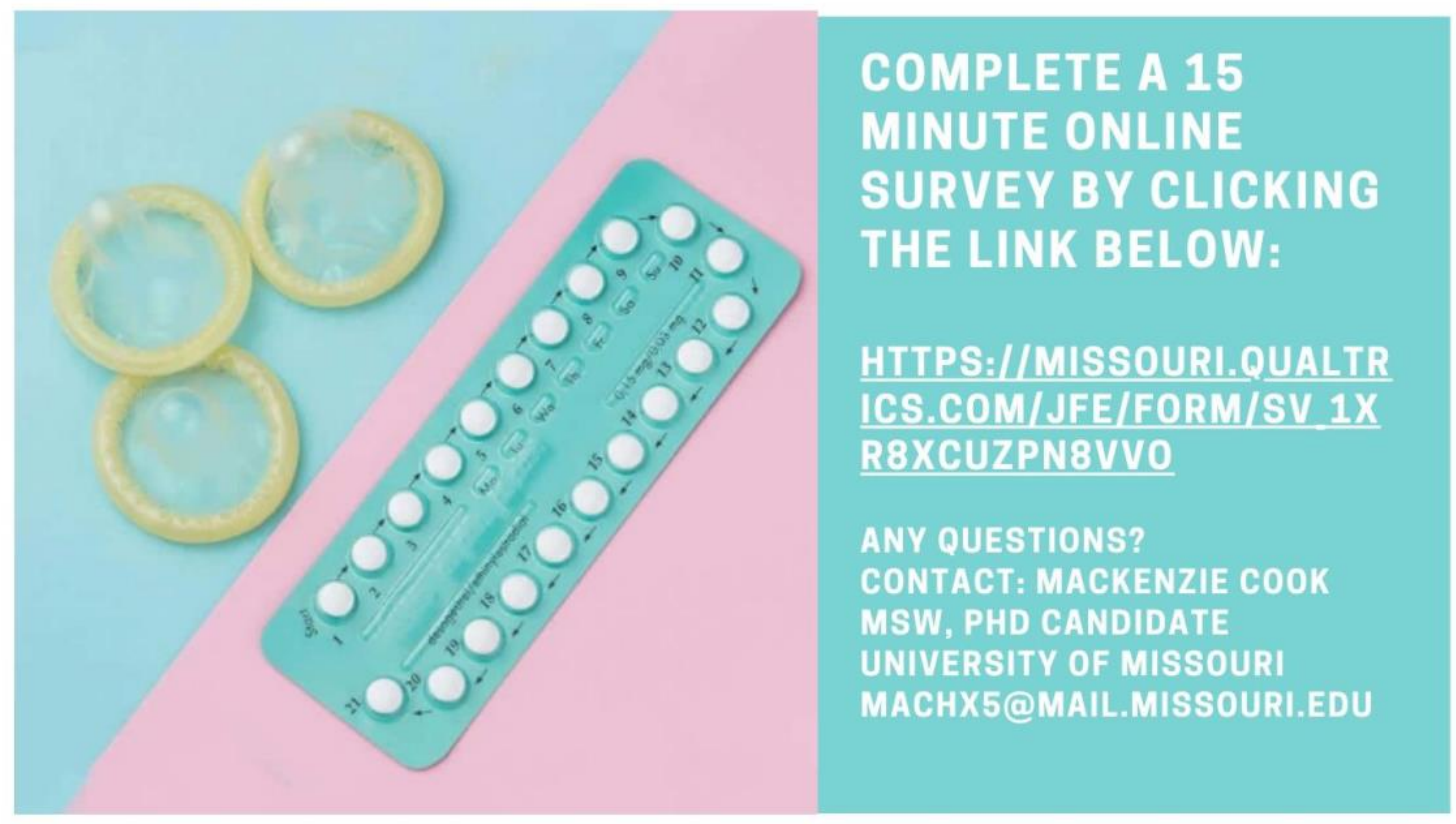




\section{References}

Aldelman, S., Free, C., \& Smith, C. (2019). Predictors of postabortion contraception use in Cambodia. Contraception, 99(3), 155-159.

Ajzen, I. (1991). The theory of planned behavior. Organizational Behavior and Human Decision Processes, 50(2), 179-211.

Bailo, L., Vergani, L., \& Pravettoni, G. (2019). Patient preferences as guidance for information framing in a medical shared decision-making approach: the bridge between nudging and patient preferences. Patient preference and adherence, 13, 2225.

Bandura, A. (1977). Self-efficacy: Toward a unifying theory of behavioral change. Psychological Review, 84(2), 191.

Bandura, A. (1982). Self-efficacy mechanism in human agency. American Psychologist, $37(2), 122$.

Bandura, A. (2005). The evolution of social cognitive theory. Great Minds in Management, 9-35.

Barr, N. G. (2010). Managing adverse effects of hormonal contraceptives. American Family Physician, 82(12).

Becker, M. H. (1974). The health belief model and sick role behavior. Health Education Monographs, 2(4), 409-419.

Beckett, C. (2006). Essential theory for social work practice. Sage.

Begun, S., Kattari, S., McKay, K., Ramseyer Winter, V., \& O’Neill, E. (2016). Exploring U.S. social work students' sexual attitudes and abortion viewpoints. Journal of Sex Research, 54(6), 752-763. 
Billy, J. O., Udry, J. R., \& Rodgers, J. L. (1984). Adolescent sexual behavior and friendship choice. Social Forces, 62(3), 653-678.

Bissell, M. (2000). Socio-economic outcomes of teen pregnancy and parenthood: A review of the literature. The Canadian Journal of Human Sexuality, 9(3), 191.

Brewster, K. L. (1994). Race differences in sexual activity among adolescent women: The role of neighborhood characteristics. American Sociological Review, 408424.

Brown, W., Ottney, A., \& Nguyen, S. (2011). Breaking the barrier: The health belief model and patient perceptions regarding contraception. Contraception, 83(5), 453-458.

Brückner, H., Martin, A., \& Bearman, P. S. (2004). Ambivalence and pregnancy: Adolescents' attitudes, contraceptive use and pregnancy. Perspectives on Sexual and Reproductive Health, 36(6), 248-257.

Carolei, A., Marini, C., \& De Matteis, G. A. (1996). History of migraine and risk of cerebral ischaemia in young adults. The Lancet, 347(9014), 1503-1506.

Cashdollar, S. E. (2018). Neither accidental nor intended: Pregnancy as an adolescent identity project among Hispanic teenage mothers in Doña Ana County, New Mexico. Journal of Adolescent Research, 33(5), 598-622.

Centers for Disease Control and Prevention (CDC). (2019). Natality Public-Use Data on CDC WONDER Online Database, for years 2007-2018 [Interactive Data Tables]. https://wonder.cdc.gov/natality-current.html 
Chambers, B. D., \& Erausquin, J. T. (2018). Reframing the way we think about teenage motherhood. In Global Perspectives on Women's Sexual and Reproductive Health Across the Lifecourse (pp. 59-71). Springer, Cham.

Chipeta, E. K., Chimwaza, W., \& Kalilani-Phiri, L. (2010). Contraceptive knowledge, beliefs and attitudes in rural Malawi: Misinformation, misbeliefs and misperceptions. Malawi Medical Journal, 22(2).

Chuang, C. H., Hwang, S. W., McCall-Hosenfeld, J. S., Rosenwasser, L., Hillemeier, M. M., \& Weisman, C. S. (2012). Primary care physicians' perceptions of barriers to preventive reproductive health care in rural communities. Perspectives on Sexual and Reproductive Health, 44(2), 78-83.

Cole, J. A., Norman, H., Doherty, M., \& Walker, A. M. (2007). Venous thromboembolism, myocardial infarction, and stroke among transdermal contraceptive system users. Obstetrics \& Gynecology, 109(2), 339-346.

Combs, K. M., Brown, S. M., Begun, S., \& Taussig, H. (2018). Pregnancy attitudes and contraceptive use among young adults with histories of foster care. Children and Youth Services Review, 94, 284-289.

Commendador, K. A. (2010). Parental influences on adolescent decision making and contraceptive use. Pediatric Nursing, 36(3), 147.

Condelli, L. (1998). The contraceptive utilities, intention, and knowledge scale. Handbook of Sexuality-Related Measures, 147-152.

Cook, M. (2019). Missouri sex education policy: Recommendations for revision to reduce teen pregnancy rates. Sexuality Research and Social Policy, 1-7. 
Cook, M. (2021). Young and pregnant: Understanding experiences of teen moms in rural Missouri [Manuscript in preparation]. School of Social Work, University of Missouri.

County Health Rankings. (2019). Missouri teen birth rates. Retrieved from https://www.countyhealthrankings.org/app/missouri/2013/measure/factors/14/data

Craig, D. M., Wade, K. E., Allison, K. R., Irving, H. M., Williams, J. I., \& Hlibka, C. M. (2000). Factors predictive of adolescents' intentions to use birth control pills, condoms, and birth control pills in combination with condoms. Canadian Journal of Public Health, 91(5), 361-365.

Curran, P. J., West, S. G., \& Finch, J. F. (1996). The robustness of test statistics to nonnormality and specification error in confirmatory factor analysis. Psychological Methods, 1(1), 16.

DeClerque, J., Tsui, A. O., Abul-Ata, M. F., \& Barcelona, D. (1986). Rumor, misinformation and oral contraceptive use in Egypt. Social Science \& Medicine, 23(1), 83-92.

Dehlendorf, C., Levy, K., Ruskin, R., \& Steinauer, J. (2010). Health care providers' knowledge about contraceptive evidence: A barrier to quality family planning care? Contraception, 81(4), 292-298.

Dehlendorf, C., Levy, K., Kelley, A., Grumbach, K., \& Steinauer, J. (2013). Women's preferences for contraceptive counseling and decision making. Contraception, 88(2), 250-256. 
Dehlendorf, C., Krajewski, C., \& Borrero, S. (2014). Contraceptive counseling: Best practices to ensure quality communication and enable effective contraceptive use. Clinical Obstetrics and Gynecology, 57(4), 659.

Domenico, D. M., \& Jones, K. H. (2007). Adolescent pregnancy in America: Causes and responses. Journal for Vocational Special Needs Education, 30(1), 4-12.

Dominelli, L. (2002). Feminist social work theory and practice. Macmillan International Higher Education.

Douglas-Hall, A., Kost, K., \& Kavanaugh, M. L. (2018). State-level estimates of contraceptive use in the United States, 2017. Guttmacher Institute, 10(2018.30267).

Eitle D, Greene K, and Eitle TM (2015) American Indians, substance use, and sexual behavior: Do predictors of sexually transmitted infections explain the race gap among young adults?” Sexually Transmitted Diseases, 42, 64-7.

Eitle, D., \& Thorsen, M. (2018). School contextual factors and race differences in adolescent sexual behaviors. International Journal of Sexual Health, 30(3), 309322.

Ellen JM, Aral SO, and Madger LS (1998) Do differences in sexual behaviors account for the racial/ethnic differences in adolescents' self-reported history of sexually transmitted diseases?” Sexually Transmitted Diseases, 25(3), 125-9.

Ewing, A. C., Kottke, M. J., Kraft, J. M., Sales, J. M., Brown, J. L., Goedken, P., Wiener, J, \& Kourtis, A. P. (2017). 2GETHER-The Dual Protection Project: Design and rationale of a randomized controlled trial to increase dual protection strategy 
selection and adherence among African American adolescent females. Contemporary Clinical Trials, 54, 1-7.

Farley, T. M., Rowe, P. J., Meirik, O., Rosenberg, M. J., \& Chen, J. H. (1992). Intrauterine devices and pelvic inflammatory disease: An international perspective. The Lancet, 339(8796), 785-788.

Faul, F., Erdfelder, E., Buchner, A., \& Lang, A. G. (2009). Statistical power analyses using G* Power 3.1: Tests for correlation and regression analyses. Behavior Research Methods, 41(4), 1149-1160.

Fortier, E., \& Foster, A. M. (2017). “It was kind of like if it happens it happens. It wasn't planned, it wasn't intentional": Young mothers' experiences with subsequent pregnancy in Ottawa, Canada. FACETS, 2(2), 859-871.

Fridman, I., Hart, J. L., Yadav, K. N., \& Higgins, E. T. (2018). Perspectives on using decision-making nudges in physician-patient communications. PloS one, 13(9), e0202874.

Furstenberg Jr, F. F., Herceg-Baron, R., Shea, J., \& Webb, D. (1984). Family communication and teenagers' contraceptive use. Family Planning Perspectives, 16(4), 163-170.

Gillum, L. A., Mamidipudi, S. K., \& Johnston, S. C. (2000). Ischemic stroke risk with oral contraceptives: a meta-analysis. Jama, 284(1), 72-78.

Godinho, A., Schell, C., \& Cunningham, J. A. (2020). Out damn bot, out: Recruiting real people into substance use studies on the internet. Substance Abuse, 41(1), 3-5. 
Gilliam, M. L., Warden, M., Goldstein, C., \& Tapia, B. (2004). Concerns about contraceptive side effects among young Latinas: A focus-group approach. Contraception, 70(4), 299-305.

Goossens, G., Kadji, C., \& Delvenne, V. (2015). Teenage pregnancy: A psychopathological risk for mothers and babies. Psychiatria Danubina, 27(1), 499-503.

Gostin, L. O. (2015). Law, ethics, and public health in the vaccination debates: Politics of the measles outbreak. Jama, 313(11), 1099-1100.

Grand Challenges of Social Work. (2019). The Challenges.

https://grandchallengesforsocialwork.org/ensure-healthy-development-for-allyouth/

Guendelman, S., Denny, C., Mauldon, J., \& Chetkovich, C. (2000). Perceptions of hormonal contraceptive safety and side effects among low-income Latina and non-Latina women. Maternal and Child Health Journal, 4(4), 233-239.

Guttmacher Institute. (2020a). Contraceptive use among adolescents in the United States. Retrieved from https://www.guttmacher.org/fact-sheet/contraceptive-use-amongadolescents-united-states

Guttmacher Institute. (2020b). Contraceptive Use in the United States. Retrieved from https://www.guttmacher.org/fact-sheet/contraceptive-use-unitedstates\#: :text=More\%20than\%2099\%25\%20of\%20women,currently\%20using\%2 0a\%20contraceptive $\% 20$ method.\&text=Ten $\% 20$ percent $\% 20$ of $\% 20$ women $\% 20 \mathrm{at}$, currently\%20using\%20any\%20contraceptive\%20method. 
Hall, K. S., White, K. O. C., Rickert, V. I., Reame, N., \& Westhoff, C. (2012). Influence of depressed mood and psychological stress symptoms on perceived oral contraceptive side effects and discontinuation in young minority women. Contraception, 86(5), 518-525.

Hallfors DD, Iritani BJ, Miller WC, and Bauer DJ (2007) Sexual and drug behavior patterns and HIV and STD racial disparities: The need for new directions. American Journal of Public Health, 97(1), 125-32.

Hamby, S., Turner, H. A., \& Finkelhor, D. (2011). Financial strain index. Crimes Against Children Research Center.

Harris, K. M. (2009). The National Longitudinal Study of Adolescent Health (Add Health), Waves I and II, 1994-1996; Wave III, 2001-2002; Wave IV, 20072009. Carolina Population Center, University of North Carolina at Chapel Hill.

Harris, K. M. (2013). The add health study: Design and accomplishments. Chapel Hill: Carolina Population Center, University of North Carolina at Chapel Hill, 1-22.

Harris, K. M., Halpern, C. T., Whitsel, E., Hussey, J., Tabor, J., Entzel, P., \& Udry, J. R. (2009). The National Longitudinal Study of Adolescent Health: Research Design. http://www.cpc.unc.edu/projects/addhealth/design.

Heuckmann, B., Hammann, M., \& Asshoff, R. (2019). Advantages and disadvantages of modeling beliefs by single item and scale models in the context of the theory of planned behavior. Education Sciences, 9(4), 268.

Hosmer, D. W., \& Lemeshow, S. (2000). Applied logistic regression. Wiley.

Howe, D. (2009). A brief introduction to social work theory. Macmillan International Higher Education. 
Hubacher, D., Lara-Ricalde, R., Taylor, D. J., Guerra-Infante, F., \& Guzmán-Rodríguez, R. (2001). Use of copper intrauterine devices and the risk of tubal infertility among nulligravid women. New England Journal of Medicine, 345(8), 561-567.

Hung, P., Kozhimannil, K. B., Casey, M. M., \& Moscovice, I. S. (2016). Why are obstetric units in rural hospitals closing their doors? Health Services Research, 51(4), 1546-1560.

Jaccard, J., \& Dittus, P. J. (2000). Adolescent perceptions of maternal approval of contraception and sexual risk behavior. American Journal of Public Health, 90(9), 1426.

Jaccard, J., Dodge, T., \& Dittus, P. (2003). Do adolescents want to avoid pregnancy? Attitudes toward pregnancy as predictors of pregnancy. Journal of Adolescent Health, 33(2), 79-83.

Janz, N. K., \& Becker, M. H. (1984). The health belief model: A decade later. Health Education Quarterly, 11(1), 1-47.

Jick, S., Kaye, J. A., Li, L., \& Jick, H. (2007). Further results on the risk of nonfatal venous thromboembolism in users of the contraceptive transdermal patch compared to users of oral contraceptives containing norgestimate and $35 \mu \mathrm{g}$ of ethinyl estradiol. Contraception, 76(1), 4-7.

Jick, S. S., Kaye, J. A., Russmann, S., \& Jick, H. (2006). Risk of nonfatal venous thromboembolism in women using a contraceptive transdermal patch and oral contraceptives containing norgestimate and $35 \mu \mathrm{g}$ of ethinyl estradiol. Contraception, 73(3), 223-228. 
Kelley, K. (1998). Affective responses toward contraceptive topics and behavior scale. Handbook of Sexuality-Related Measures, 162.

Kirscht, J. P. (1974). The health belief model and illness behavior. Health Education Monographs, 2(4), 387-408.

Kost, K., Maddow-Zimet, I., \& Arpaio, A. (2017). Pregnancies, births and abortions among adolescents and young women in the United States, 2013: National and state trends by age, race and ethnicity. Guttmacher Institute. https://www.guttmacher.org/report/us-adolescent-pregnancy-trends-2013.

Lebese, R. T., Maputle, S. M., Ramathuba, D. U., \& Khoza, L. B. (2013). Factors influencing the uptake of contraception services by Vatsonga adolescents in rural communities of Vhembe District in Limpopo Province, South Africa. Health SA Gesondheid, 18(1).

Lindberg, L. D., VandeVusse, A., \& Mueller, J. (2020). Early impacts of the COVID-19 pandemic: Findings from the 2020 Guttmacher Survey of Reproductive Health Experiences. Guttmacher Institute.

Lindberg, S. (2018). The birth control with the most and least side effects according to doctors. Insider. https://www.insider.com/what-birth-control-should-i-take-2018$\underline{2}$

Littlejohn, K. E. (2013). "It's those pills that are ruining me": Gender and the social meanings of hormonal contraceptive side effects. Gender \& Society, 27(6), 843863.

Machiyama, K., Huda, F. A., Ahmmed, F., Odwe, G., Obare, F., Mumah, J. N., Wamukoya, M., Casterline, J. B., \& Cleland, J. (2018). Women's attitudes and 
beliefs towards specific contraceptive methods in Bangladesh and Kenya. Reproductive Health, 15(1), 75.

Maddow-Zimet, I., \& Kost, K. (2021). Pregnancies, births and abortions in the United States, 1973-2017: National and state trends by age. Guttmacher Institute. https://doi.org/10.1363/2021.32709

Maiman, L. A., \& Becker, M. H. (1974). The health belief model: Origins and correlates in psychological theory. Health Education Monographs, 2(4), 336-353.

Marcinkowski, A., Gauf, A., Goedken, P., Sales, J., Brown, J., \& Kottke, M. (2021). 7. Using the theory of planned behavior to identify predictors of contraceptive use intentions and behaviors in adolescents. Journal of Pediatric and Adolescent Gynecology, 34(2), 242.

Martinez, G. M., \& Abma, J. C. (2020). Sexual activity and contraceptive use among teenagers aged 15-19 in the United States, 2015-2017. NCHS Data Brief, no 366. National Center for Health Statistics.

McCave, E., Shepard, B., \& Ramseyer Winter, V. (2014). Human sexuality as a critical subfield in social work. Advances in Social Work, 15(2), 409-427.

McKay, K. (2015). Sexuality education within masters of social work programs. Widener University.

McLeod, J. D., \& Shanahan, M. J. (1993). Poverty, parenting, and children's mental health. American Sociological Review, 351-366.

Mollborn, S. (2017). Teenage mothers today: what we know and how it matters. Child development perspectives, 11(1), 63-69. 
Mollborn, S., Domingue, B. W., \& Boardman, J. D. (2014). Norms as group-level constructs: Investigating school-level teen pregnancy norms and behaviors. Social Forces, 93(1), 241-267.

Moore, W., Pedlow, S., Krishnamurty, P., Wolter, K., \& Chicago, I. L. (2000). National longitudinal survey of youth 1997 (NLSY97). Technical sampling report: National Opinion Research Center.

Myklestad, I., \& Rise, J. (2007). Predicting willingness to engage in unsafe sex and intention to perform sexual protective behaviors among adolescents. Health Education \& Behavior, 34(4), 686-699.

National Association of Social Workers. (2017). Code of ethics. https://www.socialworkers.org/about/ethics/code-of-ethics/code-of-ethics-english

The National Campaign to Prevent Teen and Unplanned Pregnancy. (2013). Teen childbearing in rural America. Science Says, 2013, 47.

NC Rural Health Research Program. (2019). 155 Rural Hospital Closures: January 2005-Present. https://www.shepscenter.unc.edu/programs-projects/ruralhealth/rural-hospital-closures/

O'Connell, K., Davis, A. R., \& Kerns, J. (2007). Oral contraceptives: Side effects and depression in adolescent girls. Contraception, 75(4), 299-304.

Oddens, B. J. (1999). Women's satisfaction with birth control: A population survey of physical and psychological effects of oral contraceptives, intrauterine devices, condoms, natural family planning, and sterilization among 1466 women. Contraception, 59(5), 277-286. 
Pandey, L., Tekin, E., \& Wallace, S. (2005). The Link Between Teen Childbearing and Employment in Georgia.

Planned Parenthood (2021). Birth control.

https://www.plannedparenthood.org/learn/birth-control

Power to Decide. (n.d., a). Missouri data. https://powertodecide.org/what-wedo/information/national-state-data/missouri

Power to Decide (n.d., b). National data. https://powertodecide.org/what-wedo/information/national-state-data/national

Ramseyer Winter, V., O’Neill, E., Begun, S., Kattari, S., \& McKay, K. (2016). MSW student perceptions of sexual health as relevant to the profession: Do social work educational experiences matter? Social Work in Health Care, 8, 614-634. doi: 10.1080/00981389.2016.1189476

Riley, T., Sully, E., Ahmed, Z., \& Biddlecom, A. (2020). Estimates of the potential impact of the COVID-19 pandemic on sexual and reproductive health in low-and middle-income countries. International Perspectives on Sexual and Reproductive Health, 46, 73-76.

Roderique-Davies, G., McKnight, C., John, B., Faulkner, S., \& Lancastle, D. (2016). Models of health behaviour predict intention to use long-acting reversible contraception. Women's Health, 12(6), 507-512.

Rosengard, C., Phipps, M. G., Adler, N. E., \& Ellen, J. M. (2004). Adolescent pregnancy intentions and pregnancy outcomes: A longitudinal examination. Journal of Adolescent Health, 35(6), 453-461. 
Rosenstock, I. M. (1974). Historical origins of the health belief model. Health Education Monographs, 2(4), 328-335.

Rowland, D., \& Lyons, B. (1989). Triple jeopardy: Rural, poor, and uninsured. Health Services Research, 23(6), 975-1004.

Saunders, J. A., Morrow-Howell, N., Spitznagel, E., Doré, P., Proctor, E. K., \& Pescarino, R. (2006). Imputing missing data: A comparison of methods for social work researchers. Social Work Research, 30(1), 19-31.

Seamark, C. J., \& Lings, P. (2004). Positive experiences of teenage motherhood: a qualitative study. British journal of general practice, 54(508), 813-818.

Sieving, R. E., Bearinger, L. H., Resnick, M. D., Pettingell, S., \& Skay, C. (2007). Adolescent dual method use: Relevant attitudes, normative beliefs and selfefficacy. Journal of Adolescent Health, 40(3), 275-e15.

Skovlund, C. W., Mørch, L. S., Kessing, L. V., \& Lidegaard, Ø. (2016). Association of hormonal contraception with depression. JAMA Psychiatry, 73(11), 1154-1162.

Smith, M. J., Ellenberg, S. S., Bell, L. M., \& Rubin, D. M. (2008). Media coverage of the measles-mumps-rubella vaccine and autism controversy and its relationship to MMR immunization rates in the United States. Pediatrics, 121(4), e836-e843.

Solursh, D. S., Ernst, J. L., Lewis, R. W., Prisant, L. M., Mills, T. M., Solursh, L. P., Jarvis, R. G., \& Salazar, W. H. (2003). The human sexuality education of physicians in North American medical schools. International Journal of Impotence Research, 15(5), S41-S45. 
Sucoff, C. A., \& Upchurch, D. M. (1998). Neighborhood context and the risk of childbearing among metropolitan-area black adolescents. American Sociological Review, 571-585.

Teen Pregnancy \& Prevention Partnership. (2019). 2017 Teen Pregnancy Rate for 15-19 Year Olds by Missouri County. Retrieved from https://www.teenpregnancymo.org/wp-content/uploads/2019/10/Teen-Pregnancy-Rates-2010-2017.pdf

UNFPA. Three Things You Need to Know About Contraceptives and COVID-19. Retrieved on September 25, 2020 from https://www.unfpa.org/news/three-thingsyou-need-know-about-contraceptives-and-covid-19

Von Hertzen, H., Piaggio, G., Ding, J., Chen, J., Song, S., Bartfai, G., Ng, E., GemzellDanielsson, K., Oyunbileg, A., Wu, S., Cheng, W., Ludicke, F., Pretnar-Darovec, A., Kirkman, R., Mittal, S., Khomassuridze, A., Apter, D., Peregoudov, A., \& WHO Research Group on Post-ovulatory Methods of Fertility Regulation. (2002). Low dose mifepristone and two regimens of levonorgestrel for emergency contraception: A WHO multicentre randomised trial. The Lancet, 360(9348), 1803-1810.

Walker, D. A., \& Holtfreter, K. (2021). Teen pregnancy, depression, and substance abuse: The conditioning effect of deviant peers. Deviant Behavior, 42(3), 297312.

Wang, Y., McKee, M., Torbica, A., \& Stuckler, D. (2019). Systematic literature review on the spread of health-related misinformation on social media. Social science \& medicine, 240, 112552. 
Westhoff, C. L., Heartwell, S., Edwards, S., Zieman, M., Stuart, G., Cwiak, C., Davis, A., Robilotto, T., Cushman, L., \& Kalmuss, D. (2007). Oral contraceptive discontinuation: Do side effects matter? American Journal of Obstetrics and Gynecology, 196(4), 412-e1.

World Health Organization. (2020). Pulse survey on continuity of essential health services during the COVID-19 pandemic: interim report, 27 August 2020 (No. WHO/2019-nCoV/EHS_continuity/survey/2020.1).

World Health Organization. Reproductive Health. (2010). Medical eligibility criteria for contraceptive use. World Health Organization.

Yawn, B. P., \& Yawn, R. A. (1993). Adolescent pregnancies in rural America: A review of the literature and strategies for primary prevention. Family \& Community Health: The Journal of Health Promotion \& Maintenance, 16(1), 36-45.

Young, T., Turner, J., Denny, G., \& Young, M. (2004). Examining external and internal poverty as antecedents of teen pregnancy. American Journal of Health Behavior, 28(4), 361-373. 


\section{VITA}

Mackenzie Cook Lee was born in Chesterfield, Missouri. She completed high school in West Plains, Missouri where she first found her passion for sexual health education. Mackenzie completed her Bachelor's Degree in Psychology from the University of Missouri-Columbia. She then completed the Master of Social Work program at Washington University in St. Louis, individualizing her concentration as sexual education, health, and therapy. Mackenzie began the $\mathrm{PhD}$ program in Social Work at the University of Missouri-Columbia in 2017, where she continued to research sexual health and education. She successfully defended her dissertation on May 21, 2021. 